\title{
Learning and developing professional behaviors as part of an entry-level physical therapy education: A survey of students and practicing clinicians
}

\author{
D. Scott Davis \\ West Virginia University
}

Follow this and additional works at: https://researchrepository.wvu.edu/etd

\section{Recommended Citation}

Davis, D. Scott, "Learning and developing professional behaviors as part of an entry-level physical therapy education: A survey of students and practicing clinicians" (2006). Graduate Theses, Dissertations, and Problem Reports. 3441.

https://researchrepository.wvu.edu/etd/3441

This Dissertation is protected by copyright and/or related rights. It has been brought to you by the The Research Repository @ WVU with permission from the rights-holder(s). You are free to use this Dissertation in any way that is permitted by the copyright and related rights legislation that applies to your use. For other uses you must obtain permission from the rights-holder(s) directly, unless additional rights are indicated by a Creative Commons license in the record and/ or on the work itself. This Dissertation has been accepted for inclusion in WVU Graduate Theses, Dissertations, and Problem Reports collection by an authorized administrator of The Research Repository @ WVU.

For more information, please contact researchrepository@mail.wvu.edu. 
Learning and Developing Professional Behaviors as Part of an Entry-level Physical Therapy Education: A Survey of Students and Practicing Clinicians

D. Scott Davis

A dissertation submitted to the College of Human Resources and Education

at West Virginia University in partial fulfillment of the requirement

for the degree of

Doctor of Education

in

Educational Psychology

COMMITTEE

Daniel E. Hursh PhD, Chair

Corrie A. Mancinelli, PT PhD

Anne H. Nardi, PhD

Neal Shambaugh, $\mathrm{PhD}$

Richard T. Walls, PhD

Department of Advanced Educational Studies: Educational Psychology

$$
\text { Morgantown, WV }
$$

2006

Keywords: Physical Therapy, Education, Professional Behavior

(C) Copyright 2006 D. Scott Davis 


\begin{abstract}
Learning and Developing Professional Behaviors as Part of an Entry-level Physical Therapy Education: A Survey of Students and Practicing Clinicians

D. Scott Davis
\end{abstract}

The purpose of this dissertation was to examine the state of professionalism in the physical therapy profession. The literature suggests that professionalism is a concern in many professions including medicine, law, nursing, audiology, and physical therapy. Two separate but parallel surveys were used to identify the opinions and experiences of physical therapy students and licensed physical therapists. The student survey consisted of a four-page paper and pencil survey that was mailed to 20 randomly selected CAPTE accredited physical therapy programs. Of the 1,525 available students, 336 (22\%) physical therapy students participated in the investigation. The clinician survey consisted of a four-page paper and pencil survey that was mailed to members of the American Physical Therapy Association (APTA). Of the 1,000 surveys mailed, $376(37.6 \%)$ surveys were returned. The results of these two surveys revealed that both physical therapy students and clinicians view professionalism as an integral part of a physical therapy education. Despite evidence to support the concerns of declining professionalism among physical therapy students, the overall frequency of negative behaviors of physical therapy students was found to be relatively low. The most frequent negative behaviors of physical therapy students were tardiness, verbal disrespect, non-verbal disrespect, and dress code violations. Based on the results of this investigation, professionalism is an issue of concern in the physical therapy profession, and researchers are justified in their efforts to seek ways of fostering professionalism among both physical therapy students and practicing clinicians. 


\section{ACKNOWLEDGEMENTS}

Several individuals have been instrumental in supporting my educational endeavors. First, my wife Ingrid and my three children (Leah, Lauren, and Scotty) have made many sacrifices over last few years that have allowed me to continue my educational pursuits. Despite the hardships, their support, love, and encouragement never wavered. My wife has not only supported me emotionally and spiritually, she has been my educational partner, proof reading almost every word that I have written. I would also like to acknowledge my mother and father who taught me the most valuable life lessons, hard work, perseverance, and discipline.

Secondly, I would like to thank my faculty colleagues, especially MaryBeth Mandich, John Petronis, and Corrie Mancinelli. Their support and encouragement was most valuable during the lowest moments of my educational journey. Additionally, this project would not have been possible without the financial and logistical support of the West Virginia University Division of Physical Therapy, and the School of Medicine.

Lastly, I would like to acknowledge the support, guidance, and mentorship of my committee members and many other faculty members in the College of Human Resources and Education. Despite the help and guidance of many, two individuals (Dan Hursh and Corrie Mancinelli) were instrumental in helping me complete this dissertation. 


\section{TABLE OF CONTENTS}

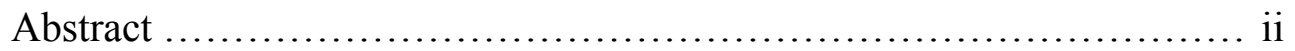

Acknowledgements ......................................... iii

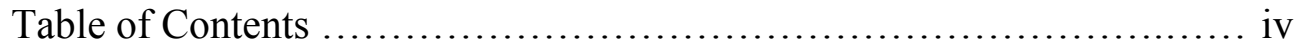

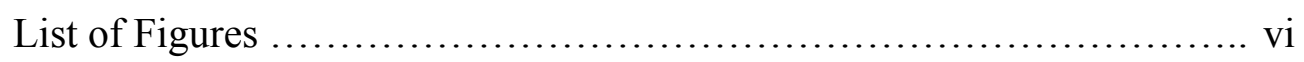

List of Tables.................................................. viii

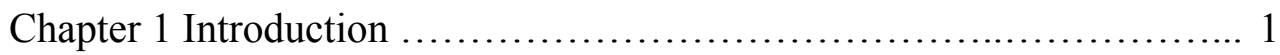

Chapter 2 Review of Literature $\ldots \ldots \ldots \ldots \ldots \ldots \ldots \ldots \ldots \ldots \ldots \ldots \ldots \ldots \ldots$

Defining Professionalism .................................. 4

Human Development Related to Professionalism ............... 7

College Student Development $\ldots \ldots \ldots \ldots \ldots \ldots \ldots \ldots \ldots \ldots \ldots \ldots \ldots . \ldots \ldots$

The Affective Domain of Learning $\ldots \ldots \ldots \ldots \ldots \ldots \ldots \ldots \ldots \ldots \ldots$

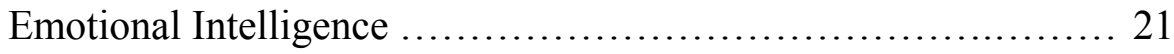

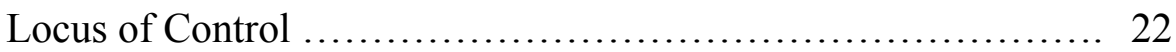

Teaching Methods ...................................... 23

Professionalism in Physical Therapy Education ................ 27

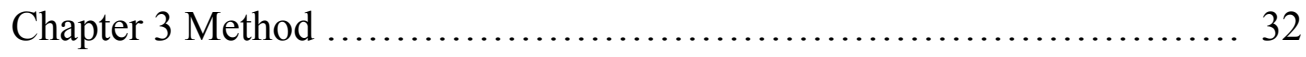

Research Questions ..................................... 32

Investigation $A$....................................... 32

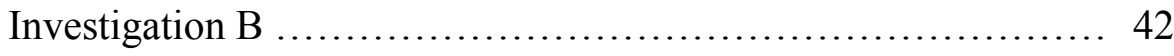




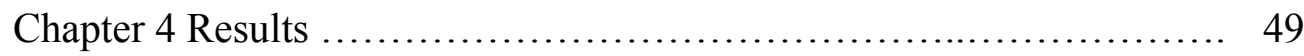

Investigation A (Student Survey) …........................ 49

Investigation B (Clinician Survey) …....................... 83

Chapter 5 Discussion and Conclusion .............................. 105

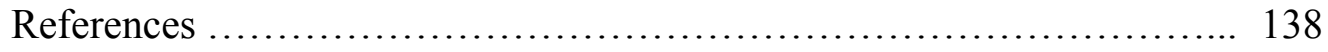

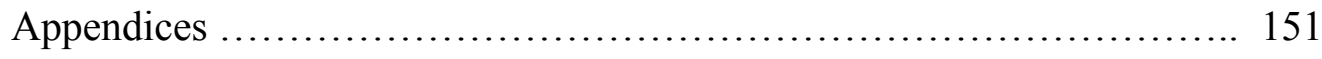

Appendix A …........................................... 151

Appendix B ................................................. 155

Appendix C ................................................. 156

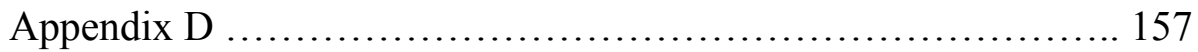

Appendix E .................................................. 158

Appendix F ................................................. 159

Appendix G .............................................. 160

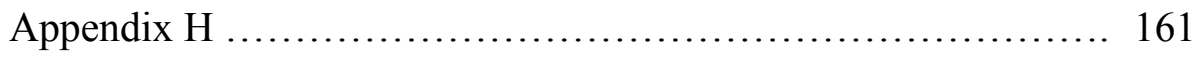

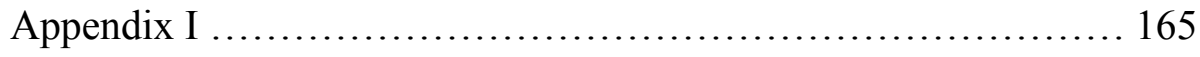

Appendix J ................................................... 166

Curriculum Vitae ............................................... 167 


\section{LIST OF FIGURES}

Figure 4.1: Age distribution of participants.

Figure 4.2: Distribution of PT school experience.

Figure 4.3: Clinical affiliation experience.

Figure 4.4: Degree designation on graduation.

Figure 4.5: Type of institution attending.

Figure 4.6: Geographic region of the PT programs.

Figure 4.7: Teaching professionalism is an important component of a PT education.

Figure 4.8: Professionalism is a construct (concept) that can be learned.

Figure 4.9: Professionalism is a construct (concept) that can be taught.

Figure 4.10: My professors demonstrate professional behaviors.

Figure 4.11: Student's self-perception of professionalism compared to that of their professors.

Figure 4.12: My clinical instructors demonstrate professional behaviors.

Figure 4.13: Student's self-perception of professionalism compared to that of their clinical instructors.

Figure 4.14: Frequency of negative behaviors by clinical instructors.

Figure 4.15: I am aware of the APTA's Core Values document.

Figure 4.16: Student ranking of professionalism for eight professional groups.

Figure 4.17: Student rating of frequency of negative behaviors by peers.

Figure 4.18: The seven most important professional behaviors for a physical therapist.

Figure 4.19: The eight least important professional behaviors.

Figure 4.20: The five most frequent teaching methods for professionalism.

Figure 4.21: The six least frequent teaching methods. 
Figure 4.22: Age distribution of participants.

Figure 4.23: Years of clinical experience.

Figure 4.24: Physical therapy degree earned.

Figure 4.25: Practice setting.

Figure 4.26: Importance of teaching and fostering professional behaviors.

Figure 4.27: Professionalism is a construct (concept) that can be learned.

Figure 4.28: Professionalism is a construct (concept) that can be taught.

Figure 4.29: Physical therapy students demonstrate professional behavior.

Figure 4.30: Professional behaviors among new graduates.

Figure 4.31: Age at the time of admission is a predictor of professional behaviors.

Figure 4.32: Median and mean ranking of professionalism for seven professional groups.

Figure 4.33: Weighted averages of negative behaviors.

Figure 4.34: The seven most frequently identified professional skills/behaviors.

Figure 4.35: The eight least frequently identified professional skills/behaviors.

Figure 4.36: Recent students are more professional than students were in previous years. 


\section{LIST OF TABLES}

Table 3.1a-b: Entry-level Student Data Analysis Procedure

Table 3.2a-b: Licensed Physical Therapist Data Analysis Procedure

Table 4.1: Distribution Characteristics of Professional Groups

Table 4.2: Non-parametric Analysis of Differences in Professionalism Based on Demographic Variables

Table 4.3: Correlation between Class Size and Professionalism

Table 4.4: Analysis of Tardiness Compared to Four Demographic Variables

Table 4.5: Analysis of Verbal Disrespect Compared to Fur Demographic Variables

Table 4.6: Analysis of Non-verbal Disrespect Compared to Four Demographic Variables

Table 4.7: Analysis of Dress Code Violations Compared to Four Demographic Variables

Table 4.8a-c: Summary of Qualitative Data (Physical Therapy Students)

Table 4.9: Distribution Characteristics of Professional Groups

Table 4.10: Student Professionalism across the Demographic Variables

Table 4.11a-c: Summary of Qualitative Data (Practicing Clinicians) 


\section{CHAPTER 1}

\section{INTRODUCTION}

Professionalism has been a long-standing tenet of most professions. However, there is concern that professionalism is declining among college students enrolled in entry-level professional programs. This trend is present in almost every profession, including medicine (Ber \& Alroy, 2002), law (Braithwaite, 1990), education (Morehead, 1998), audiology (Diefendorf, 2003), nursing (Lima-Basto, 1995), and physical therapy (MacDonald, Cox, Bartlett, \& Houghton, 2002). The concern prompted Ber and Alroy (2002) to write, "At the dawn of the twenty-first century, medical professionalism is in peril and the medical profession, and medical schools are faced with the challenge of re-establishing and teaching medical professionalism" ( $p$. 528). In response to the perceived decline in professionalism, several authors have advocated the need to question current methods of teaching and fostering professional behaviors in entry-level professional programs (Blank, Kimball, McDonald \& Merino, 2003; Happerty, 2002; Fetzer, 2003).

The medical profession has invested considerable time and resources in an effort to address the decline in professionalism among medical students and residents. To address this problem, over 90 medical associations have endorsed the Medical Professionalism Program (American Board of Internal Medicine, 2001). In 1999, the American Board of Internal Medicine (ABIM) and the American College of Physicians (ACP) sponsored a collaborative program to raise the awareness of professionalism among the medical profession. The ABIM and the ACP later received support from the European Federation of Internal Medicine (EFIM), which increased the scope of the project beyond the borders of the United States. The founders 
of the Medical Professionalism Program established a charter to guide future endeavors and promote professionalism education (Sox, 2002). The charter has been translated into ten major languages and adopted by almost every medical association in the United States and Europe. The project has spawned numerous publications that have attempted to define the problem and offer suggestions for improvement (Ber \& Alroy, 2002; Blank et al., 2003; Chauvin, 2002; Fontaine \& Wilkinson, 2003; Hemmer, Hawkins, Jackson, \& Pangaro, 2000; Larkin, 2003; MacDonald et al., 2002; Masin, 2002; Miettinen \& Fiegel, 2003; Wilkinson, Swick, Szenas, Danoff \& Whitcomb, 1999). In response to this concern, ABIM has adopted six elements or values that characterize medical professionalism; these include altruism, accountability, excellence, duty, honor/integrity, and respect of others (American Board of Internal Medicine, 2001).

In a similar attempt to address the decline of professionalism among entry-level physical therapy students, the American Physical Therapy Association (2005) developed a vision statement called "Vision 2020," which serves as a guiding document for the transition of entrylevel physical therapy education from a master's degree to a doctoral degree. One of the APTA's goals was to identify core values that should be identifiable in all physical therapy graduates. In 2002, the APTA commissioned a panel to develop a set of core professional values in a consensus-based conference. The panel's work ultimately lead to the adoption of eight practice expectations related to professionalism (Normative Model of Physical Therapy Education, 2004). These include accountability, altruism, compassion/caring, integrity, professional duty, communication, cultural competence, and clinical reasoning.

The Normative Model of Physical Therapist Professional Education (2004) is used by all 
entry-level physical therapy education programs as a guide for curricular development and modification. The Normative Model (2004) is also used by the Commission on Accreditation in Physical Therapy Education (CAPTE), as a template for accreditation review of physical therapy programs. As a result, physical therapy programs are required to ensure that these professional behaviors and skills are being taught and ultimately internalized by entry-level physical therapy students.

In response to the APTA's efforts to establish professionalism as an essential component of physical therapy education, several authors have proposed pedagogical models and educational strategies, which may be used to improve professional behaviors among entry-level physical therapy students (Jette \& Portney, 2003; MacDonald et al., 2002; Masin, 2002; Triezenberg \& Davis, 2000). Despite the efforts of many, the literature related to teaching professionalism in physical therapy, has focused on the issue from the perspective of the physical therapy educator, while no attention has been given to the problem from the perspective of the student or practicing clinician.

Therefore, the purpose of this investigation is guided by two fundamental research questions. What are the attitudes, beliefs, and experiences of entry-level physical therapy students relative to learning and practicing professional behaviors? What are the attitudes, beliefs, and experiences of licensed physical therapists relative to teaching and fostering professional behaviors among entry-level physical therapy students? 


\section{CHAPTER 2}

\section{LITERATURE REVIEW}

\section{Defining Professionalism}

What is professionalism? Cullen (1978) defined professionalism as a group of individuals who share a common educational background, and who organize as a collective body to benefit from the collaborative efforts of the group. However, the average family physician is more likely to answer the question by reciting a list of characteristics, skills, or behaviors that define the action of a professional. The difference is related to whether one is referring to professionalism at the societal or individual level. Ludmerer (1999) stated, "professionalism is defined by expert knowledge, self-regulation, and fiduciary responsibility that place the needs of the client before the needs of the professional" (p. 881).

The first professionals were priestly scholars in and around $3000 \mathrm{BC}$ who were characterized by their specialized educational training and their unique ethical behavior (Cullen, 1978). More recently, professionalism has been defined by the empirical scientific view that according to Cullen has divided our society into professional and non-professional occupations. Cullen wrote in his book, "service, ethical training, and high prestige based on the use of esoteric skills are still considered by most social scientists as the major indicators of professional status" (p. 6). Cullen also suggested that professionalism requires the occupation to provide a service to society, requires specialized training in ethics that supercedes what is provided by the family or church, and requires a set of specialized skills and knowledge that is uncommon among the society at large.

As with most concepts, there is a prototypical notion that defines that concept. In the 
case of professionalism, the long standing prototypes have been law, medicine, and clergy (Cullen, 1978). Based on Ludmerer's (1999) and Cullen's (1978) definitions of professionalism, there are numerous other occupations, which can be defined as true professions. These include nursing, physical therapy, teaching, speech pathology, occupational therapy, and engineering, just to name a few. In his book, Cullen (1978) identified several "dimensions of professionalism" which expand on his basic definition. He stated that most professions include a complex occupational task, the ability to be self-employed, altruistic service, a lengthy educational program or training, a professional organization, a code of ethics, competence testing via licensure examination or certification, and being viewed by society as a prestigious occupation. To achieve these criteria in today's society, the members are often required to have a college or university degree that integrates cognitive and technical skills with research that maintains and expands the body of knowledge of the profession.

May, Straker, and Foord-May (2001) likened professionalism to a three-legged stool where the three legs represent cognitive, psychomotor, and behavioral skills. In a more esoteric view of professionalism, Chauvin (2002) believed that professionalism must be defined in the context of the profession; therefore, a universal definition of professionalism is not achievable, because what is considered a professional behavior or skill in one profession may not be viewed as important in another.

After examining the definitions of professionalism, it is clear to see that the concept of professionalism has considerable breadth and depth. In fact, the concept of professionalism penetrates the fabric of our society so deeply that it is inconceivable to imagine a world without professionals who provide key services such as medical care, education, spiritual counseling and 
legal advice. In our society, professionals are entrusted with our most important tasks. In order to maintain this trust, professional organizations and educators are scrambling to find ways to ensure that this sacred trust is maintained by the next generation of professionals.

From the level of the individual, professionalism begins to take on a slightly different perspective. Instead of considering the characteristics that define a profession, one begins to contemplate the characteristics, attitudes, and values that define the psyche of the professional. The list of characteristics, traits, skills, and behaviors that are used to define professionalism is immense. The list includes integrity, responsibility, dedication, commitment to learning, critical thinking, good communication skills, a commitment to service, altruism, advocacy, dutifulness, ethical practice, knowledge, accountability, and information literacy.

The stakes for failing to maintain a professional demeanor are great for the individual professional and for the profession at large. Beyond the fact that patients and clients deserve to be treated in a professional manner, they often demand it. Patients have a tendency to seek damages for medical malpractice at a greater rate when they do not have a positive relationship with their caregiver. In an article titled Why Some Patients Sue: Learning from a Plaintiff's Lawyer, a strong link is identified between a lack of professional behavior and a patient's desire to sue for medical malpractice (Anderson, 1995).

With the need for professionalism clearly established, the question now becomes, as posited by Braithwaite (1990), “can professionalism be taught?" This simple question leads the curious mind to ponder other related questions. Can professionalism be learned? What are some of the ways in which professionalism can be taught or fostered? What is the best method of teaching or fostering professionalism? Unfortunately, the literature does not provide a clear 
answer to these questions, but instead leads one in a circuitous journey through several interconnected disciplines in pursuit of the answer.

\section{Human Development Related to Professionalism}

To appreciate how skills, values, and behaviors consistent with the underpinnings of professionalism are formed, requires an understanding of human development. Although the connection may not be readily apparent at first inspection, the skills, values, and behaviors related to professionalism require adequate developmental progression.

There are six major theories of development (DeHart, Sroufe \& Cooper, 2003), which have emerged over the last century. These include Piaget's theory of cognitive development (Piaget, 1965, 1972a, 1972b), information processing (Atkinson \& Shiffrin, 1968; Baddeley, 1998), sociocultural theory (Vygotsky, 1978), psychoanalytic (Erickson, 1963; Freud, 1960), social learning (Bandura \& Walters, 1963; Rotter, 1954; Skinner, 1953), and Bowlby's (1969) adaptational theory. Each of these theories will be briefly examined in terms of how they contribute to the discussion of professionalism.

Piaget's $(1965,1972 a, 1972 b)$ theory suggested that as children age they undergo qualitative changes in the way they view and understand the world. Piaget believed that a child's ability to understand certain concepts is dependent on his or her cognitive development. Piaget's theory focused on early childhood development and is divided into four major periods. He states that children cannot begin to think reasonably about abstract or hypothetical problems until the formal operational period, which typically is defined as 12-16 years. Kuhn, Langer, Kohlberg, and Haan (1977) examined formal operation in adults and found that $30 \%$ of the adults in their sample had not attained full formal operation. They also reported that most of the adults were in 
transition between concrete and formal operations and about $15 \%$ showed no formal operational thought at all. Based on Kuhn and colleagues' (1977) research, it is conceivable to consider that some college students have not attained formal operational thought by the time that they enter a professional program, which may explain the difficulty that some students have developing professional behaviors, which require abstract thought.

Professionalism and characteristics such as altruism, integrity, and ethics can be very abstract. The idea of denying oneself for the benefit or gain of another may be beyond the cognitive development of some college students. Piaget (1972a, 1972b) argued that formal operational thought allows an individual to think abstractly and systematically. Piaget suggested that logical thinking or reasoning does not need to be taught. Instead, he suggested that adolescents undergo qualitative change through their own experiences.

From an educator's point of view, it seems perplexing that formal operational thought cannot be taught or at least facilitated through proper instruction. Piaget may have been correct in the fact that certain formal operations are not attainable until a certain critical point in a person's development, but it seems logical that educators might be invaluable in offering experiences that promote and enhance formal operational thought.

Vygotsky (1978), a sociocultural theorist, believed that cognitive skills are first learned in specific social settings and are not internalized until later in life. Vygotsky described a "zone of proximal development" which suggests that humans develop skills at first with the help and support of individuals with greater knowledge and skill levels. He believed that qualitative changes occur in cognitive development when the new skill is internalized. In the case of professionalism, students may require guidance and support from experienced members of the 
profession until the development of professional skills are internalized or the values are actualized by the student. Vygotsky's (1978) theory supports the use of mentors and role models that help support, scaffold, and guide professionalism.

Much like Piaget, Vygotsky believed that cognitive development proceeds in definable qualitative changes that occur as an individual internalizes new cognitive skills. However, Vygotsky clearly recognized the value of education related to human development. Vygotsky (1978) wrote:

From this point of view, learning is not development; however, properly organized learning results in mental development and sets in motion a variety of developmental processes that would be impossible apart from learning. Thus, learning is a necessary and universal aspect of the process of developing culturally organized, specifically human, psychological function (p. 90).

Students enrolled in professional programs, such as medicine, law, education, and physical therapy are often heavily immersed in the culture of their profession and spend a great deal of time interacting with members of the profession. As a result, role modeling and mentoring is an integral component of the educational process. The impact of role modeling on social development of college students has long been recognized, but may not always be used to the fullest potential. For example, Wright and Carrese (2002) found in their research on professionalism that the most effective medical role models consciously thought about their influence on medical students and regularly analyzed how they were being perceived by their 
students.

Information-Processing Theorists (Atkinson \& Shiffrin, 1968; Baddeley, 1998;

Dempster, 1981; Plumert, 1994) take a different perspective of cognitive development. Information processing looks at cognitive development as a gradual quantitative change that occurs as the child ages and increases his or her attention and memory capabilities. They suggested that the ability to think rationally about abstract concepts like professionalism would not occur until the point where the individual had stored enough information and developed to the point where they were able to process the concept of professionalism.

Freud (1960) described the id, the ego, and the superego. The id is the primitive selfish mind; the superego is the moral mind, which is used to examine thoughts and feelings from a more societal perspective. The ego is trapped between the id and the superego, which tries to obtain the selfish desires, while at the same time doing it in a rational manner. The values and characteristics of professionalism transcend the id and focus on the needs and desires of others over the needs and desires of the professional. This inner struggle for selfish desires may play a role in the struggles some students have in making the transition to a professional demeanor.

Erikson's (1963) theory, which is an extension of Freud's (1960) theory, offers much insight into the development of professionalism. Erickson divided the lifespan into eight stages. The fifth stage, identity $v$ role confusion, thought to be dominant in 12 to 18 year olds, is the most helpful in the context of professionalism. This stage is marked by the adolescent developing a sense of identity that extends to how he/she sees oneself as a member of society. During this stage of life, adolescents begin to strive for independence and autonomy. They begin to take personal responsibility for their actions. This stage of life offers the emergence of 
many of the fundamental behaviors of professionalism like responsibility, integrity, dedication, and critical thinking. Erickson suggested that identity achievement is not accomplished until late adolescence, after a period of active exploration. Marcia (1980) and Josselson (1987) suggested that some women (Moratorium and Identity Diffusion women) do not complete the process of self-identity by the end of college and often struggle with interpersonal relationships and have a high degree of anxiety. Although there is no evidentiary support at this time, it is conceivable that these individuals may have trouble transitioning to a professional demeanor where emphasis is placed on serving the needs of others.

Social learning theorists (Bandura \& Walters, 1963; Rotter, 1954; Skinner, 1953) suggested that humans develop through the association with various consequences. They argued that individuals repeat behaviors that are rewarded and avoid behaviors that result in a negative consequence. Bandura and Walters (1963) suggested, "imitation is an indispensable aspect of learning" (p. 3).

This process is heavily dependent on the concept of modeling, where individuals observe behaviors and imitate them. Therefore, according to this theory, observation of positive professional behaviors and positive reinforcement of desirable behaviors would be essential to the development of self-directed professional behaviors. According to this theory, students who regularly observe professional behaviors are more likely to develop positive professional behaviors, than those who do not have positive role models or who never received feedback as to the appropriateness of their behaviors. This is supported by research conducted by Wilson, Gaff, Dienst, Wood, and Bavry (1975), who reported that 77 percent of college students identified at least one faculty member who had contributed to both their didactic education and their personal 
development.

Bowlby's (1969) Adaptational Theory is based on the importance of attachment relationships and how positive attachment affects cognitive, social, and emotional aspects of development. Bowlby believed that the need for attachment is biologically driven and the attachment process occurs in predictable ways. Bowlby believed that the quality of future attachment is strongly predicted by the level of attachment in earlier developmental periods.

At first glance, it may be difficult to see how Bowlby's theory, which is largely focused on the attachment between an infant and a mother, is related to the development of professionalism. However, the relationship between infancy and adulthood appears to be clearly identified in Bowlby's own words. Bowlby (1969) wrote:

Thus, we reached the conclusion that loss of mother-figure, either by itself or in combination with other variables yet to be clearly identified, is capable of generating responses and processes that are of the greatest interest to psychopathology. Not only so, but these responses and processes, we concluded, are the very same as are known to be active in older individuals who are still disturbed by separation that they suffered in early life. Amongst these responses and processes and amongst forms of disturbances are, on one hand, a tendency to make excessive demands on others and to be anxious and angry when they are not met, such as is present in dependent and hysterical personalities; and on the other, a blockage in the capacity to make deep relationships, such as is present in affectionless and psychopathic personalities (p. xiii-xiv).

Based on Bowlby's theory, adult behaviors can be a reflection of the developmental progression that occurred in infancy and childhood. Students who struggle to develop effective 
interpersonal and professional skills by be disadvantaged by inadequate developmental history. After reviewing the six theories of human development in the context of professionalism, it is plausible that students, who struggle to develop professional behaviors in their college years, may have experienced less than ideal developmental conditions as a child. This connection between early human development and college performance has been studied and will be expanded on in the next section.

\section{College Student Development}

For the last 30 years, the student development field has contributed greatly to the study of how students grow as part of the overall college experience (Evans, Forney, \& Guido-DiBrito, 1998). Based on this body of knowledge, it is well established that late adolescents and young adults undergo a significant transformation in cognitive and psychosocial development. As such, several college student development theories help to explain the process by which entry-level professional students develop and acquire professional behaviors. Although college student development theories can be grouped into four major categories (cognitive-structural, psychosocial, person-environment, typology), cognitive-structural and psychosocial theories appear to have the greatest contribution to the understanding of professionalism development (Evans et al., 1998).

In particular, two cognitive-structural theories contribute to the understanding of professional development. The first is Kohlberg's $(1972,1976)$ Theory of Moral Development. Kohlberg (1972) stated that justice is "the primary regard for the value and equality of all human beings, and for the reciprocity in human relations, is a basic and human standard" (p. 14). Kohlberg's theory has three levels that he calls preconventional, conventional and 
postconventinal. Individuals who are in the preconventional level follow rules and treat others according to socially defined practices because they fear punishment or they feel that they will obtain some sort of positive reinforcement for their behavior. Individuals in the conventional level are concerned about maintaining a persona of goodness and follow socially accepted norms because they seek approval of others. Those in the postconventional level act in socially acceptable ways because they intrinsically value and respect the notion of human rights and dignity.

Professionalism was conceived and founded on the precepts described by Kohlberg's postconventional level. In order for professionalism to be achieved, the student must intrinsically value the core behaviors that characterize the profession. Walker (1988) stated that the sequence of progression through Kohlberg's stages occur in a sequential fashion but the rate at which individuals progress is highly variable. Although it has not been investigated, it is possible that many entry-level professional students may develop along the same continuum and be motivated by the same factors as described by Kohlberg.

The second cognitive-structural theory is Gilligan's Theory of Women's Moral Development $(1977,1981)$. Gilligan's theory has three levels and three transitions between each level. The first level is Orientation to Individual Survival, and is characterized by selfpreservation and self-gratification. The second level, Goodness as Self-sacrifice, is marked by a desire for social acceptance. Women in this stage are willing to forgo their own desires to achieve social harmony. The third level, Morality of Nonviolence, is characterized by a healthy equilibrium between the needs of others and self. Based on Gilligan's theory, young women in the first stage, orientation to individual survival, may struggle with the precepts of 
professionalism and may only demonstrate positive professional behaviors if they think that it is in their best interest.

Psychosocial theories of college student development are largely an extension of the early work of Erik Erikson (1963), discussed previously. One of the most well known psychosocial theories of college student development is Chickering's vectors (1969/1978). Chickering's $(1969,1978,1993)$ original theory was based on seven vectors of development that are specific to late adolescence and young adulthood. These vectors or paths ultimately form the basis for adult identity development. Chickering believed that students progress through these vectors in a somewhat structured manner but each individual progresses at his or her own pace and in a loosely structured sequential manner. The original seven vectors were developing competence, managing emotions, becoming autonomous, freeing interpersonal relationships, establishing identity, clarifying purpose, and developing integrity or wholeness (Chickering, 1969). These vectors were modified in his later work (Chickering \& Reisser, 1993) and have been renamed developing competence, managing emotions, moving through autonomy toward interdependence, developing mature interpersonal relationships, establishing identity, developing purpose, and developing integrity.

Two of Chickering's vectors, developing purpose and developing integrity may be intricately linked to the process of professionalism development. Chickering described developing purpose, as the process of developing a sense of purpose and a commitment to clear vocational interests. As such, students begin to identify themselves with their chosen vocation. An important part of this vector is the incorporation of personal values that are consistent with the chosen occupation or profession (Chickering \& Reisser, 1993). 
Chickering identified three stages in the process of developing integrity. They include humanizing values, personalizing values, and developing congruence. The first sub-stage, humanizing values, is the progression from inflexible moralistic values to more humanistic values that consider the needs and desires of others. The second sub-stage, personalizing values, is the development of a set of personal "core values" that are strengthened by one's own personal experiences. The last sub-stage, developing congruence, is the integration of one's own core value system with a sense of social responsibility. These precepts are embodied in the concept of altruism, which is the unselfish concern for others. Integrity grounds an individual and makes one steadfast in moral and ethical interactions with others. Integrity is a key ingredient to establishing mature trusting relationships with friends, coworkers, clients, and significant others.

Chickering and Gamson (1999) believed that the student-faculty relationship is critical for developing adult and professional skills, emotions, and behaviors. Chickering espoused the importance of student-faculty interaction in a variety of settings that extend beyond the classroom. He believed that it is imperative for students to recognize that professors are interested in more than academic accomplishment. To that end, Chickering thought that it is vital that college and university professors recognize the importance of their role in college student development and actively pursue opportunities to facilitate not only cognitive development, but also the psychosocial aspects of development. The intended outcome of this interaction is to teach or foster interdependence. Thus, Chickering and Gamson's (1999) theory supports the use of mentorship as part of a college education.

Another psychosocial theory that helps to explain the development of professionalism is Schlossberg's $(1981,1984)$ Transitional Theory. Schlossberg's theory described the process of 
transitioning from one state to another. According to Schlossberg, transition or change can occur in a wide variety of areas. These include a change in location, job activity, relationships, attitude, recreation, etc. Transitions are a natural part of the human existence; however, the process by which individuals manage transitions, from a psychological perspective is very different.

Schlossberg stated that there are four mechanisms individuals use to cope with transitions. These include the situation, self, support, and strategies. From the perspective of professionalism, the situation would refer to the unique characteristics of the professional program, the instructors, the length of the program, interaction with patients or clients. Self refers to the intrinsic factors or characteristics of the individual student. These characteristics may include age, gender, life experience, ethnicity, and psychological well-being. Support refers to the degree and nature of the individual's social support system. In this case, the relationship the student has with his or her parents, siblings, friends, instructors, and classmates may be vital to the transition to professionalism. Based on Schlossberg's theory, a student who is socially isolated may experience greater difficulty making the transition to professional behaviors. Strategies refer to the process the individual uses to cope with the transition. For instance, one student may embrace the idea of becoming a professional, actively seeking opportunities for personal growth, while another student may actively resist the change.

The transition from undergraduate education to a graduate professional program can be overwhelming to some students who lack the four mechanisms described by Schlossberg. Students who lack intrinsic characteristics that are congruent with the tenants of professionalism or who lack adequate support and coping strategies may have a more difficult transition to 
professional behavior compared to students who do possess these mechanisms.

\section{The Affective Domain of Learning}

The examination of teaching and learning related to professionalism requires a thorough understanding of the linkage between professionalism and the affective domain of learning. According to Bloom (1956), there are three domains of learning. These include the cognitive, psychomotor, and affective domains. Despite the recognition of each of these domains, educational research has largely focused on teaching and learning in the cognitive domain (Bloom, 1956; Spielberger, Gonzalez, Fletcher, 1979; Ringness, 1975). Likewise, physical therapy education has traditionally placed a heavy emphasis on cognitive and psychomotor learning, with relatively little attention given to the affective domain (Masin, 2002).

The relative neglect of the affective domain may occur because content in the affective domain is more difficult to define; it is harder to write learning objectives and plan instructional strategies, and it is harder to assess outcomes related to affective learning. Ringness (1975) also suggested that teaching values and morals in the classroom often result in conflicts with family and religious teachings. This may be particularly true in state-supported colleges and universities. The difficulty working with the affective domain is underscored by Bloom's own struggles with defining the taxonomy for this domain. Bloom (1956) stated, "It is difficult to describe the behaviors appropriate to these objectives since the internal or covert feelings and emotions are as significant for this domain as are the overt behavioral manifestations" (p. 7).

According to Bloom (1956), the affective domain relates to a student interests, attitudes, values, and appreciation of learning. As such, the affective domain is subdivided into five major areas, which include receiving, responding, valuing, organization, and characterization by the 
value (Bloom, 1956). Ringness (1975) stated that the affective domain encompasses the “emotional aspects of one's behaviors" (p. 3). These include attitudes, values, morals, and character. Ringness also states that learning rarely takes place along only one domain, but instead, learning usually encompasses more than one domain, but one domain is typically dominant.

Bloom's taxonomy on the affective domain represents a "continuum of internalization" from simple awareness of the idea to a deep characterization of self, based on the idea (Ringness, 1975). For instance, a physical therapy student may first become aware of the term or concept of "altruism" by being exposed to a definition in a first year seminar. Eventually, the student may internalize the value of altruism by enthusiastically providing pro bono physical therapy service to the under-served patients within the community. The process of becoming "altruistic" is not suddenly achieved but rather it is a gradual transformation.

Using altruism as an example, each of the five phases of the affective domain will be described. Receiving occurs as the student is introduced to the concept or idea. Since the student is just being introduced to the concept, there are no preconceived ideas. The student then develops interest in the idea and is willing to learn more about the topic, but remains relatively naïve and open-mined. For many college students in a professional program, receiving may not be an entry point in the affective domain since they may already have been exposed to some of the concepts or behaviors previously. From an assessment perspective, students would be able to define the term altruism, but would have a limited base from which to discuss their attitudes and beliefs related to altruism. 
The second level, responding is characterized by developing a position. At this level, the student adopts a particular point of view related to the issue. Their opinions are often weak and they lack a strong emotional connection to attitudes and beliefs. Gradually the student's emotions strengthen relative to their view of the behavior. For example, the students would be able to discuss why altruism is needed in society, but because they have not internalized the concept, they remain uncommitted on a personal level.

In the third level, the student begins to internalize commitment to the concept or idea. Value is placed on belief of the behavior. For example, students intrinsically believe that physical therapists should be altruistic. During the third level, they are able to be independent of how others view altruism; thus, they have established some degree of conviction related to their belief. At this level, the student would be able to thoroughly discuss the need for a physical therapist to be altruistic, and support it with strong conviction.

The fourth level involves the organization of the concept or idea into the person's own value system. Students begin to see the connection of the behavior to other concepts they have previously internalized. Therefore, they would see altruism as one part of the larger domain of professionalism. At this level, an observer would be able to identify the student placing the needs of the patient ahead of his or her own needs. For example, the student may stay late to assist a patient who needs extra care.

The fifth level is referred to as characterization by the value and is the highest level of internalization. At this phase, altruism would be deeply ingrained in the person's being and is reflected in subconscious actions. Students may have such strong emotions related to altruism that they may become advocates for altruism education as part of a physical therapy curriculum. 
A central concept of teaching in the affective domain relates to how the material is being presented. Ringness (1975) made a distinction between training and educating. Training is referred to as the process of indoctrination of thought by the teacher or parent, while education refers to the enlightenment and self-actualization of the student that results from the instructional experience. Although neglect of the affective domain in the classroom can be problematic, Ringness (1975) cautioned against using training as the means of affective learning. Thus, avoiding a discussion of a controversial topic in class due to concerns about the emotional ramifications would serve as neglect of the affective domain, while presenting the issue from one perspective and encouraging a specific emotional response may serve as training. According to Ringness (1975), neglect is not desirable, but "training" may be even more problematic.

\section{Emotional Intelligence}

According to Salovey and Mayer (1990), emotional intelligence refers to the "ability to monitor one's own and other's feelings and emotions" (p. 185) and to be able to process and discriminate information, which will enable one to guide one's own behavior. Emotional intelligence has several components. The first is the person's ability to accurately monitor his or her own mood and current emotional state. The second is the person's ability to express emotions. Individuals who are unable to self-monitor and express emotions are thought to suffer from alexithmyia. The third component of emotional intelligence is emotional appraisal, where the individual is able to accurately assess another person's emotions through facial expressions and body language. The fourth is emotional expression, which is the ability of a person to be able to recreate someone else's emotions. Emotional expression is thought to be related to a person's ability to be empathetic (Davies, Stankov, \& Roberts, 1998). 
It is thought that individuals, who have a high level of emotional intelligence, have an advantage, especially in social situations. Goleman (1995) believed that emotional intelligence is related to a person's ability to function effectively. He believed that the ability to control one's emotions and the ability to delay self-gratification are the keys to success in life. Based on Goleman's theory it is easy to see the possible connection between many of the desirable professional behaviors (e.g. empathy, altruism and dedication) and emotional intelligence (Goleman, 1995). To date, there has been no attempt to correlate emotional intelligence with professional development.

Locus of Control

Rotter (1966) described locus of control as "the level at which individuals ascribe control to personal achievement and failure" (p. 999). A person is said to have an internal locus of control if he/she believes success is related to internal factors such as effort, ability, and motivation. A person is said to have an external locus of control if he/she believes that success is related to external factors such as luck, fate, or the influence of others (Furnham \& Steele, 1993; Rotter, 1966).

Locus of control is based on the broader social learning theory and has been widely examined since Rotter's original work in 1966. Using the Nowicki-Strickland Locus of Control Scale (NSLCS), Miller, Finch \& Marshall (2003) compared the locus of control of at-risk students in alternative high schools to regular high school students. They found that students in the alternative school scored higher on the NSLCS than those students in regular high schools. Miller et al. concluded that problem behaviors might be related to a person's view of the origins of success. Students with problem behaviors may feel helpless and not think that they have the 
ability to affect change in their lives. The authors suggested intervention strategies that would target improvement of locus of control in at risk students (Miller et al., 2003). It is conceivable that students who struggle with the development of professional behaviors may have a more external locus of control compared to students who make an easy transition to professional behaviors.

\section{Teaching Methods}

Because of the perceived decline in professionalism among students enrolled in entrylevel professional programs, several authors have attempted to examine various teaching methods used to foster professionalism. The teaching methods which will be discussed include: role-modeling, instructional documents, case studies, trigger films, role-playing, portfolios, journals, and literature/metaphors.

The first and one of the most widely used methods of teaching professionalism is role modeling. Role modeling may be perceived as a relatively passive teaching strategy, but as discussed previously, there is considerable theoretical research to support this approach (Bandura \& Walters, 1978; Rotter, 1984; Skinner, 1953; Vygotsky, 1978). It has long been thought that professors should simply model the professional behaviors that they want their students to develop. This form of teaching requires the student to recognize the positive professional behaviors demonstrated by the role model, be able to recognize that they are unique to their own, and finally they must posses the internal desire to emulate those behaviors. Although this method of teaching has historical and intuitive appeal, it leaves the process of learning largely in the hands of the student. Some may also argue that role modeling has been present from the inception of professional education and yet there is a perceived crisis among 
many educators. Perhaps role-modeling alone is not enough to ensure the acquisition of professionalism for all students, or perhaps, role modeling is not being used to its maximal potential.

Larkin (2003) suggested that positive professional behaviors of the role model may not always be observable to all students or occur in great enough frequency to be effectively modeled (Larkin, 2003). As touched on previously, Wright and Carrese (2002) in their work with medical students, found that effective role models think about their responsibility as role models and are thus consciously aware of how they are being perceived by students. Perhaps faculty and staff development for role models could enhance the process and turn role modeling into a more active process. Wright and Carrese (2002) also concluded that students need more than one role model. This makes intuitive sense, because as students see consistency of behaviors among multiple role models, they begin to make connections about appropriate and inappropriate behavior.

A second form of subtle encouragement of professionalism is the use of instructional documents such as student handbooks and posters, which convey professional values and desired behaviors (Blank et al., 2003). This again assumes that the student is interested and selfmotivated enough to read and internalize the words that are written in the documents. From a logical perspective, instructional documents may be helpful to clearly articulate the desired professional values and behaviors and may serve as a visual reminder, but based on Bloom's (1956) taxonomy, this approach only reaches the receiving level.

A third teaching method involves the use of case studies that convey the use of negative or positive behaviors in a simulated real-life patient or client encounter (Blank et al., 2003; 
Borden, 1998). Case studies are usually followed by a group discussion of the pertinent aspects of the case. This discussion allows the students to verbalize their thoughts and to hear how other students interpreted the scenario. Case studies have a long historical record of use as a means of teaching affective content. Case studies were first used in this way in the late 1800 's in teaching law students (Borden, 1998). Case studies have become a common method of teaching real-life situations through recreation of actual events or through hypothetical situations that are constructed to teach a particular concept. Despite the apparent effectiveness of case studies, Borden (1998) suggested two common pitfalls that must be avoided. They include the lack of theoretical background and a lack of details surrounding the case.

A fourth method of teaching professionalism is a logical extension of the third method. In this case, short trigger films are produced by the instructor and untrained actors who simulate a patient case scenario (Ber \& Alroy, 2002). It is identical to a case study but brings the case to life. Again, the film is discussed in small groups that are led by the professor. Ber and Alroy (2002) have reported success with the use of trigger films in teaching professionalism to medical students. They suggest that the students role-play the alternative positive behaviors that could have been used by the professional in the trigger film.

A fifth method of teaching professionalism is the use of role-playing with the use of simulated patients (Ber \& Alroy, 2002). The intuitive appeal of role-playing is that students have an opportunity to actually demonstrate positive professional behaviors and receive reinforcement for their behavior, albeit in a simulated environment. Role-playing has been shown to be an effective educational tool to learn other types of behaviors (McAlister, Vartiainen \& Lehtovuori, 2000; McGregor, 1993). 
The sixth method that has been used to teach professionalism is portfolios and journals that are designed to promote self-reflection (Blank et al., 2003; Friedman-Ben-David et al., 2001; Gordon, 2003). Gordon (2003) described how they have been used in medical schools to promote self-assessment of professional behaviors. The student is responsible for preparing a summative portfolio that documents professional development during the first year of medical school. The typical portfolio contains personal excerpts from clinical experiences, as well as their observation of other students while in class. Gordon (2003) suggested that students will often share ethical dilemmas that they have experienced or observed. Each portfolio is read by a professor who attempts to determine if honest self-assessment has occurred. The student and professor then meet to discuss the portfolios. Gordon (2003) reported that $91 \%$ of 178 medical students agreed that the portfolios were of value in promoting professional development.

The seventh and final approach to teaching professionalism is the use of literature and metaphors to teach professionalism. Wear and LaCivita-Nixon (2002) toke exception to many of the teaching methods suggested by the Medical Professionalism Program. They cite the fact that the very word used by ABIM to describe professionalism education (inculcate) is a fundamental flaw. They refer to the original definition of inculcate from the Latin word incucare as "to cram in" or "impress upon." They state that professionalism should not be crammed into students, but rather the concept of professionalism should be fostered or illuminated using narratives, memoirs, essays, and poetry. They stated that narratives suggest rather than dictate appropriate responses. Wear and LaCivita-Nixon's theory is supported by the work of Bloom (1956) and Ringness (1975) who warn against training as a means of teaching in the affective domain. 


\section{Professionalism in Physical Therapy Education}

Several years before the development of the Medical Professionalism Program, May, Morgan, Lemke, Karst, and Stone (1995) developed a professional behaviors model they called ability-based assessment, which was designed to assess the development of professional behaviors and skills as part of an entry-level physical therapy education. This model or approach was later called Generic Abilities. Generic Abilities are attributes, characteristics, and behaviors that are thought to be important for the success of a practicing physical therapist. The ten abilities include commitment to learning, effective interpersonal skills, communications skills, effective use of time and resources, the ability to use constructive feedback, problem solving skills, professionalism, responsibility, critical thinking and effective stress management skills.

It should be recognized that generic abilities are skills and behaviors rather than values. This is an important distinction, since the APTA and the ABIM documents consist primarily of values. In addition to the list of ten generic abilities, May and colleagues (1995) defined the ten Generic Abilities and developed a set of behavioral criteria that are used to measure student development across a physical therapy curriculum. They divided the criteria into three phases that include beginning, developing, and advanced.

In a logical follow-up investigation, Jette and Portney (2003) attempted to determine the construct validity of seven Generic Abilities against the behavioral criteria identified by May and colleagues. This research suggest that professionalism, interpersonal skills, and working relationships did not show any significant change based on clinical experience across the physical therapy curriculum. However, critical thinking, professional development, communication management, and personal balance were found to change over the course of an 
entry-level physical therapy program. As stated by Jette and Portney (2003), the investigation had several limitations. These included data obtained from only two physical therapy programs in close geographic proximity, and a response rate of 60 percent that resulted in a sample size of 183 participants.

In contrast to the Generic Abilities model, Triezenberg and Davis (2000) suggested that to improve professional behavior, students need to develop along a moral continuum.

Triezenberg and Davis define moral as "personal characteristics and actions" (p. 48). This is in contrast to the term ethical, which they define as "a systematic study of behaviors and evaluation of how the actions of an individual conform to professional standards of conduct" (p. 48). Based on their definition, moral behavior is an individualistic concept and ethical behavior is a concept that encompasses a larger societal or organizational context.

Triezenberg and Davis (2000) also suggested that physical therapy educators should serve as moral agents, who function to create a learning environment that fosters moral character development. They suggest that the moral continuum progresses from moral sensitivity (identifying moral issues) to moral reasoning (the ability to analyze moral issues), and finally to moral character (the attributes and skills needed to act in a moral way). Triezenberg and Davis touched on an important concept that connects life-skills with moral development. They stated that skills such as listening, learning to be an effective communicator, and team building are skills required for moral development. In other words, to develop along the moral continuum, students need additional life skills to be able to reach the optimal level of moral character.

Triezenberg and Davis (2000) suggested that the educational environment, which includes the faculty, staff, and the curriculum must reflect the values and behaviors that are being 
taught. They offer a conceptual model for moral development that can be used to as part of an entry-level education. They also offer instructional strategies for helping to promote moral development.

MacDonald et al. (2002) espoused that Generic Abilities and the Clinical Performance Instrument (CPI) (Task Force for the Development of Student Clinical Performance Instrument, 2002) provide objective methods for identification and assessment of professional behaviors, but that the missing piece is a strategy for teaching and fostering the development of these behaviors. MacDonald et al. (2002) developed a set of five teaching strategies to foster professional behaviors using a consensus-based focus group using nominal group technique and the Delphi process. They identified five teaching methods they termed lead by example, explicit teaching, mentoring, reflective imaging, and wider context education. Each teaching method was further defined based on a maturity continuum model. They developed active learning strategies for each of the five teaching methods that progress from dependence to independence and ultimately interdependence. MacDonald and colleagues' model for professional behavior development offers tangible teaching strategies. To date however, there is no evidence to suggest that their model is effective in improving professional behaviors in an entry-level physical therapy program. One major limitation of their investigation is the relatively small number of participants $(\mathrm{n}=11)$ and the geographical proximity of the consensus group members.

Masin (2002) clearly stated the importance of the affective domain in physical therapy education in the following quote, "This ability to self-assess both clinical and affective skills facilitates the development of professional behaviors and is one of the keys to effective patient education and patient management" (p. 37). Masin (2002) has developed a participant-centered 
problem-solving model that is used to teach, assess, and remediate professional behaviors. Masin (2002) offered a detailed description of a process that can be used to teach and foster professionalism in a physical therapy curriculum, which emphasizes congruency between the faculty member and the student. Despite the intuitive appeal of this approach, the participantcentered problem-solving model has not been validated.

Gandy and Jensen (1992) asked a critical question that is just as germane today as it was in 1992. They asked, "What teaching methods could be used in our classrooms and laboratories to facilitate the development of professional behaviors necessary for today's practice?" (p. 7). Gandy and Jensen suggested that small group discussion and reflective activities hold great promise for developing the desired professional behaviors. They cited that small group learning promotes collaboration, collegiality, divergent thinking, communication, and creative problem solving. As part of the reflective activities, Gandy and Jensen (1992), suggested that reflective journals offer educators with insight into how students think about issues they encounter.

Mostrom (2004) discussed the issue of teaching professionalism as part of an entry-level physical therapy curriculum. Referring to the Professionalism in Physical Therapy: Core Values document, Mostrom states:

As I read through the definitions and indicators put forth in this document, I couldn't help but think that teaching and learning about these values and dimensions of professionalism is not so much about what is being taught and learned, as it is about how we are teaching, and perhaps most importantly, who we are as teachers in relation to our students. (p. 2)

Mostrom's quote and article allude to the idea that content belonging to the affective domain 
may require a different teaching strategy than content that belongs to the cognitive or psychomotor domains. Based on the overwhelming perception that professional behavior is on the decline, it seems critical to identify the frequency of negative behaviors among entry-level physical therapy students, and to identify current teaching methods. Working on the assumption that a solution is easier to identify when the problem is understood, physical therapy educators need to have a clear understanding of the current state of professionalism that encompasses the attitudes and opinions of not only physical therapy educators, but also students and practicing clinicians as well.

In reviewing the literature related to professionalism, it is clear to see that the scope of professionalism is broad and encompasses the areas of human development, college student development, psychology, sociology, and education. Despite the efforts of many theorists, educators, and investigators, there is a lack of understanding about the process of developing professional behaviors in physical therapy from the perspective of the student and the practicing clinician. Therefore, the purpose of this investigation is to assess the attitudes, beliefs, and experiences of entry-level physical therapy students and practicing clinicians relative to learning and practicing professional behaviors in the physical therapy profession. 


\section{CHAPTER 3}

\section{METHOD}

\section{Research Questions}

This investigation was designed to investigate the state of professionalism among entrylevel physical therapy students and licensed physical therapists. As such, this investigation was guided by two primary research questions:

Investigation A: What are the attitudes, beliefs, and experiences of entry-level physical therapy students in the United States relative to learning, developing, and practicing professional behaviors?

Investigation B: What are the attitudes, beliefs, and experiences of licensed physical therapists in the United States relative to developing and fostering professional behaviors among entry-level physical therapy students and new graduates?

Two separate, but parallel investigations were designed to answer each of the primary research questions. To ensure clarity, each investigation (Investigation A and B) is described separately. Additionally, a subset of specific research questions will be identified for each of the primary research questions.

Investigation A (Entry-level Physical Therapy Student Survey)

The research design was primarily descriptive (Babbie, 1990), using a cross-sectional survey design. The survey instrument was a paper and pencil questionnaire that was designed to identify the attitudes, beliefs, and experiences of entry-level students relative to learning and practicing professional behaviors. The following section outlines the specific research questions for Investigation A. 
Specific research questions.

1. Do entry-level physical therapy students have an appreciation for the importance of learning professional behaviors as part of a physical therapy education? (Items 1, 5, and 6)

2. Do entry-level physical therapy students view their professors as positive professional role models? (Items 2 and 9)

3. Do entry-level physical therapy students view their clinical instructors as positive professional role models? (Items 3, 10, and 14)

4. Are physical therapy students aware of the American Physical Therapy Associations efforts to promote professionalism? (Item 8)

5. Compared to other professions, how do entry-level physical therapy students view professionalism in the physical therapy profession? (Item 12)

6. From an entry-level students' perspective, what are the most frequent negative behaviors demonstrated by physical therapy students? (Item 13)

7. From an entry-level students' perspective, what are the seven most important professional skills for a practicing physical therapist? (Item 15)

8. Which educational strategies are being used to teach professionalism and do entry-level physical therapy students find these strategies appealing? (Items 16 and 17) 
9. Is there a difference in self-perception of professionalism based on the following demographic variables? (Items 12 and 18)
a. Years in college
b. Length of study in a PT program
c. GPA
d. Age
e. Gender
f. Clinical affiliation experience
g. Type of program

10. Is there a difference in the frequency of observed negative behaviors based on selected program and demographic variables? (Items 13 and 18)
a. Degree Type
b. Institution Type
c. Size of the University
d. Years in PT school

Entry-level student survey instrument. As stated previously, the entry-level student survey instrument (Appendix A) was a four-page locally developed paper and pencil survey that was designed to assess the attitudes, beliefs, and experiences of physical therapy students relative to learning and developing professional behaviors as part of an entry-level physical therapy education. The survey instrument was subdivided into seven sections (A-G) based on the nature of the questions.

Section A contained eight closed-ended questions that were designed to assess the participant's attitudes and experiences related to the importance of incorporating professionalism education in a physical therapy curriculum. This section also attempted to identify how familiar students are with the efforts of the American Physical Therapy Association to promote professionalism education. 
Section B of the survey contained four questions that were designed as a self-assessment of the student's professional behaviors, and to compare the student's level of professionalism to faculty, clinical instructors, and classmates. This section also attempted to compare the student's perception of professionalism in physical therapy to two of the three (medicine and clergy) prototypical professions identified by Cullen (1978) and other healthcare professions.

Section C contained two questions that were designed to assess the frequency of negative behaviors of the respondent's classmates compared to the negative behaviors observed by the respondent's clinical instructors. Each negative behavior was assessed with a five-point modified Likert scale (never, infrequently, occasionally, often, and very often).

Section D of the survey contained one question, and attempted to identify key or core professional skills and behaviors that are required for successful practice as a physical therapist. The participants were asked to identify the seven most important core values or skills necessary for successful practice as a physical therapist. This allowed for comparison of the student responses to the seven core values identified by the APTA, and by practicing clinicians.

Section $\mathrm{E}$ of the survey contained two questions that were intended to assess the utilization of various teaching strategies in the respondent's educational program to foster professional behaviors. This section also asked the participants to identify the educational strategies that are most appealing to them as a method of learning professional behaviors. Teaching methods included portfolios, reading assignments, role-playing, small group discussions, lecture, case studies, generic abilities, formal meetings with advisors, literature/metaphors, journals, and role-modeling.

Section $\mathrm{F}$ of the survey contained questions related to demographic information of the 
participants. Items included years in college, years in PT school, overall grade point average, grade point average in PT school, age, and gender). This section also attempted to categorize the participant's program by public or private, number of students enrolled in the program, degree type [Masters of Physical Therapy (MPT) or Doctor of Physical Therapy (DPT)], and the size of the institution.

Section $\mathrm{G}$ was designed as an open-ended qualitative assessment, which allowed participants to offer additional information relating to their experience learning and developing professionalism during their entry-level physical therapy education. Respondents were free to express their comments in any chosen format. The open-ended question was important in order to capture any information not otherwise obtained by the closed-ended questions.

Content validity, pilot testing, and IRB approval. In order to establish content validity of the survey instrument, the questionnaire was reviewed by three physical therapy faculty members at West Virginia University, five doctoral committee members, and pilot tested with 10 entry-level physical therapy students at West Virginia University. The faculty reviewers and the students were asked to complete the survey and to provide additional comments related to the content of the questions and the ease of completion. The survey instrument was revised based on the feedback and responses of these individuals. Based on the pilot testing, 10-15 minutes was required to complete the survey. Before the administration of the survey, an exemption from the West Virginia University Institutional Review Board for the Protection of Human Subjects was obtained.

Participants. All entry-level physical therapy students $(2,030)$ at 20 randomly selected accredited physical therapy programs were targeted to receive the paper and pencil survey. 
Based on data obtained from the Physical Therapy Education Fact Sheet (2005) there are 197 accredited physical therapy programs in the United States. The average class size is reported to be 31.7 students. The average number of classes (cohorts) per program is three. Therefore, the estimated total number of physical therapy students in the United States is $(197 \times 31.7 \times 3=$ $18,735)$. Thus, the mailing $(2,030 / 18,735)$ represented $10.8 \%$ of the available population. The anticipated response rate before the investigation was 20-30 percent, thus the anticipated number of completed and returned surveys ranged between 380 and 571 .

Sampling procedure. Several variables, geographic region, number of faculty, class size, faculty student ratio, institutional type, and program type were considered as potential stratification variables. However, a simple random sample was ultimately used because there was no available information to suggest an alternative sampling strategy.

The random sample was obtained by listing all 197 accredited physical therapy programs in an Excel spreadsheet. Using the Excel random number generator, a random number was assigned to each program. The 20 programs (Appendix B) with the smallest random numbers were selected for inclusion in this investigation.

To ensure that the random sample was representative of the population, a detailed analysis (Appendix C) of program characteristics was compared to normative data obtained from the American Physical Therapy Association. The detailed analysis of essential program characteristics revealed that the random sample of programs was representative of the population of interest.

Distribution procedures. The chairperson's name and address for each of the 20 randomly selected programs was obtained from information available on the Internet. A package 
containing a cover letter to the chairperson (Appendix D), and the specified number of student survey packets was mailed to the chairperson of each program. The chairperson was asked to ensure the distribution of the surveys to all students enrolled in the professional phase of the physical therapy program. The chairpersons were asked to notify the investigator if they chose not to participate in the investigation.

The student packet included an IRB approved cover letter (Appendix E), a student survey instrument, and a self-addressed stamped postcard (Appendix F) that served as an entry form for a random drawing. The random drawing was for a $\$ 100.00$ APTA gift certificate that could be used for any APTA sponsored product (dues, books, seminars, etc). Each survey was coded by geographic region (Northeast, South, Midwest, West) according to the U.S. Census Bureau map (Appendix G).

Follow-up procedure. Approximately two weeks after the initial mailing an electronic mail message was sent to the chairperson of each selected program thanking him or her for their participation and asking them to encourage student participation. Follow-up with each participant was impossible because of lack of contact information. An apriori plan was in place to randomly select a replacement program if a chairperson chose not to participate in the investigation (Babbie, 1990).

Data analysis. Each of the closed-ended questions produced data that were measured on a nominal, ordinal, or continuous scale. Therefore, quantitative data analysis consisted primarily of reporting frequency distributions with both actual numbers and percentages. A statistical software package (JMP, Cary, NC) was used for all quantitative data analysis. Due to a lack of normality, several research questions were answered using non-parametric inferential statistical 
analysis. Non-parametric exploratory data analysis utilized the Mann-Whitney U-test (two levels of the independent variable), the Kruskal-Wallis test (greater than two levels of the independent variable), or a Pearson Product Moment Correlation. An alpha level of 0.05 was established a priori. Post-hoc analysis was performed using a Mann-Whitney U-test with a Bonferroni correction to control for Type I error.

Qualitative analysis of the open-ended question consisted of content analysis using coding, clustering, and counting to organize responses and identify key themes. For each theme, representative examples were reported. All responses to the open-ended question were read and then organized according to the emergent themes. Responses were coded based on the concepts or ideas that were identified. After all concepts were coded or classified, they were clustered into like responses. Each cluster was counted and reported in a table format with three columns, which were labeled theme, count, and representative examples (Gay \& Airasian, 2000; Patton, 1990; Smith \& Osborn, 2003).

Data analysis procedure. To promote systematic analysis, a data analysis procedure table (Table 3.1) was created. The table contains three columns that represent the research question, the variables of interest, and the statistical method that was used to answer the research question. 
Table 3.1a

Entry-level Student Data Analysis Procedure

\section{Research Question}

Variables

Data Analysis

1. Do entry-level physical therapy students have

Item 1 , ordinal variable

Frequency count

a positive appreciation for the importance of

Item 5, ordinal variable

Frequency count

learning professionalism as part of a physical

Item 6 , ordinal variable

Frequency count

therapy education?

2. Do entry-level physical therapy students view Item 2, ordinal variable

Frequency count

their professors as positive professional role

Item 9, ordinal variable

Frequency count

models that possess a high level of

professionalism compared to their own?

3. Do entry-level physical therapy students view Item 3, ordinal variable

Frequency count

their clinical instructors as positive

Item 10 , ordinal variable

Frequency count

professional role models that possess a high

Item 14 , ordinal variable

Weighted averages

level of professionalism compared to their

own?

4. Are physical therapy students aware of the

Item 8 , ordinal variable

Frequency count American Physical Therapy Associations

efforts to promote professionalism?

5. Compared to other professions, how do entry- Item 12, interval variable

Median and Mean level physical therapy student view the level

Shapiro-Wilk Test

of professionalism of the physical therapy

profession? 
Table $3.1 \mathrm{~b}$

Entry-level Student Data Analysis Procedure

6. From an entry-level physical therapy student's perspective, what are the most frequent negative behaviors demonstrated by physical therapy students?

7. From an entry-level physical therapy student's perspective, what are the seven most important professional skills?

8. Which teaching strategies are being used to teach professionalism and do entry-level physical therapy students find these strategies appealing?

9. Is there a relationship or difference in selfperception of professionalism based on the following demographic variables?
Item 13 , ordinal variable

Weighed averages
Item 15 , nominal variable

Item 16, nominal variable

Item 17 , nominal variable
Frequency count

Frequency count
Item 12 , interval variable and selected items from Item 18: Years in PT program (Ordinal) GPA (Ordinal) Age (Ordinal) Gender (Nominal)

Clinical experience (Ordinal) Degree type (Nominal) Class size (Interval)

Item 13 (Ordinal Variable) and selected items from Item 18: Degree Type (Nominal) Institution Type (Nominal) Size of the University (Ordinal) Years in PT school (Ordinal)
Kruskal-Wallis Test Kruskal-Wallis Test Kruskal-Wallis Test Mann-Whitney U Kruskal-Wallis Test Mann-Whitney U Pearson Correlation
10. Is there a difference in the frequency of observed negative behaviors based on selected program and demographic variables?
Mann-Whitney U Mann-Whitney U Kruskal-Wallis Test Kruskal-Wallis Test 
Investigation B (Licensed Physical Therapist Survey)

As discussed with the entry-level student survey, the research design for Investigation B, was descriptive and exploratory (Babbie, 1990), using a cross-sectional survey design. The survey instrument was a four-page paper and pencil questionnaire that was designed to identify the attitudes, beliefs, and experiences of licensed physical therapists relative to teaching and fostering professional behaviors among entry-level physical therapy students and new graduates. The following section outlines the specific research questions for Investigation B.

\section{Specific research questions.}

1. Do licensed physical therapists have an appreciation for the importance of learning professionalism as part of a physical therapy education? (Items 1, 5, and 6)

2. Based on their observation of physical therapy students, do licensed physical therapists view PT students as possessing positive professional behaviors? (Item 2)

3. Based on their observation of new graduates during the first year of clinical practice, do licensed physical therapist view new graduates as possessing positive professional behaviors? (Item 3)

4. Do licensed physical therapist believe that age is a predictor of professional behaviors among entry-level physical therapy students? (Item 8)

5. Compared to other professions, how do licensed physical therapists view the level of professionalism of the physical therapy profession? (Item 9)

6. From a licensed physical therapist's perspective, what are the most frequent negative behaviors demonstrated by entry-level physical therapy students? (Item 10)

7. From a licensed physical therapist's perspective, what are the seven most 
important professional skills for a practicing physical therapist? (Item 13)

8. Based on the opinion of licensed physical therapist with seven or more years of experience, are students and new graduates today, more professional than students or new graduates in previous years? (Item 15)

9. Based on the opinion of licensed physical therapists, is there a difference in the level of student professionalism based on the following therapist demographic variables? (Items 9 and 18)
a. Years of clinical experience
b. Age
c. Gender
d. Work status
e. Practice setting
f. Geographic region
g. Membership status

Survey instrument. The licensed physical therapist survey instrument (Appendix H) was a four-page locally developed paper and pencil survey that was designed to assess the attitudes, beliefs, and experiences of licensed physical therapist regarding the state of professionalism in physical therapy. The survey instrument was subdivided into five sections (A-E) based on the nature of the questions.

Section A contained eight closed questions that were designed to assess the participant's attitudes related to the importance of incorporating professionalism education in a physical therapy curriculum. This section also attempted to identify the current level of professionalism among entry-level physical therapy students and new graduates.

Section B of the survey contained four questions that were designed to compare the degree of professionalism of physical therapists with that of prototypical professions and other 
health care related professions. This section also attempted to identify the most common negative behaviors identified by entry-level physical therapy students, new graduates, and practicing physical therapists.

Section C contained three questions designed to identify key or core professional skills or behaviors that are required for successful practice as a physical therapist and to determine if there is a perceived decline in professional behaviors among entry-level physical therapy students by licensed therapists who have been practicing for seven or more years.

Section D of the survey contained questions related to demographic information of the participants. Items include degree type, years of clinical experience, age, gender, work status, practice setting, size of the facility, and APTA membership status.

Section E was designed as an open-ended qualitative assessment, which allowed participants to offer additional information relating to their experience teaching and fostering professionalism among entry-level physical therapy students. Respondents were free to express their comments in any chosen format. The open-ended question was important in order to capture any information not otherwise obtained by the closed-ended questions.

Content validity, pilot testing, and IRB approval. In order to establish content validity of the survey instrument, the survey was reviewed by three physical therapy faculty members at West Virginia University, five doctoral committee members, and pilot tested with 10 licensed physical therapists in the Morgantown area. The faculty reviewers and the physical therapists were asked to complete the survey and to provide additional comments related to the content of the questions and the ease of completion. Based on the reviews from these individuals, no changes were suggested for this survey instrument. Based on the pilot testing, it was anticipated 
that it required 10-15 minutes for the respondents to complete the survey. Before the administration of the survey, an exemption from the West Virginia University Institutional Review Board for the Protection of Human Subjects was obtained.

Participants. Participants included 1,000 licensed physical therapist targeted to receive the paper and pencil survey. Based on data from the APTA, 42,188 APTA members are licensed physical therapists. Thus, the proposed sample $(1,000 / 42,188)$ represents $2 \%$ of the available population. The anticipated response rate was 20-30 percent, thus the anticipated number of completed and returned surveys ranged between 200 and 300 .

Sampling Procedure. As stated previously, the goal of any investigation is to ensure that the sample is representative of the population of interest. Given the lack of evidence to support another sampling method, a simple random sample was chosen.

The random sample was obtained by purchasing a randomly selected mailing list from the American Physical Therapy Association. According to the staff at the APTA, a random number generator was used to randomly select the 1,000 names and addresses from the full list of names available.

Distribution procedures. A package containing an IRB approved cover letter (Appendix I), the survey instrument, an entry form for a $\$ 100.00$ APTA gift certificate and a self-addressed stamped envelope were mailed directly to the home address of each randomly selected physical therapist.

Follow-up procedure. In order to maximize the response rate, a follow-up letter was mailed approximately two weeks after the initial mailing. The letter served as a reminder and to thank the participants for responding. 
Data analysis. Each of the closed-ended questions produced data that were measured on a nominal, ordinal, or continuous scale. Therefore, quantitative data analysis consisted primarily of reporting frequency distributions with both actual numbers and percentages. A statistical software package (JMP, Cary, NC) was used for all quantitative data analysis. Due to a lack of normality, several research questions were answered using non-parametric inferential statistical analysis. Non-parametric exploratory data analysis utilized the Mann-Whitney U-test (two levels of the independent variable), the Kruskal-Wallis test (greater than two levels of the independent variable), or a Pearson Product Moment Correlation. An alpha level of 0.05 was established a priori. Post-hoc analysis was performed using a Mann-Whitney U-test with a Bonferroni correction to control for Type I error.

Qualitative analysis of the open-ended question consisted of content analysis using coding, clustering and counting to organize responses and identify key themes. For each theme, representative examples were reported. All responses to the open-ended questions were read and then organized based on the emergence of themes. Responses were coded based on the concepts or ideas that were identified. After all concepts were coded or classified, they were clustered into like responses. Each cluster was counted and reported in a table format with three columns, which were labeled theme, count, and representative examples (Gay \& Airasian, 2000; Patton, 1990; Smith \& Osborn, 2003).

Data analysis procedure. To promote clarity, a data analysis procedure table (Table 3.2) was created. The table contains three columns that represent the research question, the variables of interest, and the statistical methods that were used to answer the research question. 
Table 3.2a

Licensed Physical Therapist Data Analysis Procedure

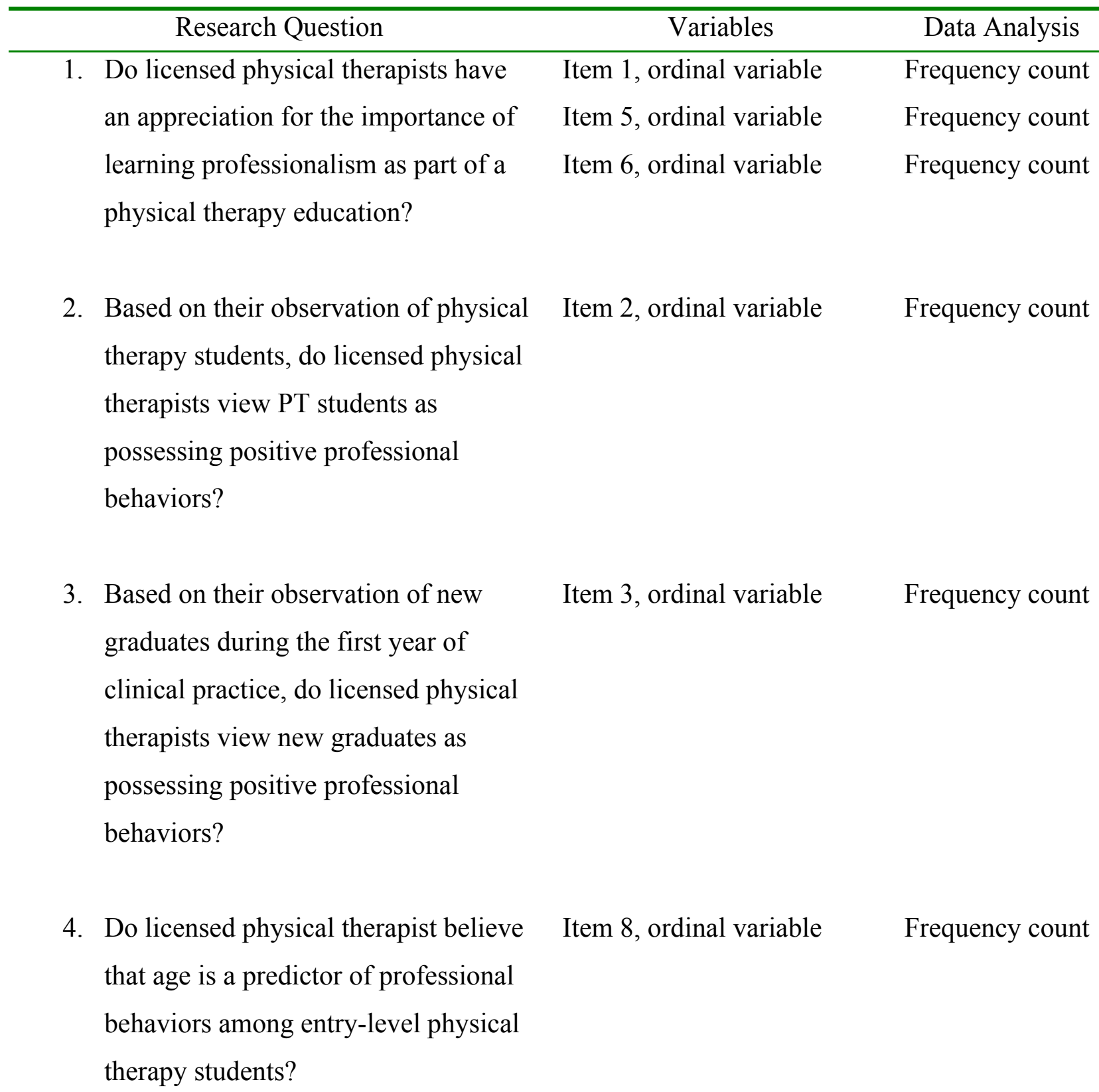


Table $3.2 b$

Licensed Physical Therapist Data Analysis Procedure

5. Compared to other professions, how Item 9, interval variable do licensed physical therapists view the level of professionalism of the physical therapy profession?

6. From a licensed physical therapist's perspective, what are the most

frequent negative behaviors

demonstrated by entry-level physical therapy students?

7. From a licensed physical therapist's perspective, what are the seven most important professional skills?

8. Based on the opinion of licensed physical therapist with seven or more years of experience, are students and new graduates today, more professional than students or new graduates in previous years?

9. Based on the opinion of licensed physical therapists, is there a difference in the level of student professionalism based on the following therapist demographic variables?
Item 9 , interval variable and selected items from Item 18:

PT degree

Years of clinical exp.

Age

Gender

Work status

Practice setting

Geographic region
Median and Mean Shapiro Wilk Test

Weighted Averages

Weighted Averages
Item 13, nominal variable Frequency count

Item 15, ordinal variable Frequency count
Mann-Whitney U

Kruskal-Wallis Test Kruskal-Wallis Test Mann-Whitney U Mann-Whitney U Kruskal-Wallis Test Kruskal-Wallis Test 


\section{CHAPTER 4}

\section{RESULTS}

Physical Therapy Student Survey (Investigation A)

Respondents. A total of 336 surveys from the 2,030 student surveys mailed were returned. The cover letter accompanying the student surveys, asked the chairperson to contact the investigator if they were unable to participate in the investigation. The chairperson from one program (University of Indianapolis) contacted the primary investigator asking for additional information to ensure the West Virginia University Institutional Review Board for the Protection of Human Subjects approved the survey. After additional information was sent to this chairperson, he agreed to participate by distributing the surveys to his students. One chairperson (Hampton University) contacted the primary investigator because the program's student enrollment had dramatically fallen. The chairperson returned 41 extra surveys.

Following data collection, it was recognized that the enrollment numbers obtained from the survey were less than the numbers reported on the program web sites. Therefore, a postanalysis phone survey was conducted to determine an accurate count of the total number of available students from the 20 randomly selected programs at the time of the survey. The posthoc phone survey revealed that one program (Sacred Heart University) never received the student survey package. Thus, the survey actually sampled 19 programs. The phone survey revealed that the total number of students available for participation was 1,525 (see Appendix J). Therefore, the response rate $(336 / 1,525)$ for the student survey was $22.0 \%$.

Demographic variables. All 336 respondents indicated their gender. Of the 336 students reporting gender, $255(75.9 \%)$ were women and $81(24.1 \%)$ were men. The age distribution of 
the respondents is listed in Figure 4.1. Of the 336 surveys returned, 332 respondents indicated their age, while four participants left the item blank. The majority, $276(83.1 \%)$ students were between 21 and 30 years of age.

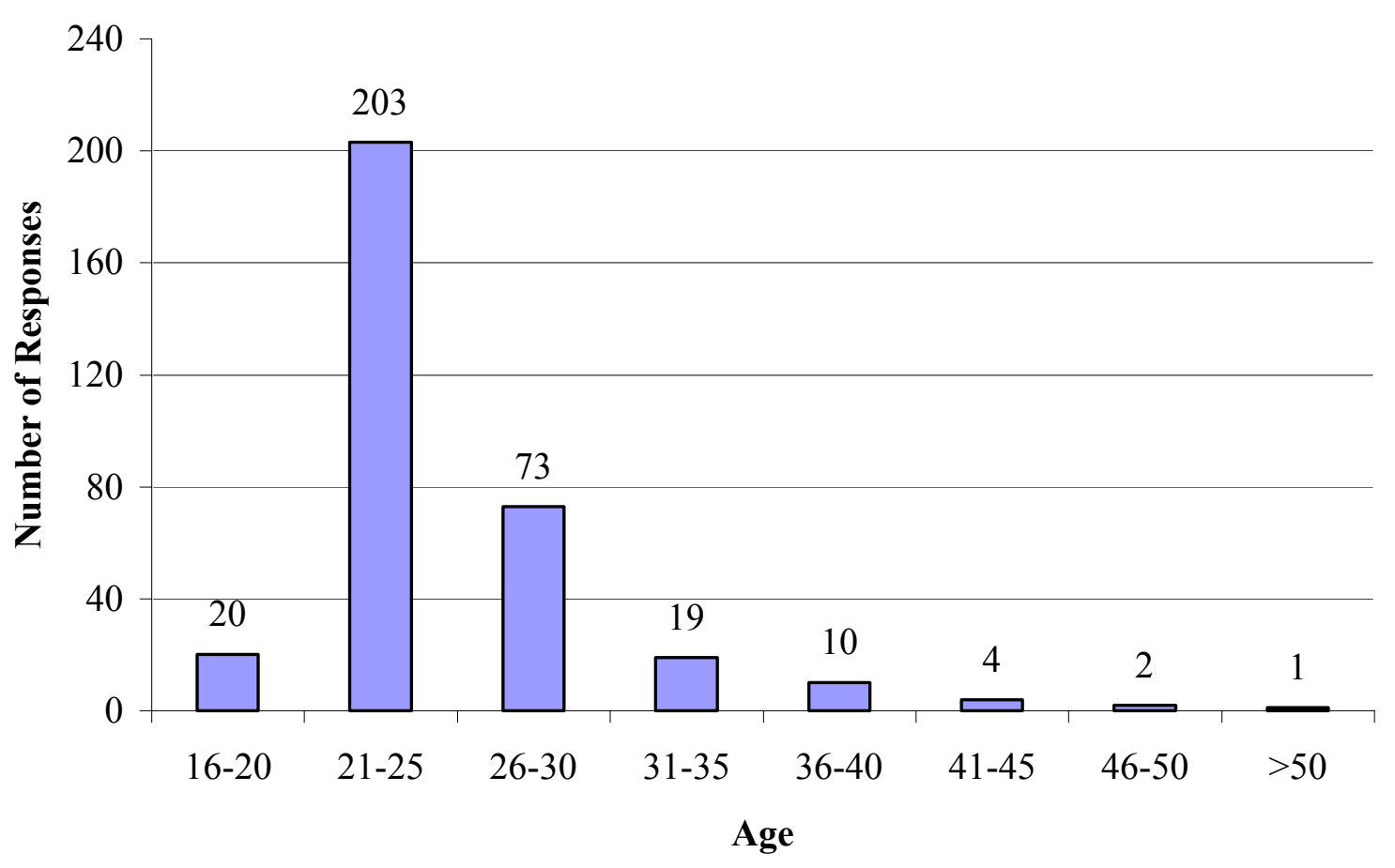

Figure 4.1. Age distribution of participants.

All 336 respondents indicated their attendance status (full or part-time). Of the 336 respondents, $333(99 \%)$ indicated that they were attending full-time, while only three (1\%) participants indicated they were attending part-time. Of the 336 returned surveys, 228 students indicated the number of years they have attended college. The average number of years enrolled in college was 5.5 years with a median of 5 years.

A total of 333 respondents indicated the number of years enrolled in physical therapy 
school. The distribution of years in physical therapy school is presented in Figure 4.2. One student indicated that they had been in the PT program 4 years. Since no schools offer a fouryear program, it is possible that this student had repeated a year.

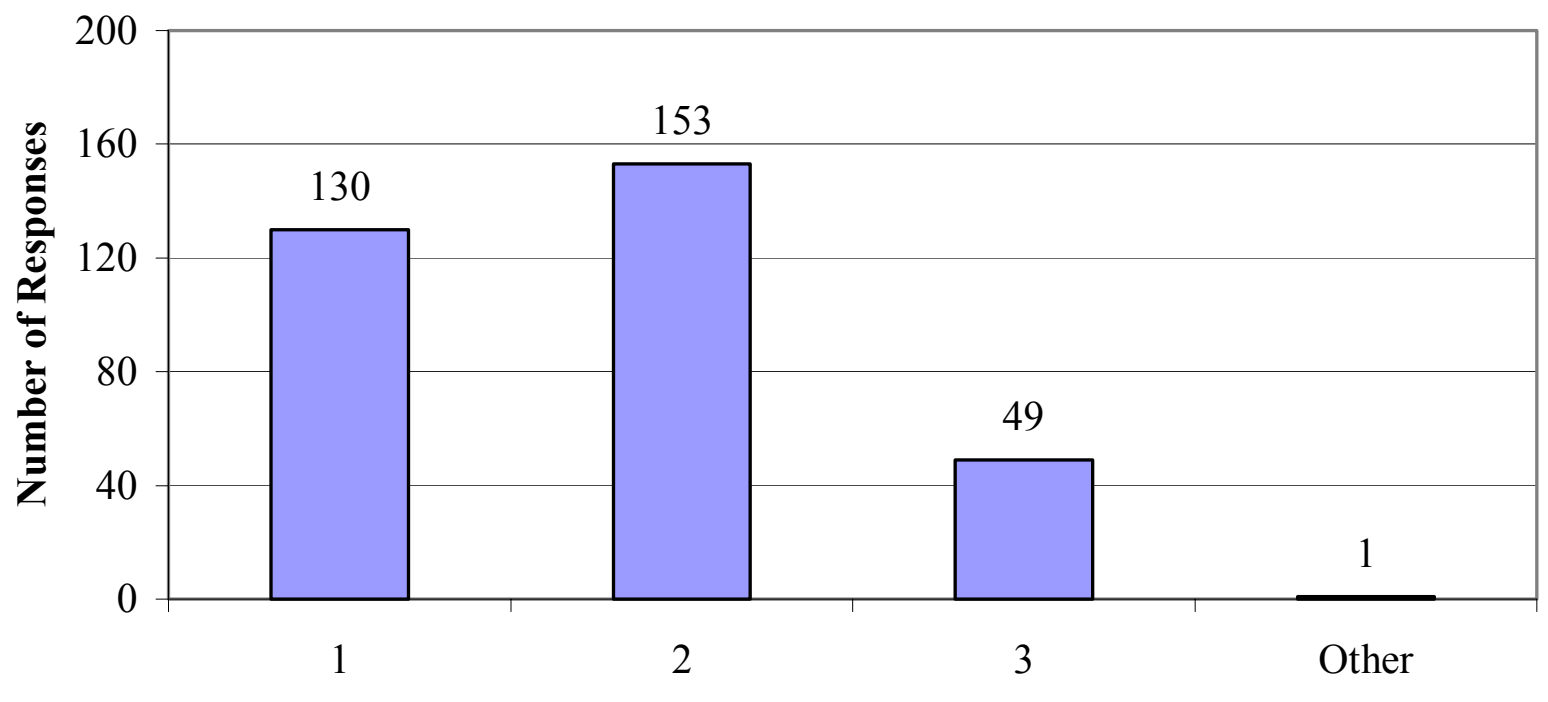

Years in PT school

Figure 4.2. Distribution of PT school experience.

All but one respondent $(n=335)$ indicated their degree of clinical experience. Figure 4.3 depicted the distribution of clinical experience of the respondents. The distribution revealed that $249(74.3 \%)$ students had less than seven weeks of clinical experience. It is important to note that an error was made in the construction of this survey item. Inadvertently, the survey fails to account for students with six weeks of clinical experience. Students were forced to choose $<6$ weeks or 7-12 weeks. Since only one respondent failed to answer this item, it is presumed that the participants with exactly six weeks of clinical experience chose to round up or round down their answer to fit one of the available responses. None of the respondents made a mark on their survey indicating concern or difficulty answering this question due to the error. 


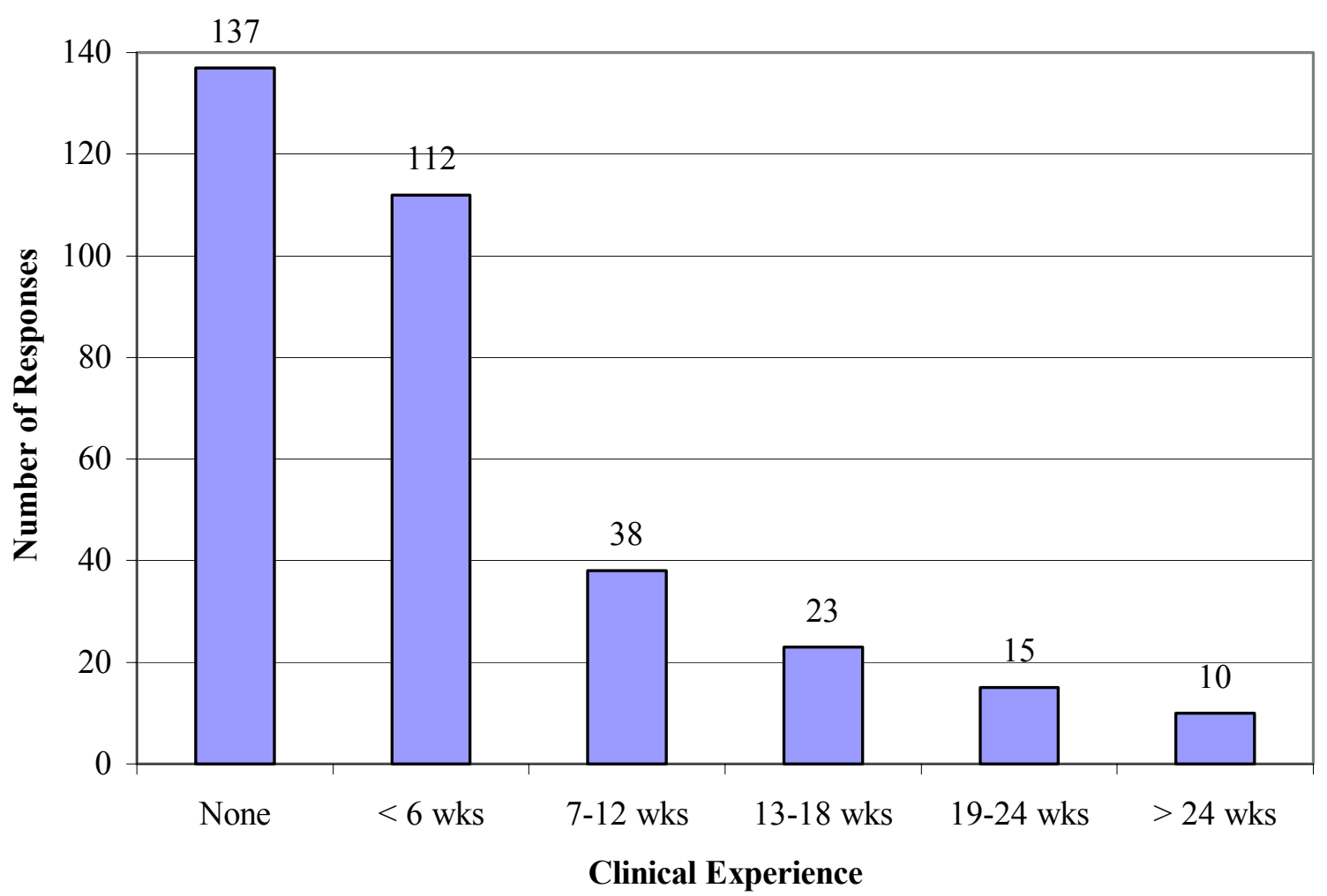

Figure 4.3. Clinical affiliation experience.

Every respondent $(n=336)$ indicated the type of degree program in which he or she was enrolled. In this sample, $74.1 \%$ of respondents were enrolled in a program that offered the DPT degree. Figure 4.4 depicts the distribution of responses based on degree type. 


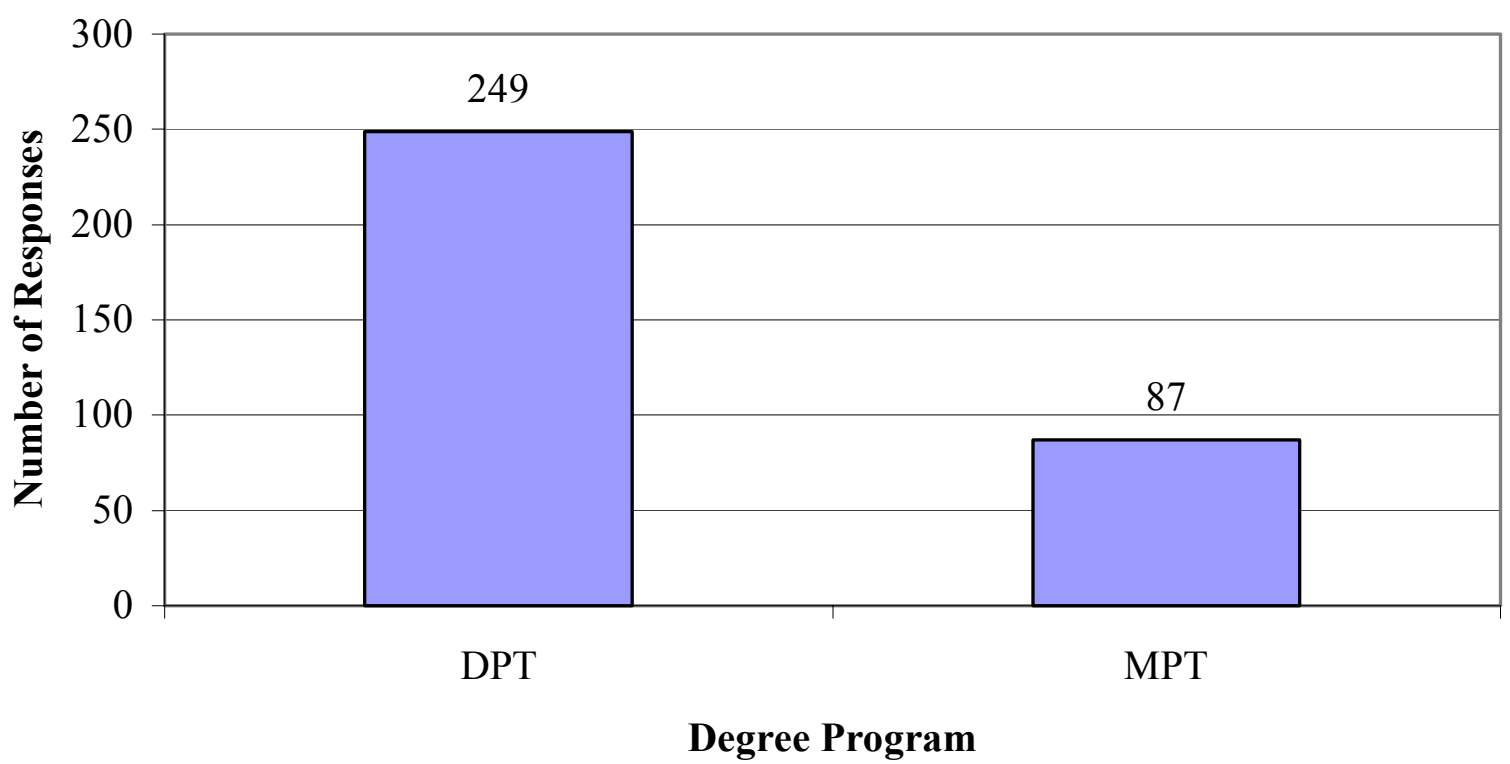

Figure 4.4. Degree designation on graduation.

Additional variables related to program characteristics include class size and the number of full-time faculty. All 336 respondents indicated their class size. The average class size in this sample was 33.6, with a median of 32 . The class sizes ranged from 8-52. Of the 336 returned surveys, $280(83 \%)$ indicated the number of full-time faculty at their program. The average number of full-time faculty was 8.7 with a median of eight.

All but two $(n=334)$ respondents indicated institution type. The distribution of institution type (public or private) is presented in Figure 4.5. The percentage of respondents from public programs in this sample was $52.7 \%$. 


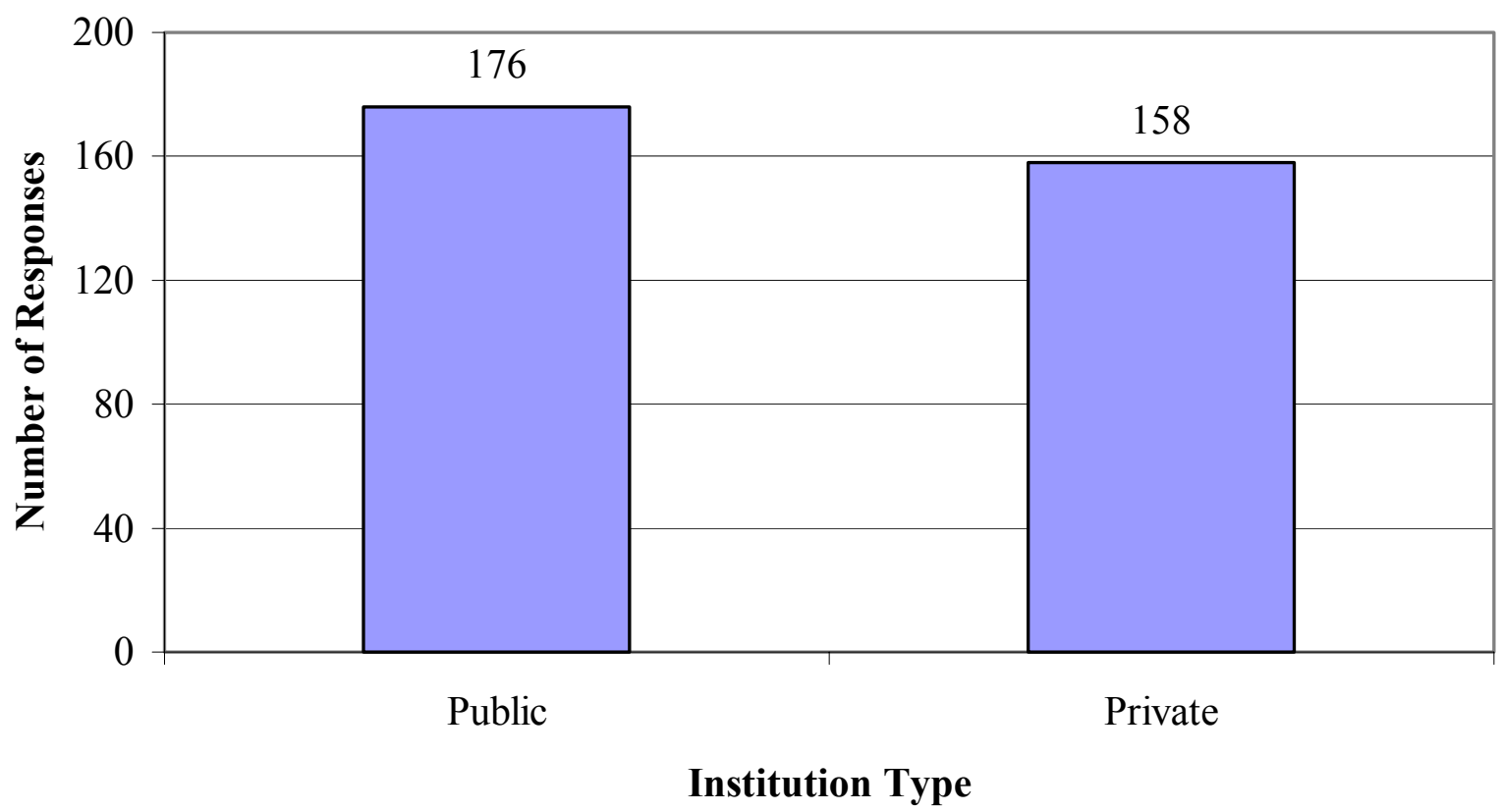

Figure 4.5. Type of institution attending.

The last demographic variable of interest was geographic region. The distribution of geographic region is presented in Figure 4.6. The largest percentage of respondents was from the South $(37.3 \%)$, while the lowest percentage of respondents was from the Northeast $(6.0 \%)$. 


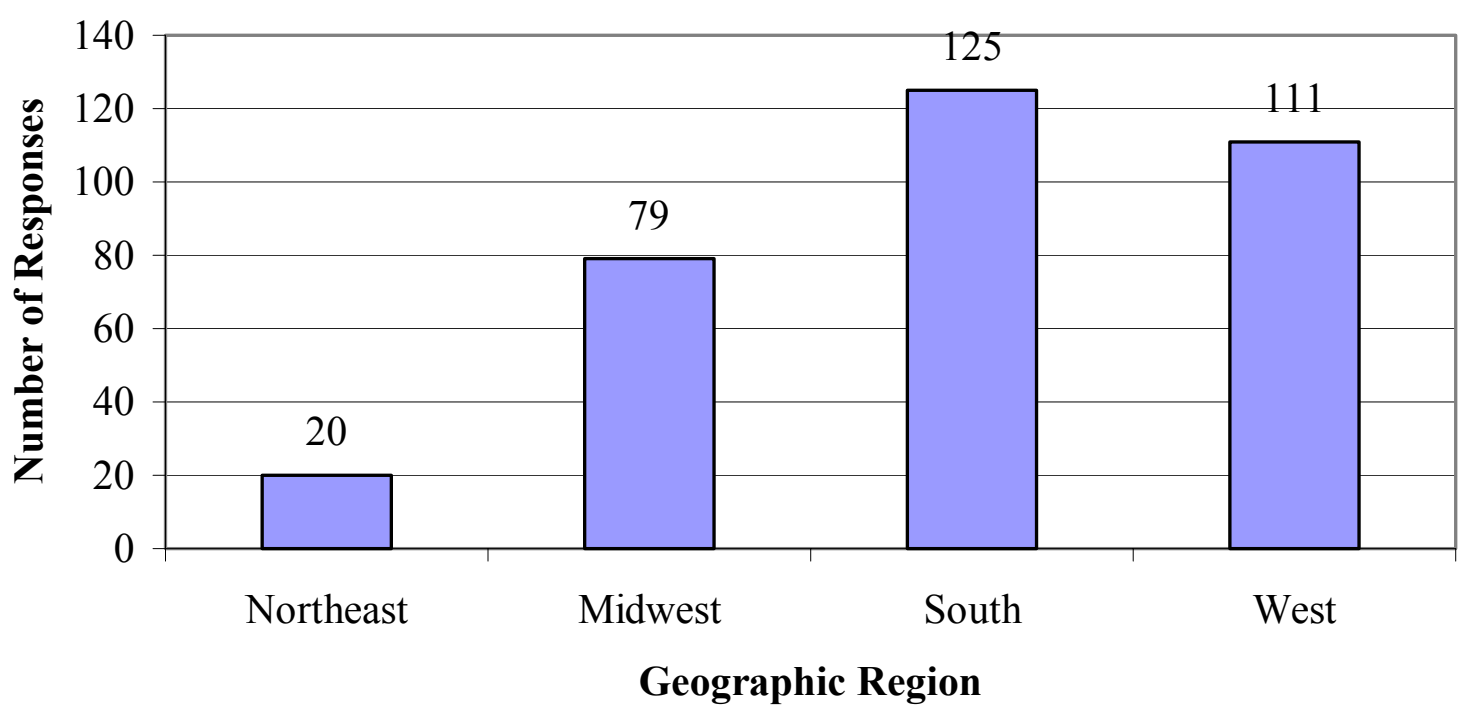

Figure 4.6. Geographic region of the PT programs.

Specific Research Questions

Research question 1 (Student Survey). Do entry-level physical therapy students have a positive appreciation for the importance of learning professionalism as part of a physical therapy education?

Three items from the survey (Items 1, 5, and 6) were used to answer this research question. Item 1 asked the participants to respond to the following statement using a modified Likert scale from strongly disagrees to strongly agrees: Teaching and fostering professional behaviors is an important part of a physical therapy education. Figure 4.7 depicts a frequency distribution of the responses. Of the 336 surveys returned, 335 participants responded to Item 1. Ninety eight percent of the respondents agreed or strongly agreed to the statement, supporting their appreciation of teaching and fostering professionalism as part of a physical therapy education. 


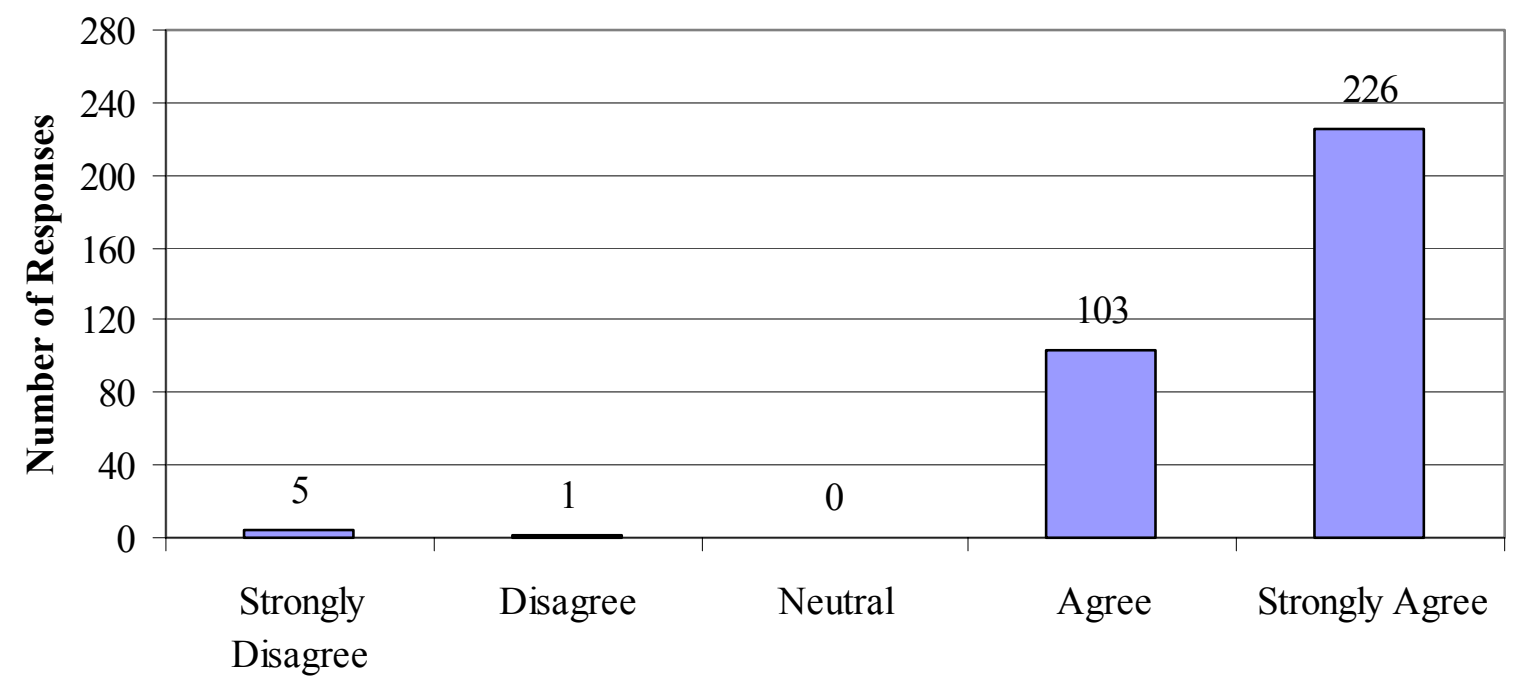

\section{Opinion}

Figure 4.7. Teaching professionalism is an important component of a PT education.

Item 5 was also used to answer this research question. This item asked the participant to respond to the following statement with the same modified Likert scale: Professionalism is a construct (concept) that can be learned. Of the 336 surveys returned 334 (99\%) participants responded to this item. Figure 4.8 displays a summary of the participants' responses. Again, a large percentage $(87.7 \%)$ of the respondents agreed or strongly agreed to this item, while only $2.3 \%$ disagreed or strongly disagreed. 


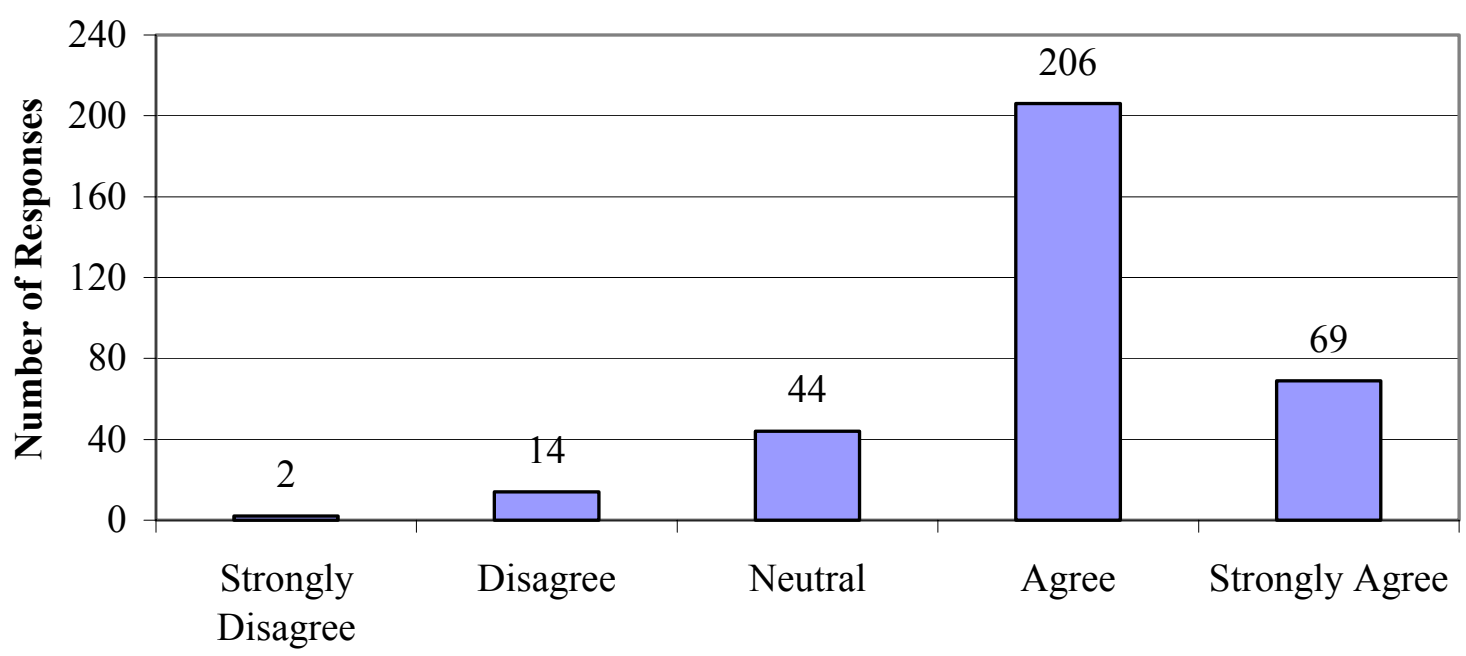

Opinion

Figure 4.8. Professionalism is a construct (concept) that can be learned.

The third survey item used to answer this research question was Item 6: Professionalism is a construct (concept) that can be taught. Of the 336 surveys returned, 335 participants answered this item. Figure 4.9 depicts a summary of the participant's responses. Again, a large percentage (82\%) of the respondents agreed or strongly agreed to the statement, while only $4.8 \%$ disagreed or strongly disagreed.

Answer Research Question 1 (Student Survey). Based on the responses of the participants to these three items, entry-level physical therapy students do have a positive appreciation for the importance of learning professionalism as part of a physical therapy education. 


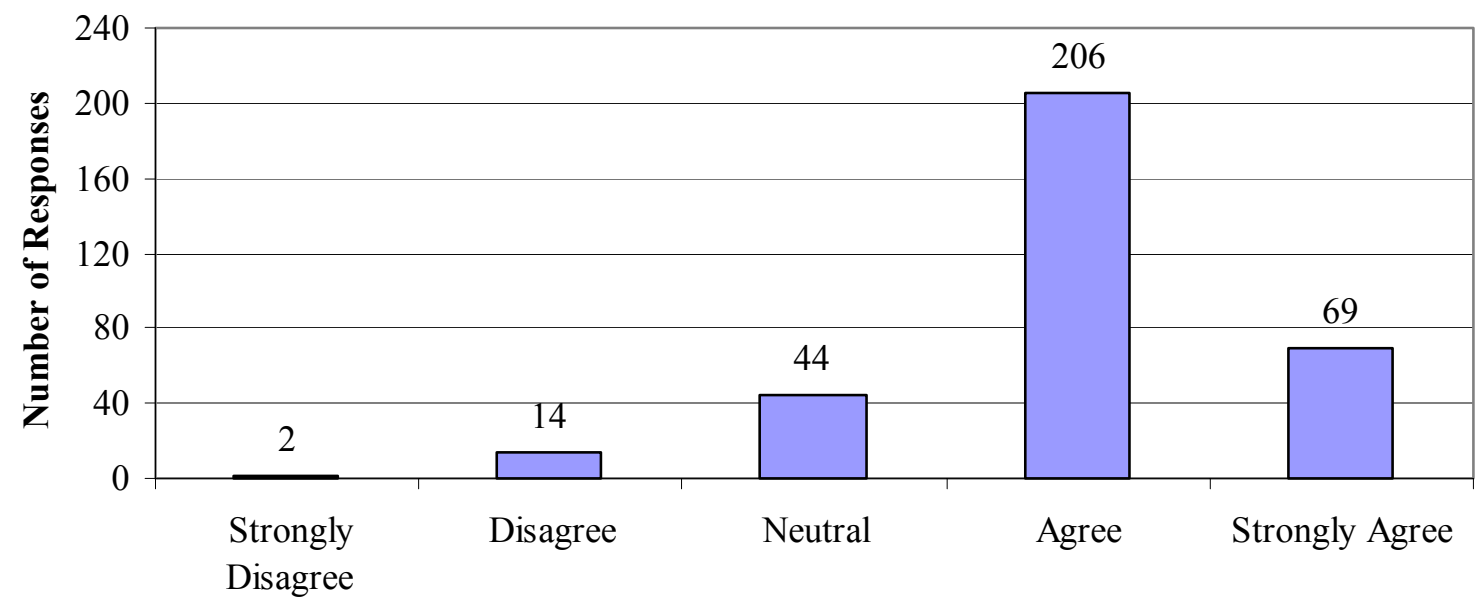

Opinion

Figure 4.9. Professionalism is a construct (concept) that can be taught.

Research question 2 (Student Survey). Do entry-level physical therapy students view their professors as positive professional role models that possess a high level of professionalism compared to their own?

Two items from the survey (Items 2 and 9) were used to answer this research question. The first item (Item 2) asked the participants to use a modified Likert scale to respond to the following statement: My professors demonstrate professional behaviors suitable for a professional role model.

All 336 participants responded to Item 2. The distribution of responses is presented in Figure 4.10. Of the 336 participants, 316 (94\%) agreed or strongly agreed that their professors demonstrate professional behaviors suitable for a professional role model. 


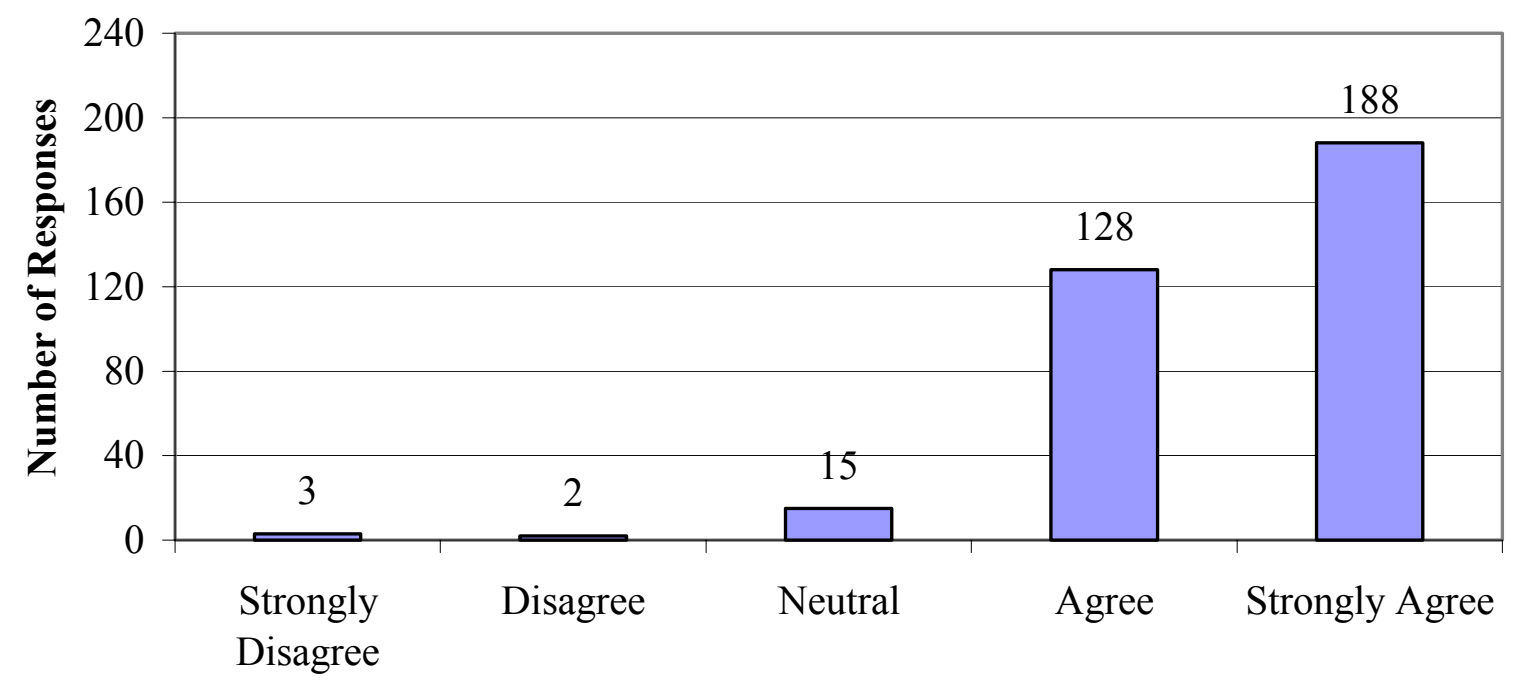

Opinion

Figure 4.10. My professors demonstrate professional behaviors.

The second item used to answer this question was Item 9, which was rated on a modified Likert scale from much less too much more. Participants were asked to respond to the following statement: How would you rate your degree of professionalism compared to your professors? All 336 respondents answered this item. The distribution of responses is displayed in Figure 4.11. Of the 336 responses 214 (63.7\%) indicated that they possessed the same degree of professionalism as their professors, while $6.5 \%$ indicated that they were more professional than their professors. Only $29.8 \%$ rated themselves as possessing less or much less professionalism than their professors.

Answer Research Question 2 (Student Survey). Based on the responses of the participants, physical therapy students view their professors as positive professional role models; however, some students do not recognize a differential between the their own level of professionalism and that of their clinical instructors. 


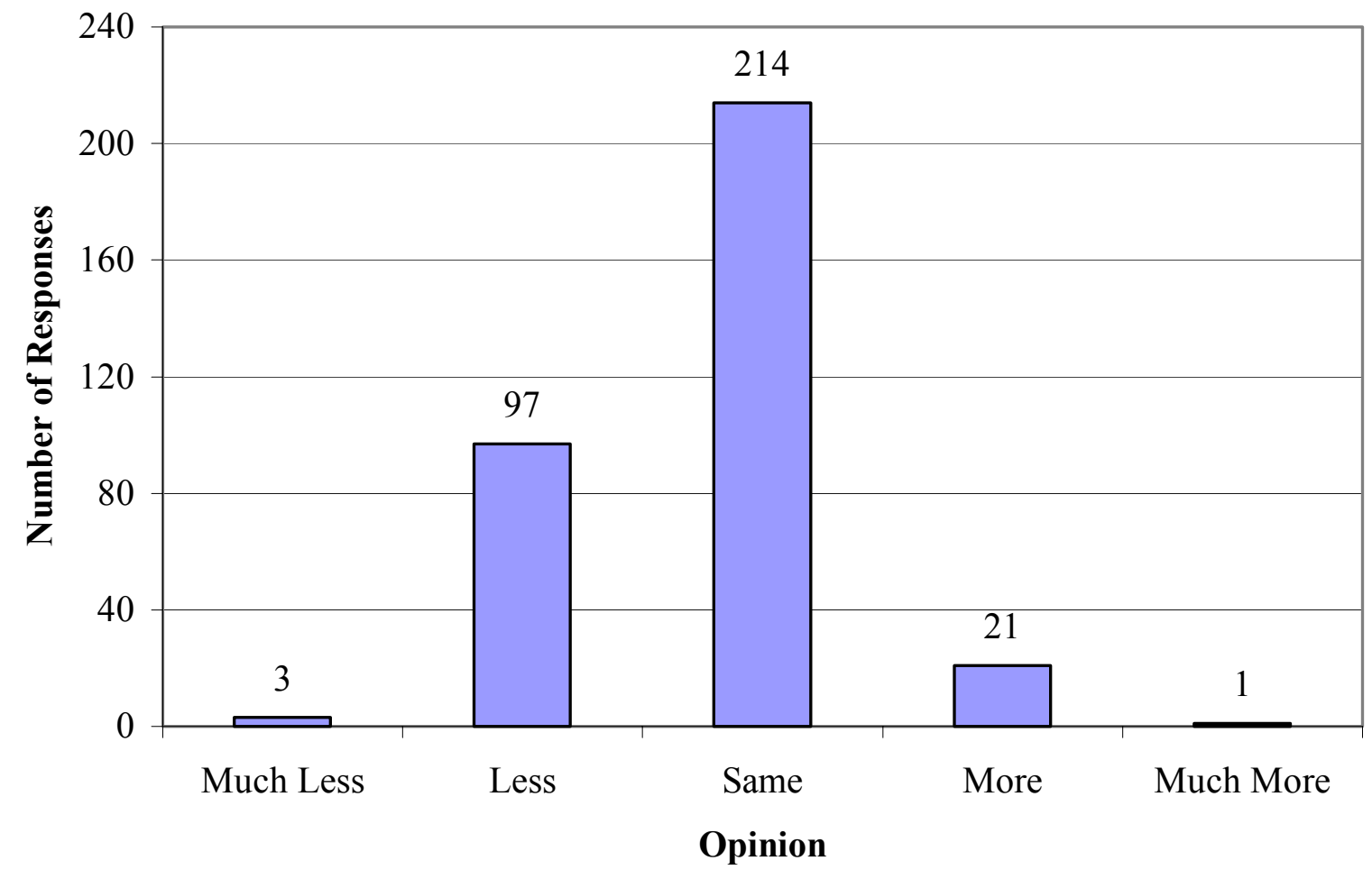

Figure 4.11. Students' self-perceptions of professionalism compared to that of their professors

Research question 3 (Student Survey). Do entry-level physical therapy students view their clinical instructors as positive professional role models who possess a high level of professionalism compared to their own?

This research question was answered by analyzing Items 3, 10, and 14. Item 3 asked participants to respond to the following statement using a modified Likert scale from strongly disagree to strongly agree: My clinical instructors demonstrate professional behaviors suitable for a professional role model. Of the 336 surveys returned, 218 (65\%) participants responded to this item. The remaining 118 participants indicated that they did not have any clinical 
experience to date. Figure 4.12 shows the distribution of the responses. Of the 218 responses, $194(89 \%)$ agreed or strongly agreed with this statement, while 5.5\% disagreed or strongly disagreed.

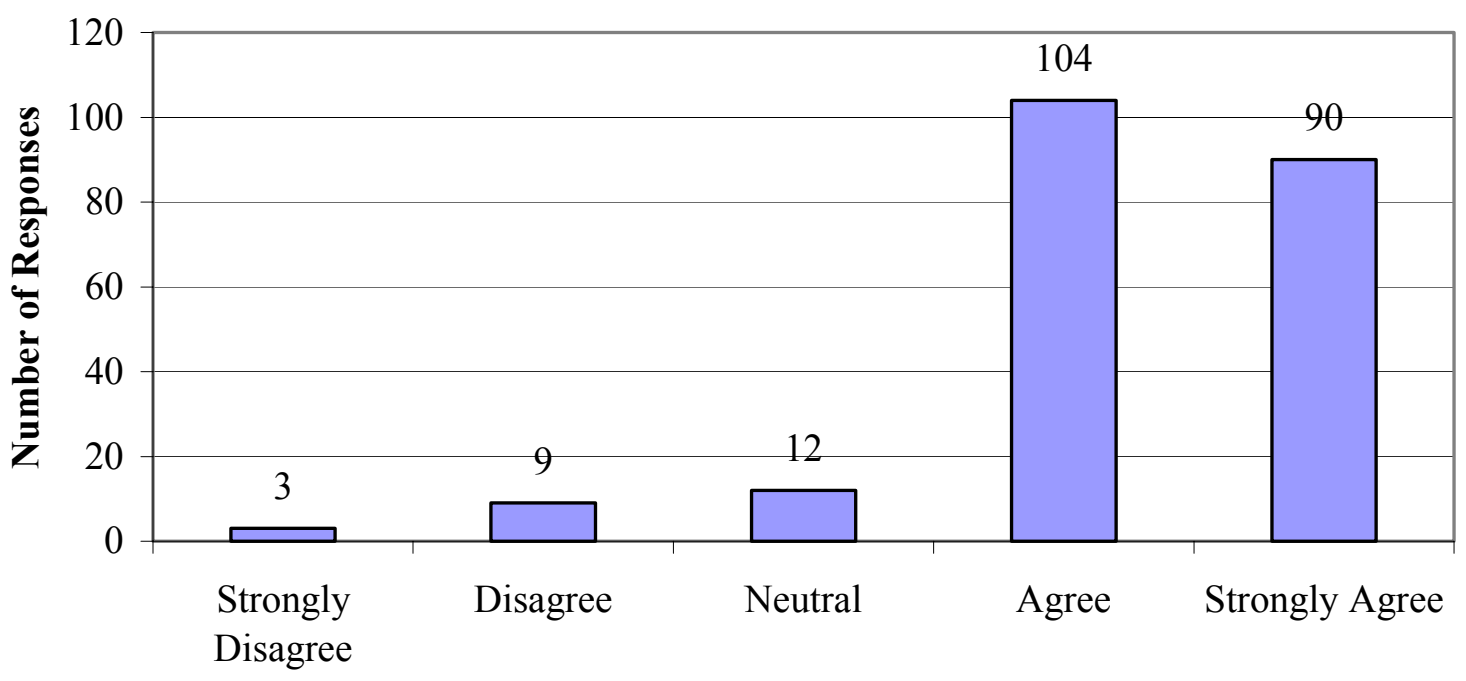

Opinion

Figure 4.12. My clinical instructors demonstrate professional behaviors.

The second item used to answer this question was Item 10, which asked the students to respond to the following question on a modified Likert scale from much less to much more: How would you rate your degree of professionalism compared to your clinical instructors? The distribution is presented in Figure 4.13. Of the 336 surveys returned, 215 (64\%) participants responded to Item 10. Of the 215 responses 46 (21.4\%) indicated that they possessed more or much more professionalism than their clinical instructors, while $36(16.8 \%)$ responded that they possessed less or much less professionalism than their clinical instructors. 


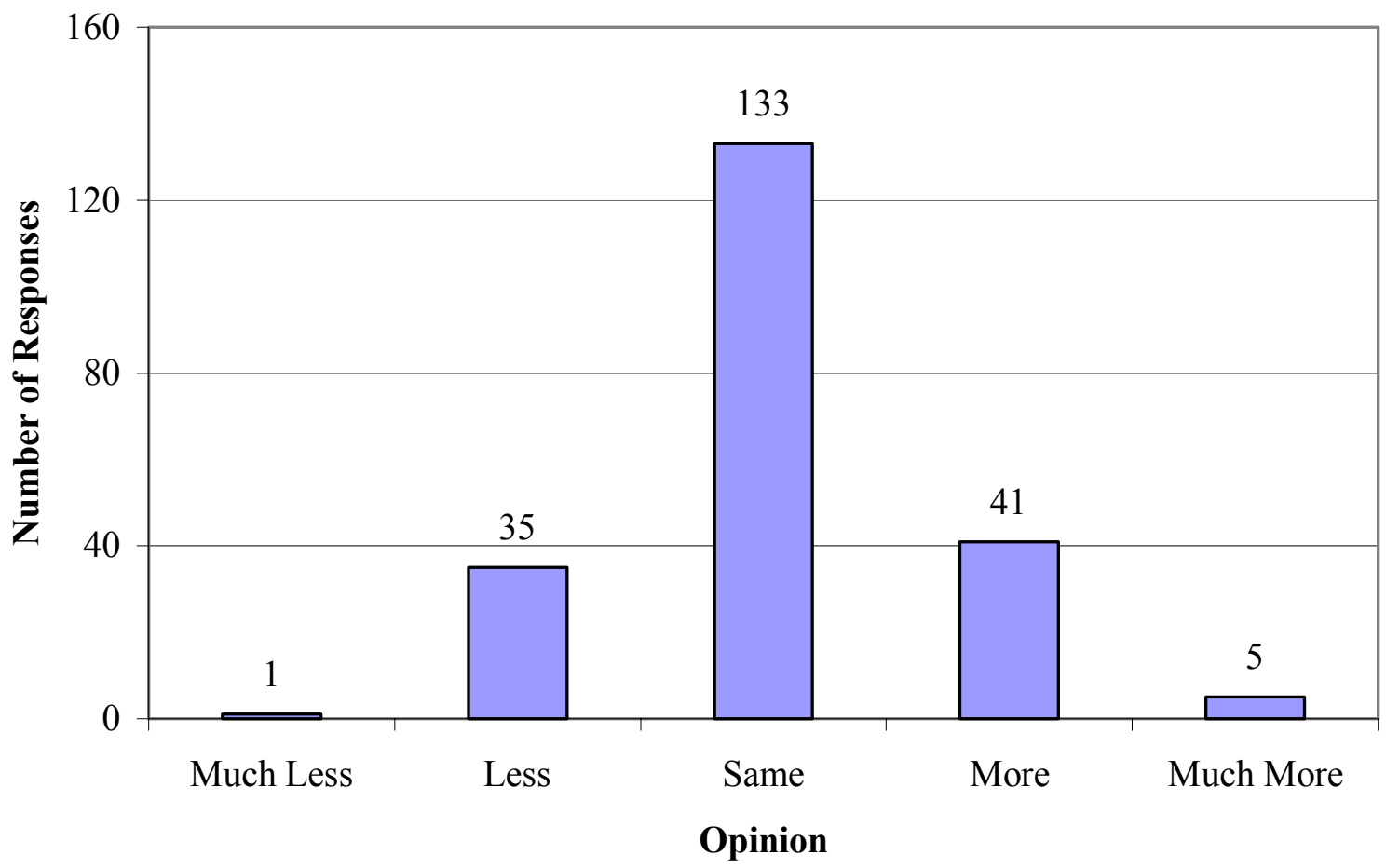

Figure 4.13. Student's self-perception of professionalism compared to clinical instructors.

The third item used to answer this research question was Item 14, which asked the participants to rank their clinical instructors on a modified Likert scale. The frequency of negative behaviors is presented as weighted averages in Figure 4.14. Weighted averages were produced by assigning a weight (1-5) to each of the five ranks. The weighted ranks were then averaged as a measure of central tendency. Of the 336 surveys returned 206 (61\%) participants responded to Item 14. The three most frequent negative behaviors were tardiness, verbal disrespect, and nonverbal disrespect; however, the frequency of these negative behaviors was between never and infrequently. 
Answer Research Question 3 (Student Survey). Based on the responses of the participants, physical therapy students view their clinical instructors as positive professional role models; however, some students do not recognize a differential between the their own level of professionalism and that of their clinical instructors.

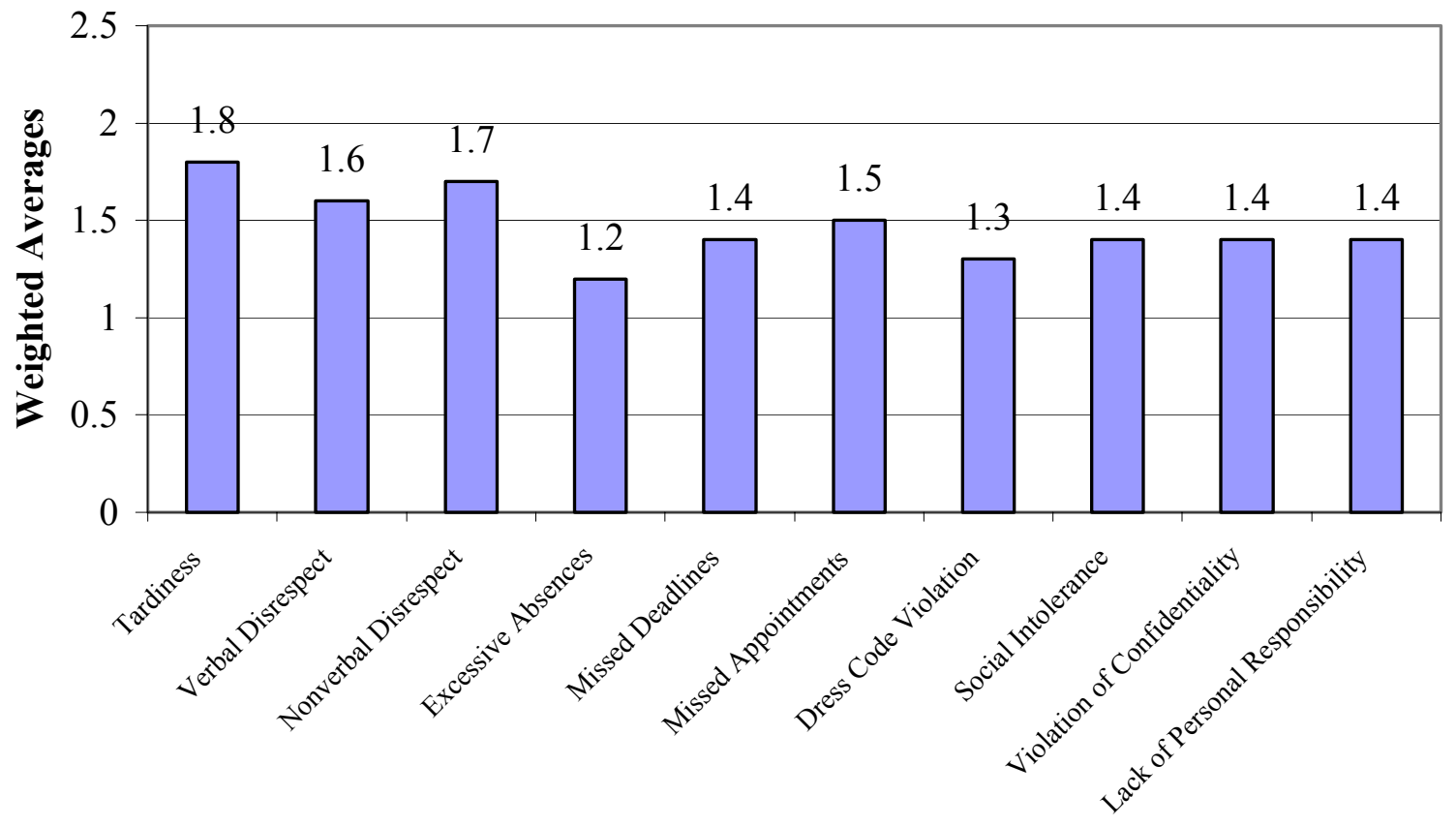

Negative Behaviors

Figure 4.14. Frequency of negative behaviors by clinical instructors.

Research question 4 (Student Survey). Are physical therapy students aware of the American Physical Therapy Associations efforts to promote professionalism?

This question was answered by analyzing Item 8 of the survey, which asked the participants to respond to the following statement on a modified Likert scale from strongly disagree to strongly agree: I am aware of the APTA's "Core Values" as it is stated in the 
Normative Model of Physical Therapy Education. All but one of the 336 participants responded to Item 8. The distribution of responses is presented in Figure 4.15. Of the 335 respondents, 41 (12.2\%) disagreed or strongly disagreed to being familiar with the APTA's Core Values, while $70.1 \%$ agreed or strongly agreed with the statement.

Answer Research Question 4 (Student Survey). Based on these results, it appears that most physical therapy students are aware of the American Physical Therapy Associations efforts to promote professionalism.

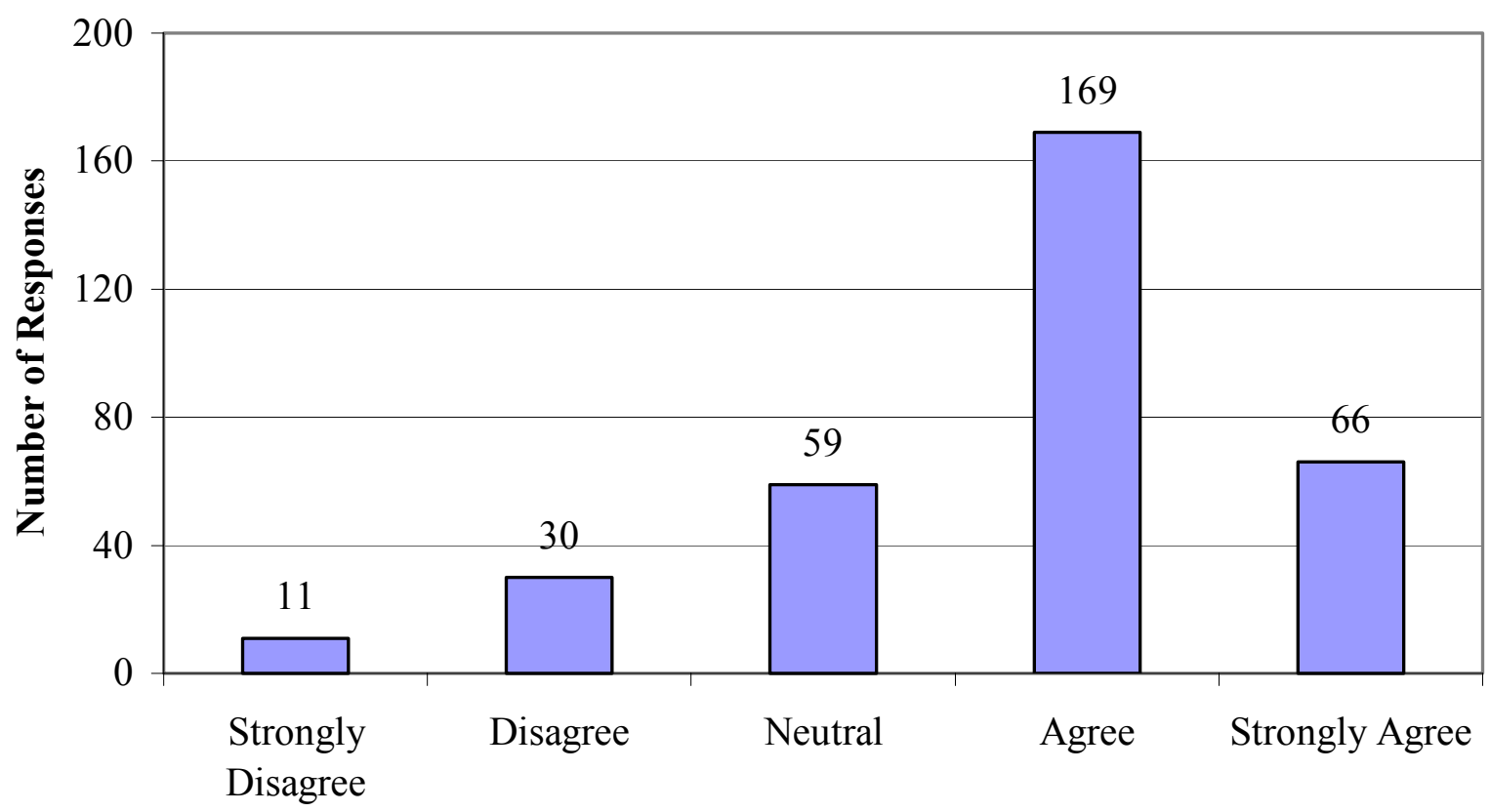

\section{Opinion}

Figure 4.15. I am aware of the APTA's Core Values document.

Research question 5 (Student Survey). Compared to other professions, how do entrylevel physical therapy students view the level of professionalism of the physical therapy profession? 
To answer this research question, Item 12 was analyzed. This item asked the participants to rate the professional behavior of eight professional groups (themselves, classmates, clinical instructors, faculty, medical doctors, occupational therapists, speech pathologists, and clergy) on a scale of 1-10 (10 being the highest degree of professionalism). Data from this section were treated as continuous; however, due to significant skewness and a significant Shapiro-Wilk test (lack of normality) for each professional group, further analysis utilized nonparametric statistical analysis. Table 4.1 contains the skewness coefficient, the Shapiro-Wilk statistic, and the corresponding p-value. A negative skewness coefficient indicates that the distribution is skewed to the left. The Shapiro-Wilk test is a test for the assumption of normality of the distribution. A corresponding p-value of less than 0.05 indicates that the distribution is not normally distributed.

Figure 4.16 shows the median and mean ranking for each professional group. For example, the mean score for clinical instructors was 8.5 on a scale of $0-10$.

Answer Research Question 5 (Student Survey). Based on these results, it appears that physical therapy students view the level of professionalism among the physical therapy profession consistent with other professional groups. 
Table 4.1

Distribution Characteristics of Professional Groups

\begin{tabular}{lcccc}
\hline \multicolumn{1}{c}{ Professional Group } & Skewness Coefficient & $\mathbf{n}$ & $\begin{array}{c}\text { Shapiro-Wilk } \\
\text { statistic }\end{array}$ & p-value \\
\hline Them self & -0.39 & 335 & 0.92 & $<0.0001^{*}$ \\
Classmates & -0.39 & 329 & 0.84 & $<0.0001^{*}$ \\
Clinical Instructors & -1.91 & 231 & 0.87 & $<0.0001^{*}$ \\
Faculty & -1.45 & 334 & 0.81 & $<0.0001^{*}$ \\
Medical Doctors & -1.23 & 271 & 0.85 & $<0.0001^{*}$ \\
Occupational Therapists & -0.87 & 193 & 0.88 & $<0.0001^{*}$ \\
Speech Pathologists & -0.96 & 154 & 0.87 & $<0.0001^{*}$ \\
Clergy & -2.46 & 217 & 0.74 & $<0.0001^{*}$ \\
\hline
\end{tabular}

$* \mathrm{p}<0.05$ 


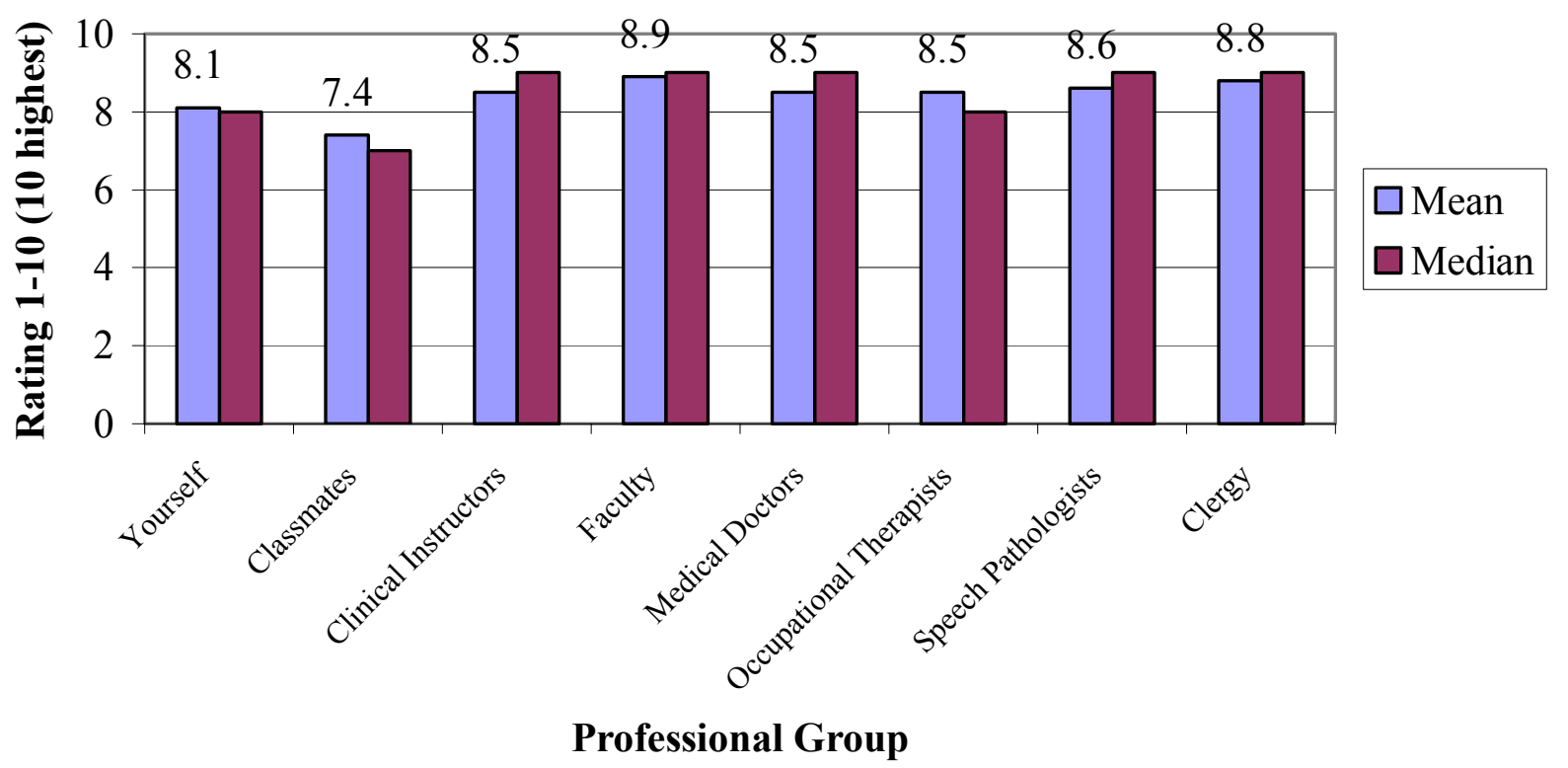

Figure 4.16. Student ranking of professionalism for eight groups.

Research question 6 (Student Survey). From an entry-level physical therapy student's perspective, what are the most frequent negative behaviors demonstrated by physical therapy students?

Item 13 was analyzed using weighted averages of the ordinal ranks in an attempt to more clearly quantify the frequency of negative behaviors. Respondents rated the frequency of negative behaviors of their classmates on a modified Likert scale from never to very often. Each rank was assigned a weighted average of 1-5. The weighted averages are presented in Figure 4.17.

Answer Research Question 6 (Student Survey). Based on these results, the three most frequent negative behaviors demonstrated by physical therapy students were tardiness, verbal disrespect, and nonverbal disrespect. 


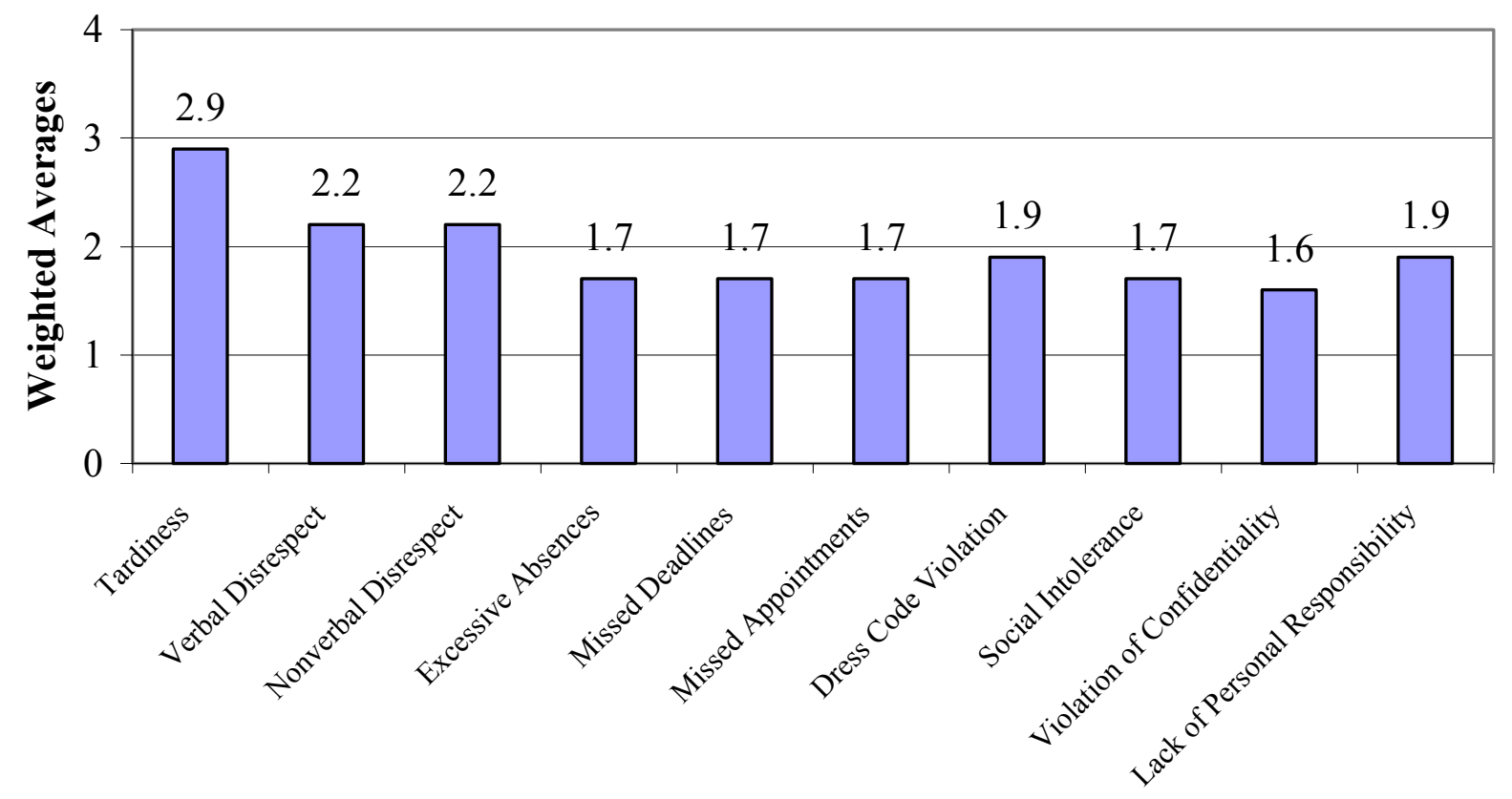

Negative Student Behaviors

Figure 4.17. Student rating of frequency of negative behaviors by peers.

Research question 7 (Student Survey). From an entry-level physical therapy student's perspective, what are the seven most important professional skills?

Item 15 of the survey was used to answer this research question. This item asked respondents to identify the seven most important professional skills or behaviors from a list of 15 skills or behaviors that have been reported in the literature. The seven behaviors receiving the greatest number of responses are listed in Figure 4.18, while the eight lowest behaviors are listed in Figure 4.19. Each figure is presented from the highest frequency to the lowest frequency. All 336 participants responded to Item 15 . 
Answer Research Question 7 (Student Survey). Based on these results, the seven most important professional behaviors were oral communication, clinical reasoning, responsibility, compassion/caring, integrity, honesty, and accountability.

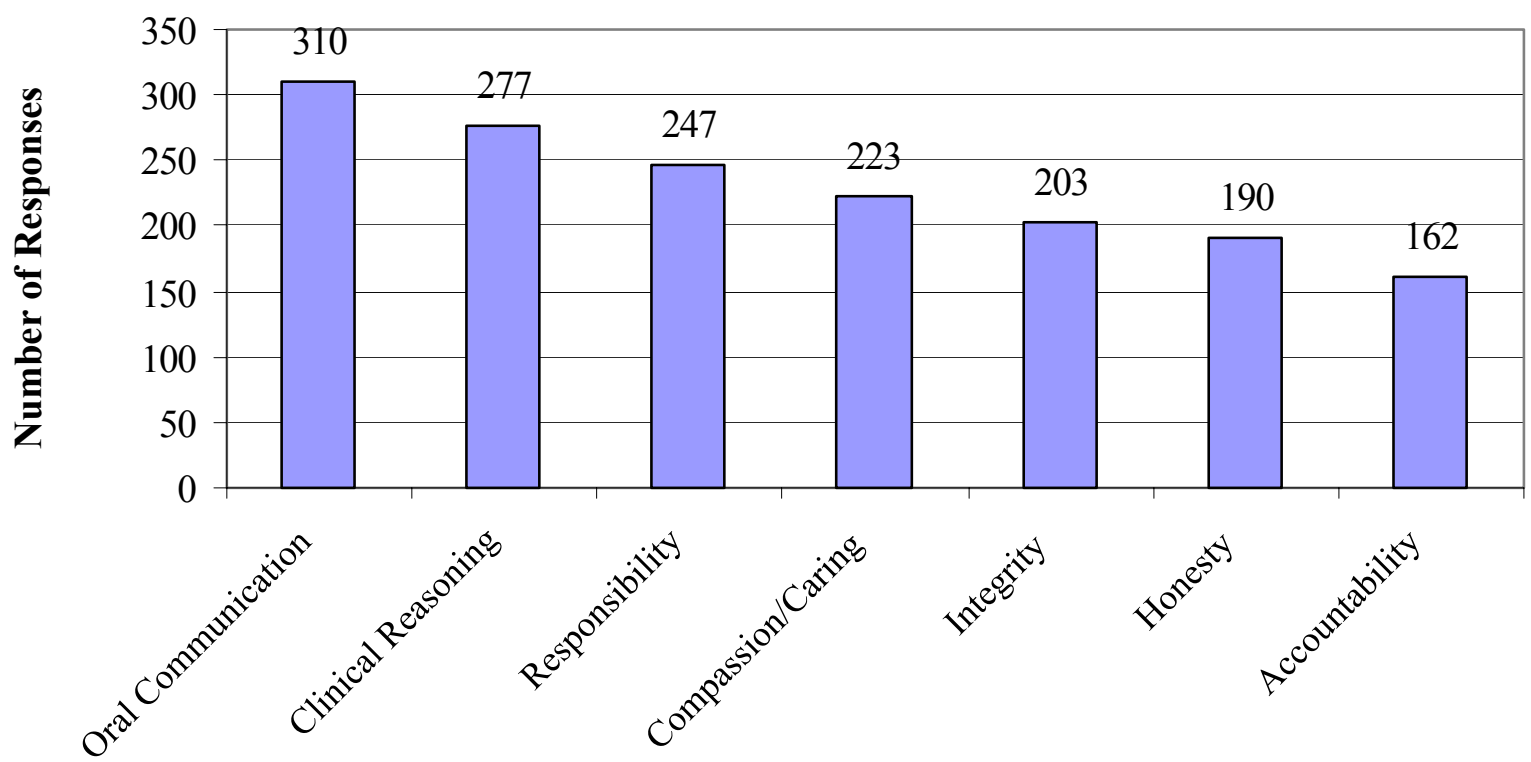

Professional Behaviors

Figure 4.18. The seven most important professional behaviors for a physical therapist. 


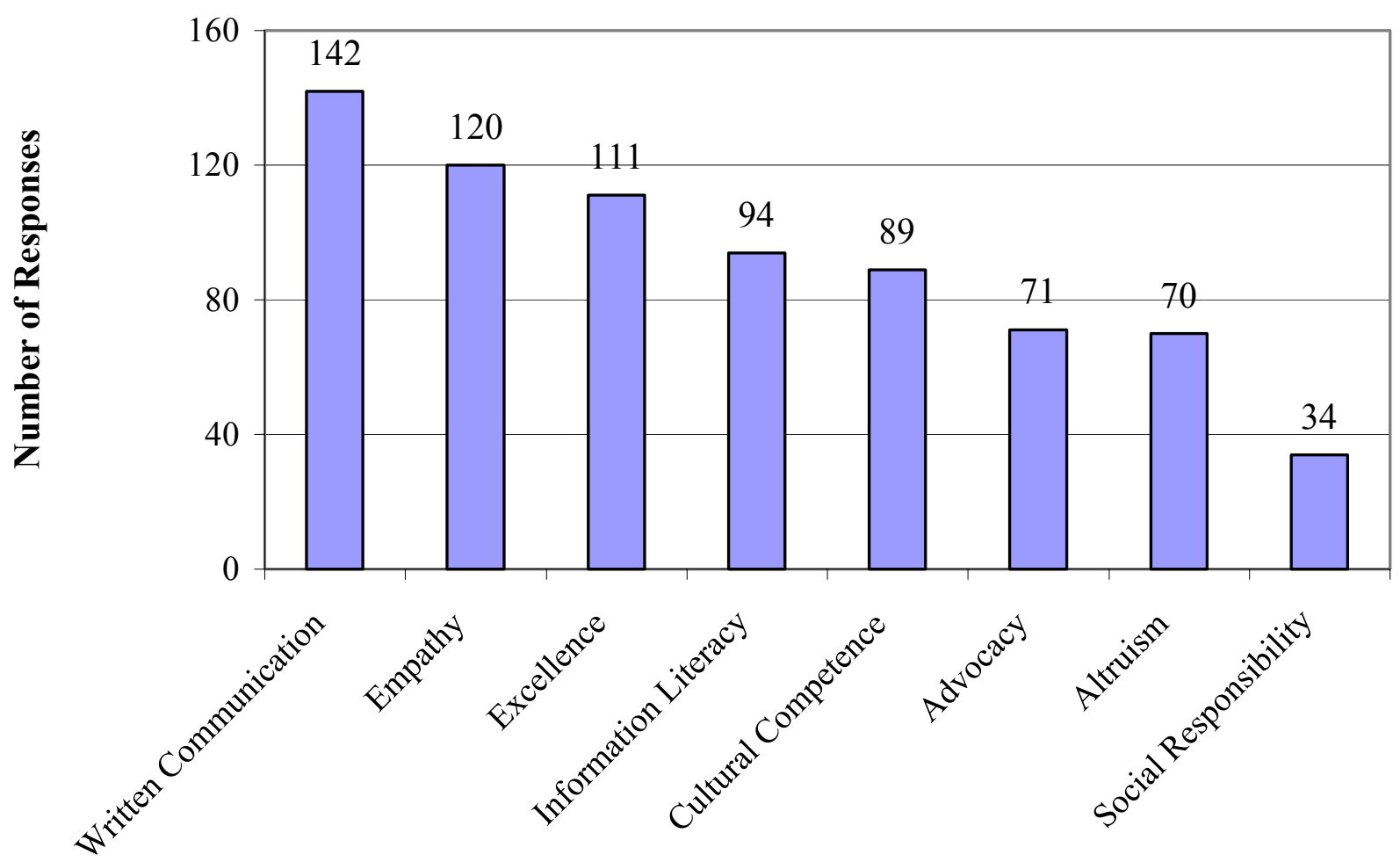

Professional Behaviors

Figure 4.19. The eight least important professional behaviors.

Research question 8 (Student Survey). Which teaching strategies are being used to teach professionalism, and do entry-level physical therapy students find these strategies appealing?

Items 16 and 17 were used to answer this research question. In Item 16, students were asked to identify all the teaching methods that are used in their program to teach professionalism. In Item 17, participants were asked to identify their preferred teaching methods for fostering professionalism. Figure 4.20 displays the actual and desired frequency of the five highest rated teaching methods. Figure 4.21 displays the actual and desired frequency of the remaining six teaching methods. 
Answer Research Question 8 (Student Survey). Based on these results, lecture, small group discussion, reading assignments, Generic Abilities, and role modeling were the five most frequent teaching methods used to teach professionalism in entry-level physical therapy programs.

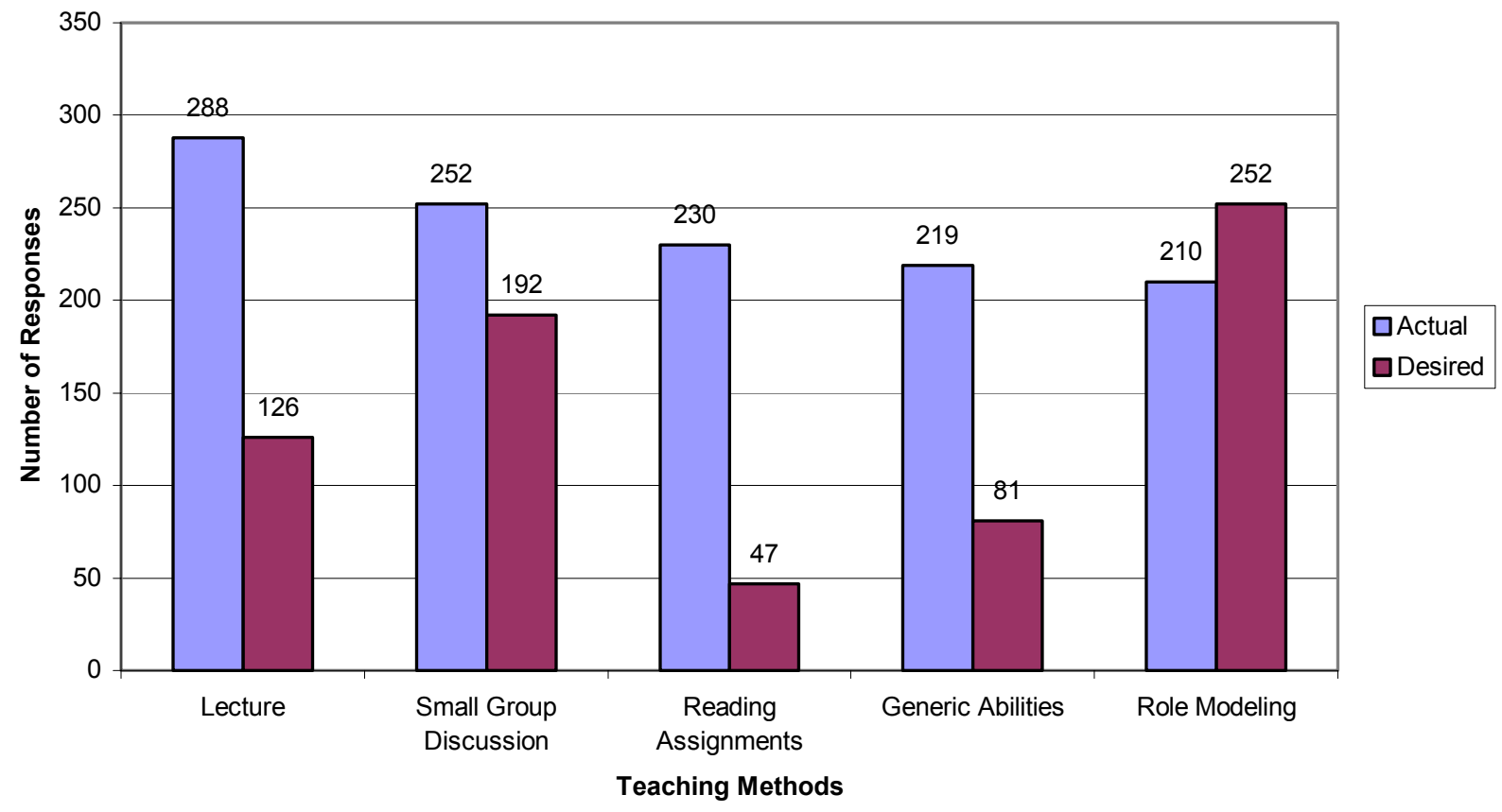

Figure 4.20. The five most frequent teaching methods. 


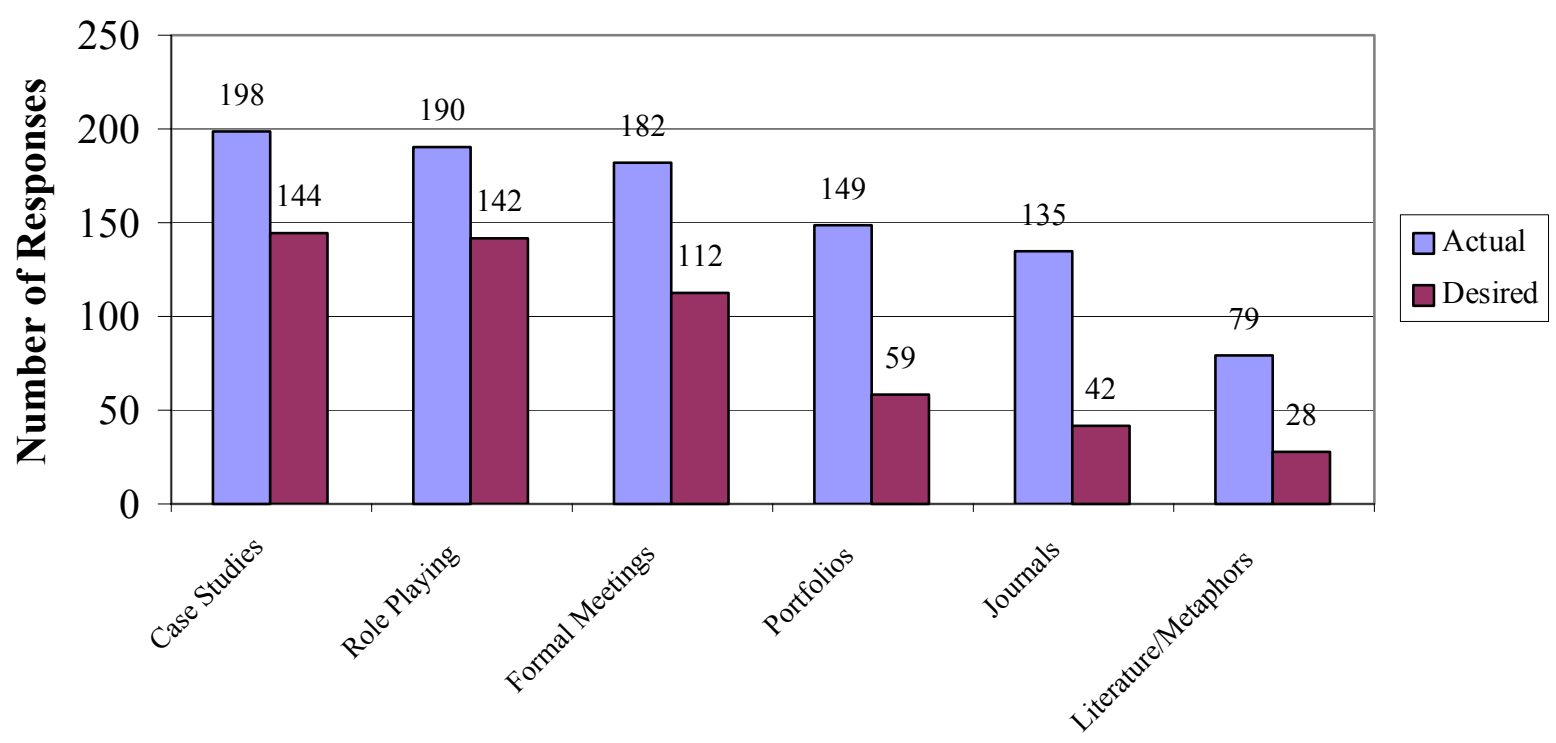

Teaching Methods

Figure 4.21. The six least frequent teaching methods.

Research question 9 (Student Survey). Is there a relationship or difference in self-perception of professionalism based on the following demographic variables?

- Years in PT program (Ordinal)

- PT GPA (Ordinal)

- Age (Ordinal)

- Gender (Nominal)

- Clinical experience (Ordinal)

- Degree Type (Nominal)

- Size of Class (Continuous)

Tables 4.2 and 4.3 contain the results of the analysis for each independent variable. For example, clinical experience in Table 4.2 was found to have a p-value less than 0.05 , indicating that students had a statistically significant difference in self-perception of professionalism based on how much clinical experience they possess. Students with no clinical experience were found 
to have a lower self-perception score than students with some degree of clinical experience. A comparison of a student's self-perception of professionalism based on years in the PT program revealed a significant difference between first, second and third year students. First-year students reported significantly less professionalism (7.8) than second (8.2) and third-year (8.4) students. There was no statistical difference between second and third-year students.

A comparison of self-perception of professionalism compared to the degree of clinical experience, revealed a statistical difference among experience levels. Post-hoc analysis revealed that those students with no clinical experience rated themselves lower than those who had at least some clinical experience. There was no statistical difference in a student's self-perception of professionalism based on PT GPA, age, gender, or degree type. Additionally, there was no significant correlation between a student's self-perception of professionalism and class size. Answer Research Question 9 (Student Survey). Based on these results, there appears to be a change in a student's self-perception of professionalism based on the length of time enrolled in the PT program and the amount of clinical experience. 
Table 4.2

Non-parametric Analysis of Differences in Professionalism Based on Demographic Variables

\begin{tabular}{|c|c|c|c|}
\hline Independent Variable & Kruskal-Wallis Statistic & p-value & Post-hoc Comparisons \\
\hline Years in PT program & 11.15 & $0.0038^{*}$ & $\begin{array}{l}1^{\text {st }} \mathrm{yr}<2^{\text {nd }} \mathrm{yr} \\
1^{\text {st }} \mathrm{yr}<3^{\text {rd }} \mathrm{yr} \\
2^{\text {nd }} \mathrm{yr}=3^{\text {rd }} \mathrm{yr}\end{array}$ \\
\hline PT GPA & 2.24 & 0.5236 & \\
\hline Age & 9.20 & 0.2389 & \\
\hline Gender & 0.08 & 0.7792 & \\
\hline Clinical Experience & 11.92 & $0.0360^{*}$ & No $\operatorname{Exp}<$ Some Exp \\
\hline Degree (MPT v DPT) & 2.63 & 0.1046 & \\
\hline
\end{tabular}

$* \mathrm{p}<0.05$

Table 4.3.

Correlation between Class Size and Professionalism

Correlation Variable $\quad$ Pearson Correlation $\quad$-value

$\begin{array}{lll}\text { Class Size } & -0.07 & 0.1754\end{array}$

Research question 10 (Student Survey). Is there a difference in the frequency of observed negative behaviors based on selected program and demographic variables?

This research question was answered by examining the frequency of the four most common negative student behaviors (tardiness, verbal disrespect, nonverbal disrespect, and dress code violations) from Item 13, compared to four demographic variables (degree type, institution type, size of the university and geographic region). Table 4.4 displays the 
corresponding statistic and p-value of each independent variable compared to tardiness. Three independent variables (size of the institution, geographic region, and institutional type) were found to be statistically significant using Kruskal-Wallis statistic. The only variable that was not significant was degree type. It was found that public schools had a higher incidence of tardiness than in private schools.

Large schools $(>15,000)$ had a higher degree of tardiness than medium schools $(4,000$ $15,000)$, but were not different from small sized schools $(<4,000)$. Additionally, the Midwest had the lowest reported tardiness, but was only statistically less than the Northeast and the West. The South was also significantly less than the West, but not different from the Midwest or Northeast. 
Table 4.4.

Analysis of Tardiness Compared to Four Demographic Variables

\begin{tabular}{|c|c|c|c|}
\hline Independent Variable & $\begin{array}{c}\text { Kruskal-Wallis } \\
\text { Statistic }\end{array}$ & p-value & Post-hoc Comparisons \\
\hline Degree Type $(B S, M P T, D P T)$ & 0.07 & 0.7861 & \\
\hline Institution Type (Public, Private) & 7.14 & $0.0075 *$ & Public $>$ Private \\
\hline $\begin{array}{l}\text { Size of the University } \\
\text { (Small, Medium, Large) }\end{array}$ & 14.42 & $0.0007 *$ & $\begin{array}{c}\text { Large }>\text { Medium } \\
\text { Large }=\text { Small } \\
\text { Medium }=\text { Small }\end{array}$ \\
\hline Geographic Region (NE, $S, M W, W$ ) & 19.13 & $0.0003 *$ & $\begin{array}{c}\mathrm{MW}<\mathrm{NE} \\
\mathrm{MW}<\mathrm{W} \\
\mathrm{S}<\mathrm{W} \\
\mathrm{MW}=\mathrm{S} \\
\mathrm{NE}=\mathrm{S} \\
\mathrm{NE}=\mathrm{W}\end{array}$ \\
\hline
\end{tabular}

$* \mathrm{p}<0.05$

Table 4.5

Analysis of Verbal Disrespect Compared to Four Demographic Variables

\begin{tabular}{lcc}
\hline \multicolumn{1}{c}{ Independent Variable } & Kruskal-Wallis Statistic & p-value \\
\hline Degree Type (BS, MPT, DPT) & 1.26 & 0.2612 \\
$\begin{array}{l}\text { Institution Type (Public, Private) } \\
\text { Size of the University } \\
\text { (Small, Medium, Large) }\end{array}$ & 0.95 & 0.3285 \\
& 5.19 & 0.0745 \\
Geographic Region (NE, S, MW, W) & 1.70 & 0.6372 \\
\hline
\end{tabular}


Table 4.6 displays an examination of non-verbal disrespect compared to the four independent variables. None of the independent variables was statistically significant.

Table 4.6

Analysis of non-verbal disrespect compared to four demographic variables

\begin{tabular}{lcc}
\hline \multicolumn{1}{c}{ Independent Variable } & Kruskal-Wallis Statistic & p-value \\
\hline Degree Type (BS, MPT, DPT) & 0.007 & 0.9316 \\
Institution Type (Public, Private) & 0.08 & 0.7765 \\
$\begin{array}{l}\text { Size of the University } \\
\text { (Small, Medium, Large) }\end{array}$ & 2.66 & 0.2645 \\
$\begin{array}{l}\text { Geographic Region (NE, } S, M W, W) \\
\text { M }\end{array}$ & 3.15 & 0.3685 \\
\hline
\end{tabular}

Table 4.7 displays the examination of dress code violation with respect to the four independent variables. Two variables (institution type and size of the university) were statistically significant. Public schools were found to have a higher incidence of dress code violations than private schools. Additionally, large schools were found to have a higher degree of dress code violations than small and medium sized schools, but there was no difference between small and medium sized schools. 
Table 4.7

Analysis of Dress Code Violation Compared to Four Demographic Variables

\begin{tabular}{|c|c|c|c|}
\hline Independent Variable & $\begin{array}{l}\text { Kruskal- } \\
\text { Wallis } \\
\text { Statistic }\end{array}$ & p-value & Post-hoc Comparisons \\
\hline Degree Type $(B S, M P T, D P T)$ & 3.74 & 0.0533 & \\
\hline Institution Type (Public, Private) & 5.37 & $0.0264 *$ & Public $>$ Private \\
\hline $\begin{array}{l}\text { Size of the University } \\
\text { (Small, Medium, Large) }\end{array}$ & 15.84 & $0.0004 *$ & $\begin{array}{c}\text { Large }>\text { Small and Medium } \\
\text { Small = Medium }\end{array}$ \\
\hline Geographic Region (NE, $S, M W, W)$ & 3.25 & 0.3543 & \\
\hline
\end{tabular}

Answer Research Question 9 (Student Survey). Based on these results, the frequency of tardiness appears to be affected by institutional type, size of the institution, and geographic region. Additionally, the frequency of dress code violations appears to be affected by institutional type and the size of the institution. The frequency of verbal and non-verbal disrespect was not affected by any of the demographic variables.

Qualitative data analysis (Student Survey). Of the 336 surveys returned, 35 (10.4\%) participants provided qualitative data in the form of a written response to Item 19, which stated: Please offer any additional information regarding your experience with learning or observing professionalism while in physical therapy school. The initial screening of the comments provided in Item 19 revealed five broad themes. These included mentoring/role-modeling $(\mathrm{n}=$ 7), program stressed professionalism $(n=10)$, negative comments related professionalism of 
faculty/clinical instructors $(n=7)$, mix of good and bad experiences related to professionalism ( $n$ $=2$ ), and teaching suggestions $(\mathrm{n}=3)$. Additionally, six responses were undefined or related to justification of why the respondent answered certain items. Tables $4.8 \mathrm{a}-4.8 \mathrm{c}$ summarize the overall qualitative findings and provide representative examples of each theme. 
Table 4.8a

Summary of Qualitative Data for Physical Therapy Student Survey

\begin{tabular}{|c|c|c|}
\hline Themes & Count & Representative Examples \\
\hline $\begin{array}{l}\text { Mentoring and } \\
\text { role-modeling }\end{array}$ & 7 & $\begin{array}{l}\text { \#280 "I believe professionalism is difficult to teach; it is more } \\
\text { commonly learned through experiences in a professional role } \\
\text { attempting to meet real expectations of real coworkers and } \\
\text { clients/patients." } \\
\# 128 \text { "Best learning is watching professors or PT's in clinic, } \\
\text { and also observing unprofessional behaviors in classmates, PT's } \\
\text { and teachers." }\end{array}$ \\
\hline $\begin{array}{l}\text { Program } \\
\text { emphasized } \\
\text { professionalism }\end{array}$ & 10 & $\begin{array}{l}\text { \# } 221 \text { "Our program does a great job emphasizing the } \\
\text { importance of professionalism and our teachers/clinical } \\
\text { instructors do a great job modeling what a good professional } \\
\text { should do." } \\
\text { \#81 "I do believe my program values professional behavior very } \\
\text { much and it is discussed frequently in our curriculum." } \\
\text { \#37 "I feel our program really emphasized professionalism in } \\
\text { great depth. We always were graded on professionalism as part } \\
\text { of our practical exams and therefore practiced it." }\end{array}$ \\
\hline
\end{tabular}


Table $4.8 b$

Summary of Qualitative Data for Physical Therapy Student Survey

\begin{tabular}{|c|c|c|}
\hline Themes & Count & Representative Examples \\
\hline Observed negative & 7 & \# 292 “ I wish what was taught was enforced- students being \\
\hline behaviors of & & held accountable." \\
\hline teachers/clinical & & \# 37 "My professors demonstrate behaviors that are truly \\
\hline \multirow[t]{5}{*}{ instructors } & & disrespectful and uncharacteristic of the PT profession." \\
\hline & & \# 177 "I had a very poor experience for my first clinical \\
\hline & & affiliation. I had a very unprofessional clinical instructor and \\
\hline & & my program was completely unaware of his professionalism \\
\hline & & before I reported my experience back to them." \\
\hline \multirow[t]{6}{*}{ Experiences were } & 2 & \#180 "Hard to comment on experiences with clinical \\
\hline & & instructors when you have had more than one and they were \\
\hline & & very different." \\
\hline & & \# 162 "It really depends on the specific clinical instructor or \\
\hline & & PT faculty you are talking about because some are very \\
\hline & & professional while others are not as professional." \\
\hline
\end{tabular}


Table $4.8 \mathrm{c}$

Summary of Qualitative Data for Physical Therapy Student Survey

\begin{tabular}{|c|c|c|}
\hline Themes & Count & Representative Examples \\
\hline $\begin{array}{l}\text { Suggestions for } \\
\text { teaching }\end{array}$ & 3 & $\begin{array}{l}\text { \#282 "I think professionalism is actively sought out by the } \\
\text { individual, it is not necessarily teachable." }\end{array}$ \\
\hline professionalism & & $\begin{array}{l}\text { \#39 "Small group teaching projects. Students teach other students } \\
\text { about professionalism." } \\
\text { \# } 188 \text { "In my opinion, professionalism can be taught/learned but a } \\
\text { great deal of it is common sense." }\end{array}$ \\
\hline $\begin{array}{l}\text { Miscellaneous } \\
\text { Comments }\end{array}$ & 6 & $\begin{array}{l}\text { \#283 "Thanks for doing this research. I think it is an area that } \\
\text { deserves much attention, especially with DPT being entry-level } \\
\text { degree." } \\
\text { \#28 "I have only been enrolled four weeks." }\end{array}$ \\
\hline
\end{tabular}


Physical Therapist Survey (Investigation B)

Respondents. From the sample of 1,000 surveys mailed to physical therapists, 18 were "returned to sender" because the address was incorrect. Therefore, the effective number of surveys successfully mailed was 982 . Of the 982 surveys successfully mailed, 372 were completed and returned. Thus, the response rate was $37.9 \%$. Of the 372 surveys returned, 367 respondents indicated their gender, while five left the item blank. Of the 367 reporting a gender, $270(73.6 \%)$ were women and $97(26.4 \%)$ were men.

The age distribution of the respondents is listed in Figure 4.22. Of the 372 surveys returned, 363 respondents indicated their age, while nine left the item blank. The vast majority, $357(98 \%)$ were between 31 and 60 years of age.

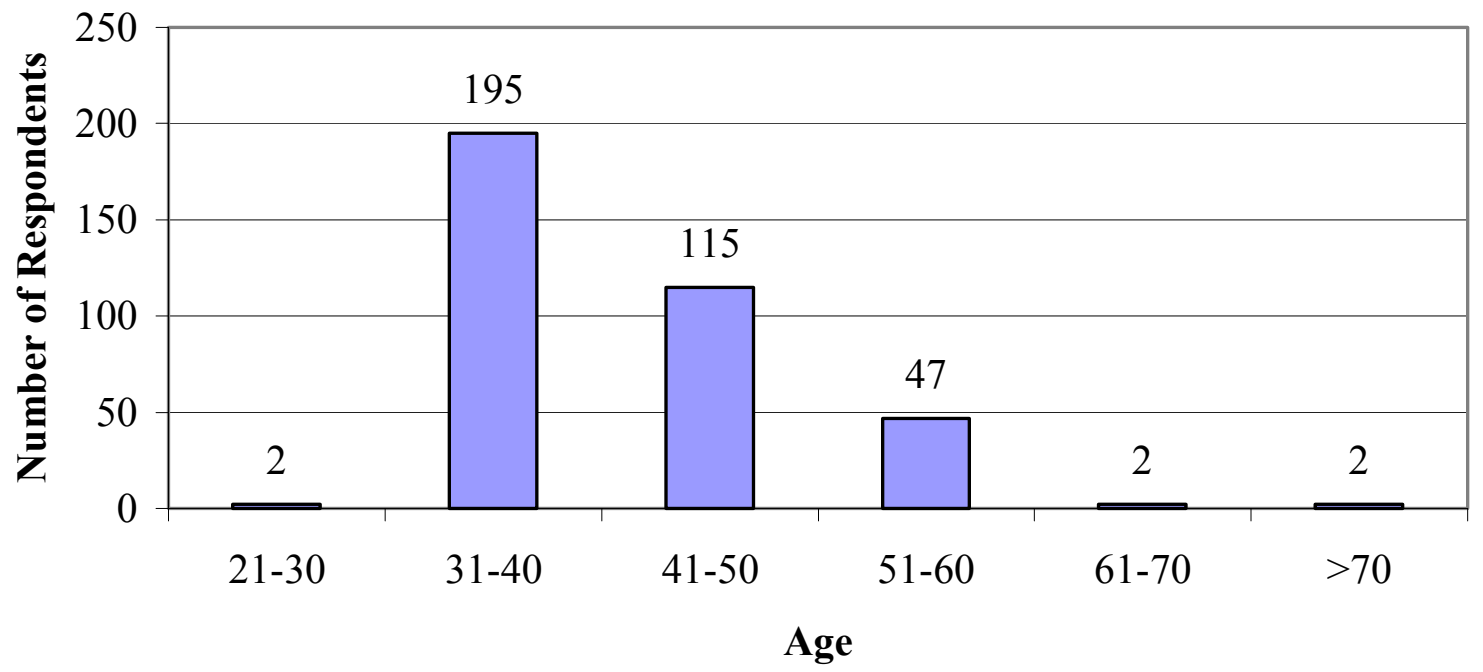

Figure 4.22. Age distribution of participants.

Out of the 372 surveys returned, 369 indicated their years of clinical experience, while three left the item blank. The distribution of clinical experience is presented in Figure 4.23. The 
largest number of respondents reported having between 11 and 20 years of clinical experience, with only eight respondents reporting less than 11 years of clinical experience.

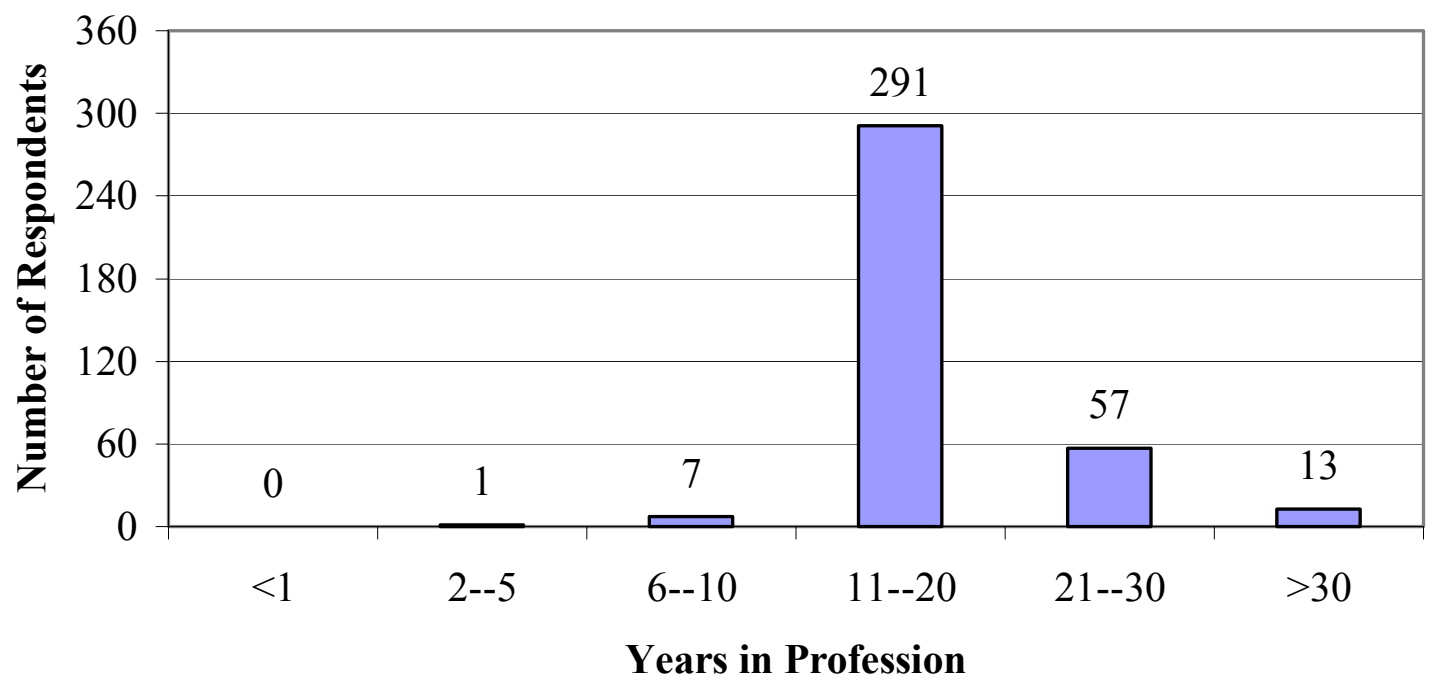

Figure 4.23. Years of clinical experience.

All 372 respondents reported their type of PT degree (DPT, MPT, BS). Figure 4.24 depicts the distribution of degree type for the sample. The majority (58.6\%) of the respondents reported having a bachelor's degree. 


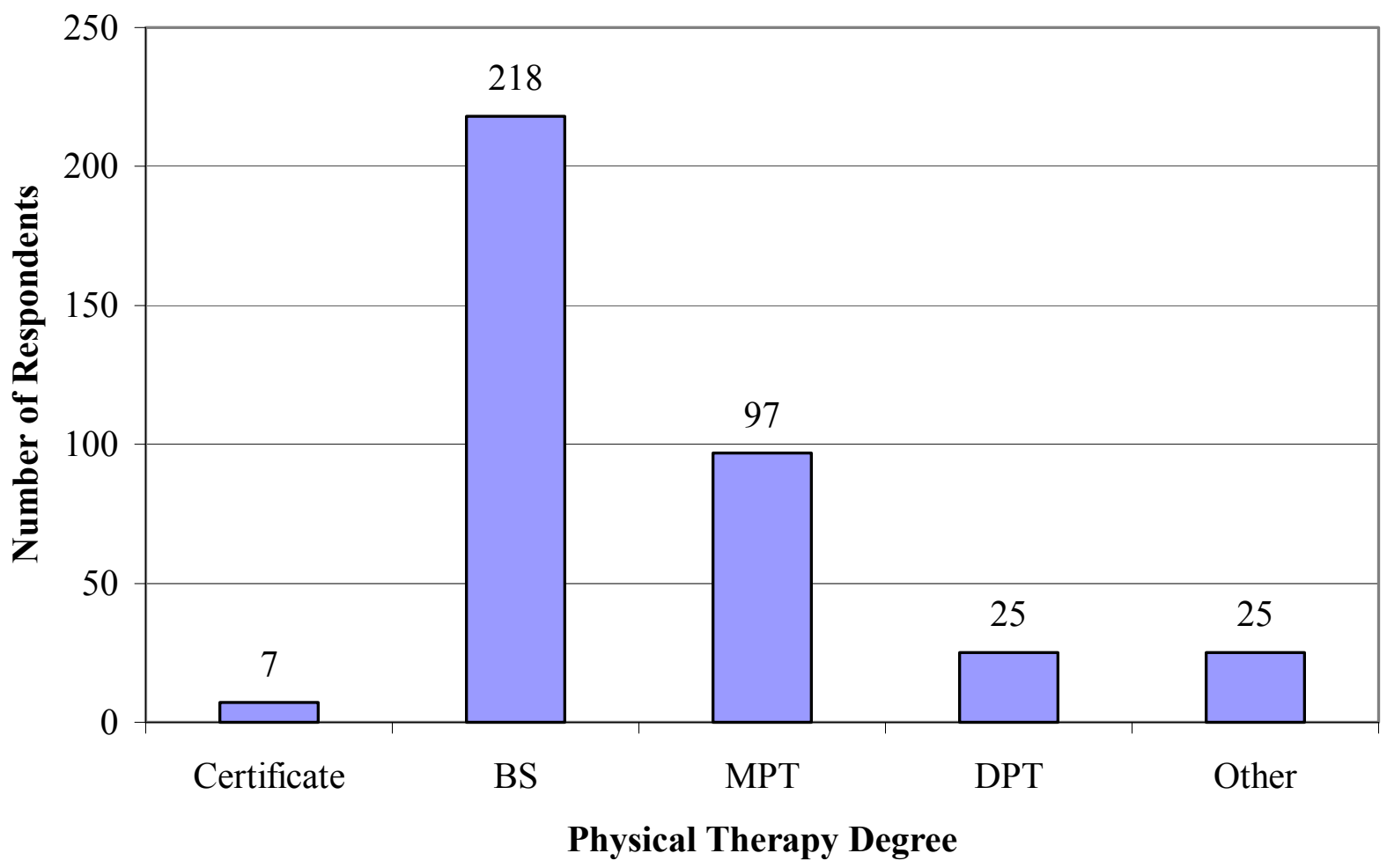

Figure 4.24. Physical therapy degree earned.

Of the 372 respondents, 371 indicated their work status. The sample in this investigation found 288 (77.6\%) of the participants work full-time, while 83 (22.4\%) work part-time.

Of the 372 respondents, 371 indicated their practice setting. Figure 4.25 depicts the distribution of work setting for the sample. The largest number of respondents, 121 (32.6\%) reported working in an outpatient setting. 


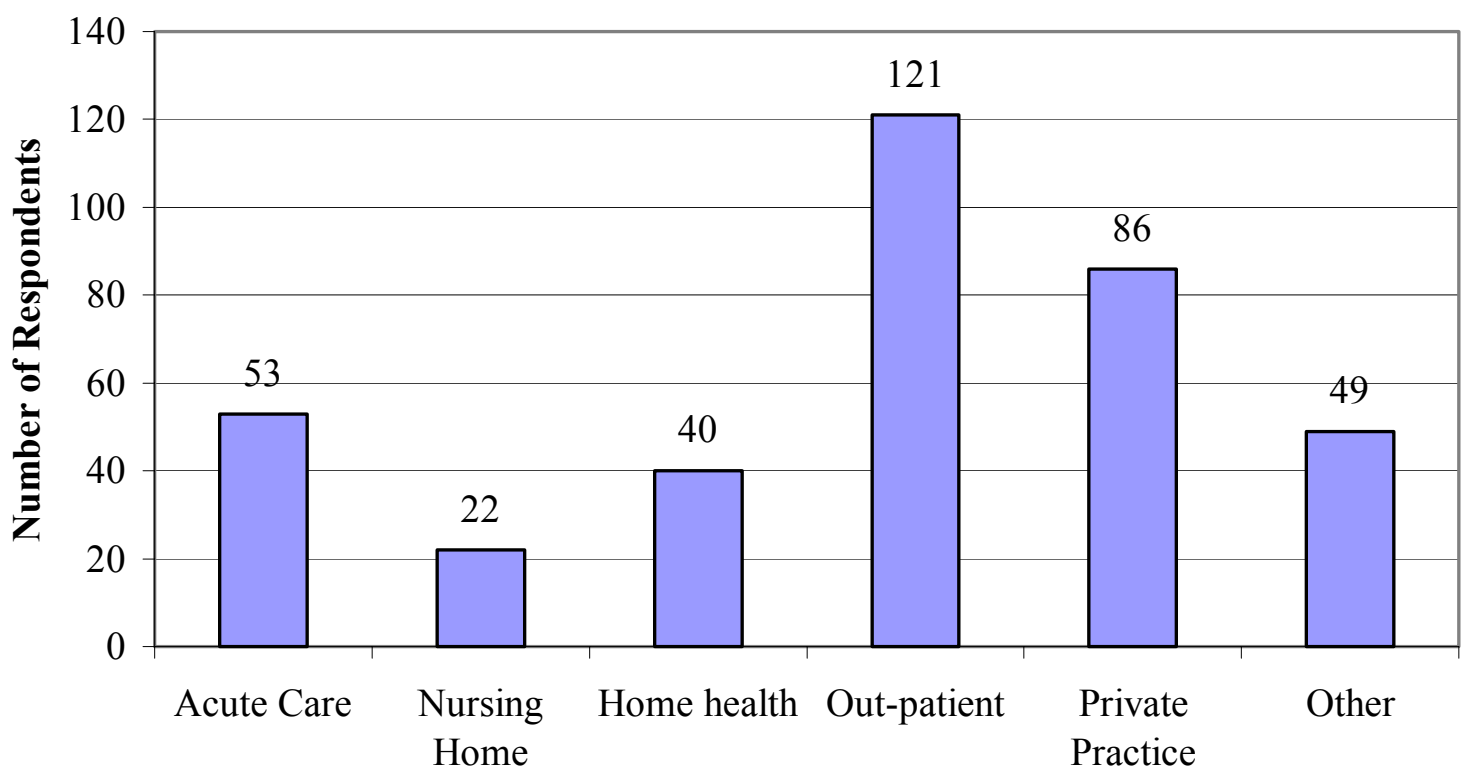

Practice Setting

Figure 4.25. Practice setting.

Specific Research Questions

Research question 1 (Clinician Survey). Do licensed physical therapists have an appreciation for the importance of learning professionalism as part of a physical therapy education?

Three items (Items 1, 5 and 6) were used to examine this question. Item 1 asked the participants to respond to the following statement on a modified Likert scale from strongly disagree to strongly agree: Teaching and fostering professionalism is an important part of a physical therapy education. Of the 372 surveys returned, 371 respondents completed Item 1, while one respondent left the item blank. The respondents' opinions are contained in Figure 4.26. The vast majority of the respondents $352(94.9 \%)$ indicated that they agree or strongly 
agree that teaching and fostering professional behaviors is an important part of a physical therapy education, while only 17 (4.6\%) disagreed or strongly disagreed.

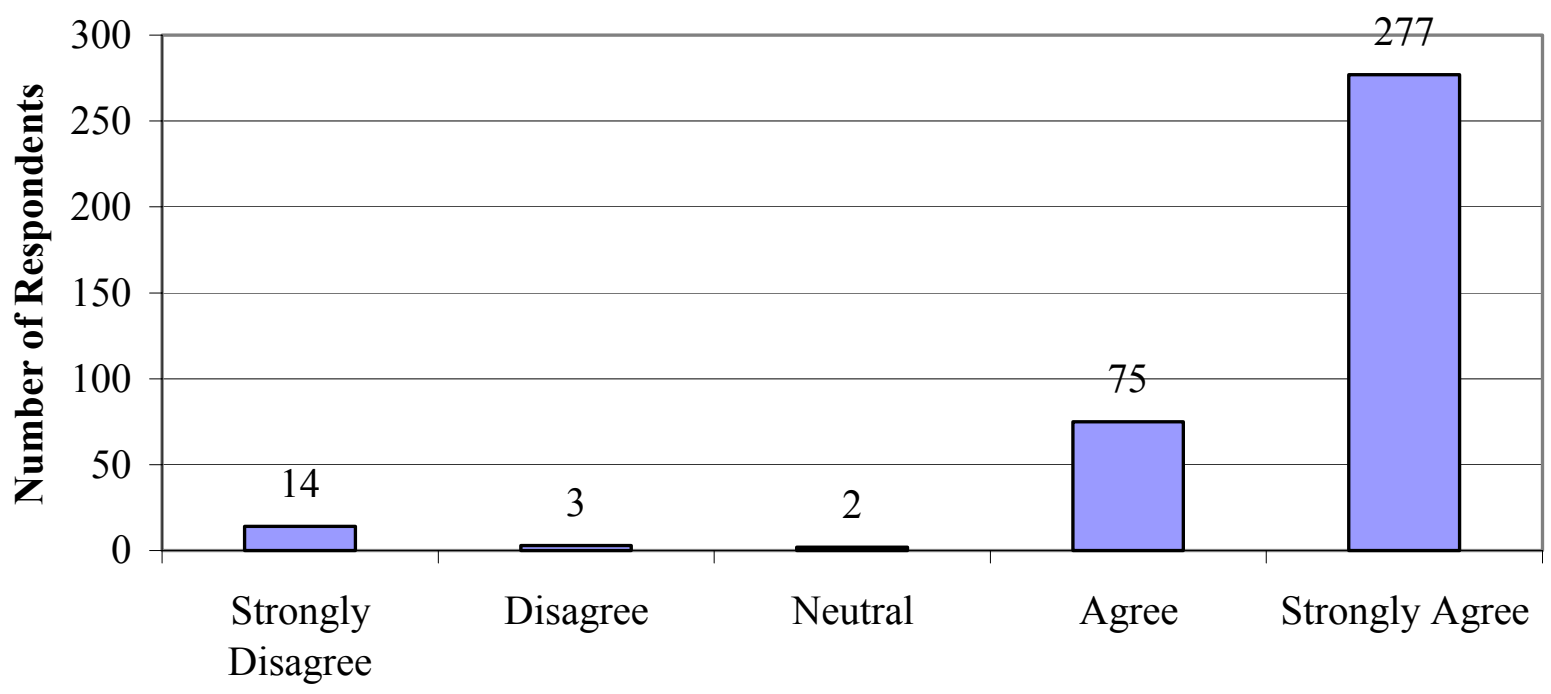

\section{Opinion}

Figure 4.26. Importance of teaching and fostering professional behaviors.

The second item used to answer this research question was Item 5. This item asked the participants to respond to the following statement using a modified Likert scale ranging from strongly disagree to strongly agree: Professionalism is a construct (concept) that can be learned. Of the 372 questionnaires returned, 370 (99.5\%) respondents marked a response. The distribution of responses is shown in Figure 4.27. Again, the vast majority (85.9\%) of the respondents agreed or strongly agreed that professionalism is a construct (concept) that can be learned.

The third item used to answer this question was Item 6. This item asked the participants to respond to the following statement using a modified Likert scale from strongly disagree to 
strongly agree: Professionalism is construct (concept) that can be taught. All 372 respondents answered this item. The responses are contained in Figure 4.28. The majority $(85.8 \%)$ of the respondents agreed or strongly agreed to the statement.

Answer Research Question 1 (Clinician Survey). Based on these results, licensed physical therapists appear to have a positive appreciation for teaching and learning professionalism as part of an entry-level physical therapy education.

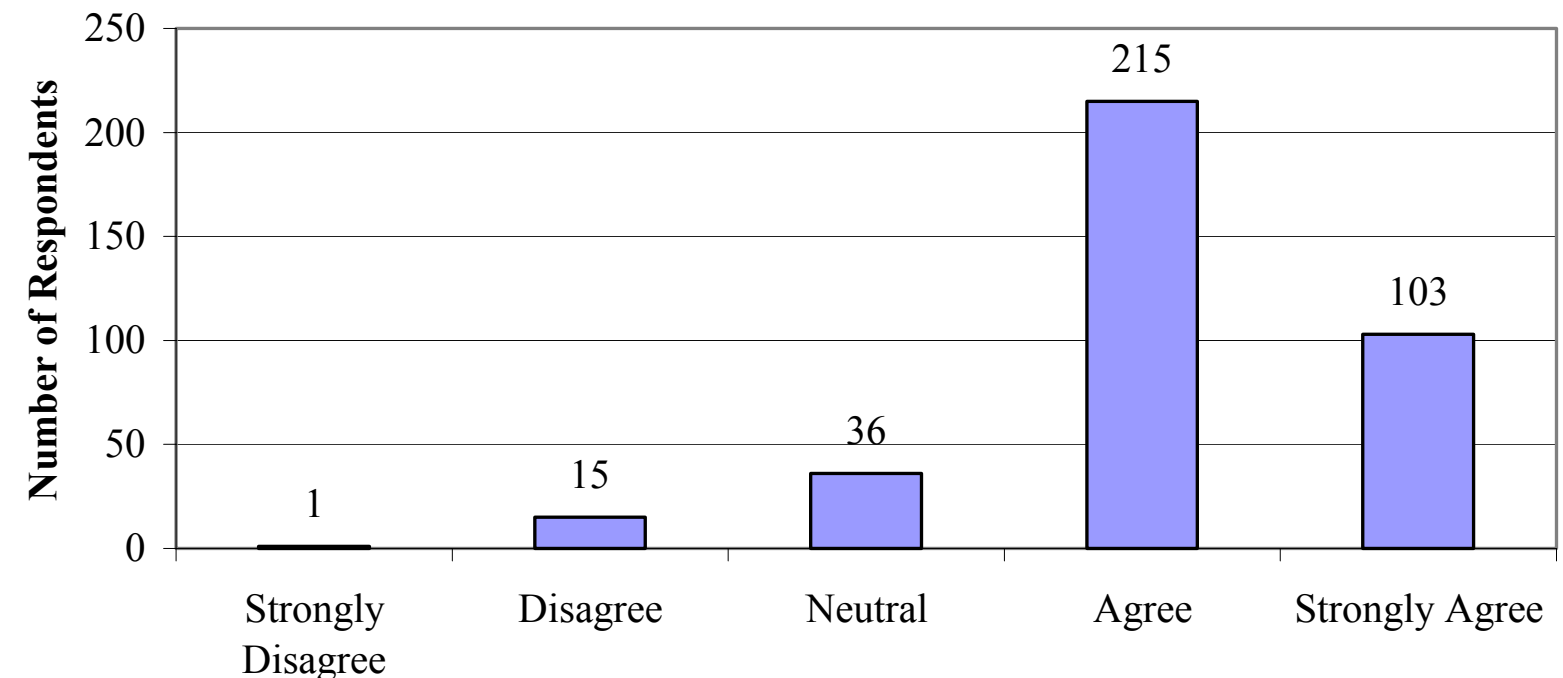

Opinion

Figure 4.27. Professionalism is a construct (concept) that can be learned. 


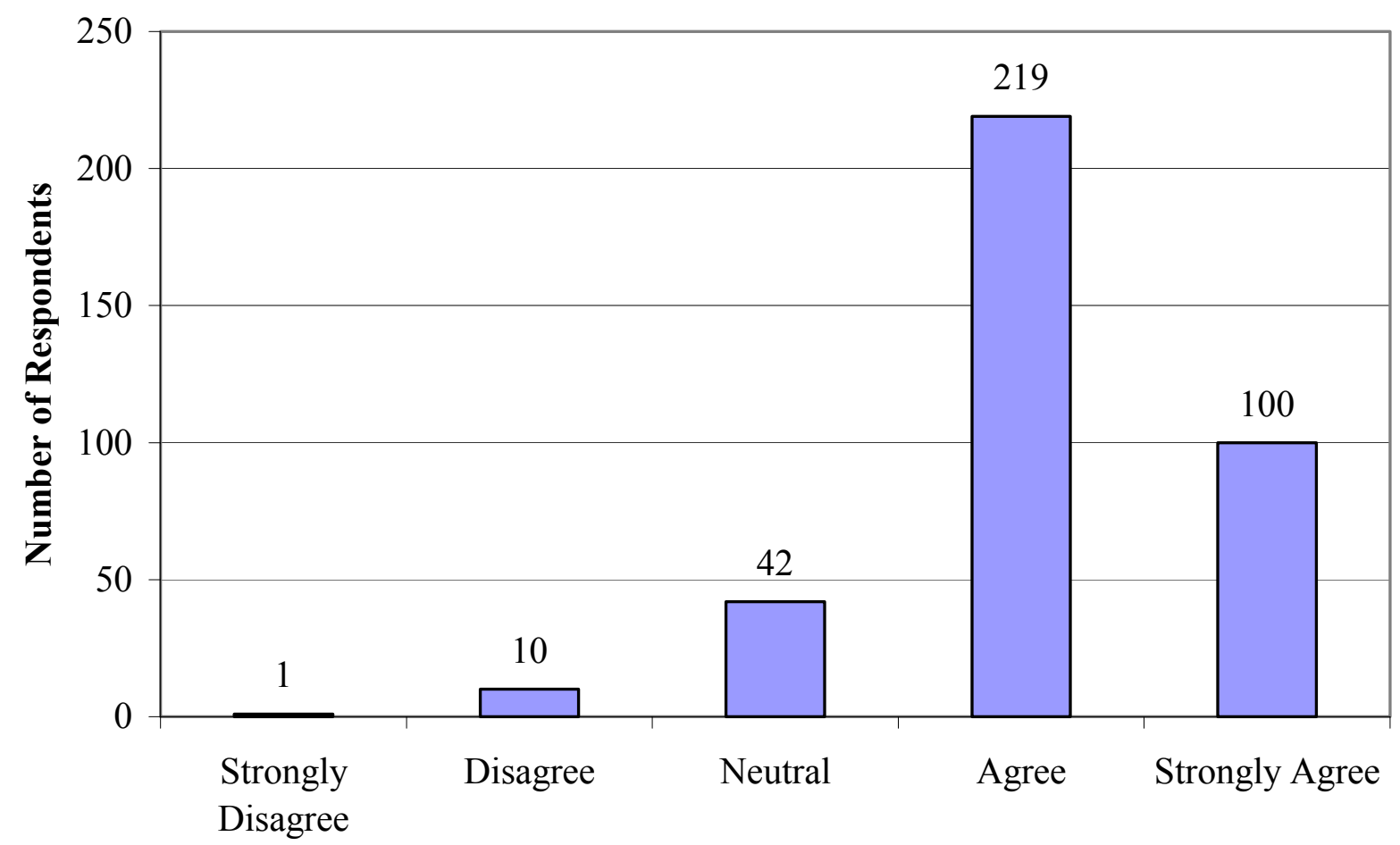

\section{Opinion}

Figure 4.28. Professionalism is a construct (concept) that can be taught.

Research question 2 (Clinician Survey). Based on their observation of physical therapy students, do licensed physical therapists view PT students as possessing positive professional behaviors?

An analysis of Item 2 was used to answer this question. Item 2 asked the participants to respond to the following statement using a modified Likert scale from strongly disagree to strongly agree: The physical therapy students that I have worked with or observed in the last two years have demonstrated professional behavior. Figure 4.29 contains the distribution of responses. Of the 372 surveys returned 354 (95.1\%) responded to Item 2, while 18 (4.8\%) left the item blank. Eighty percent of the respondents agreed or strongly agreed to the statement, 
while only $3.4 \%$ disagreed or strongly disagreed. Additionally, $16.6 \%$ of the respondents remained neutral.

Answer Research Question 2 (Clinician Survey). Based on these results, the majority of licensed physical therapists view physical therapy students as possessing positive professional behaviors.

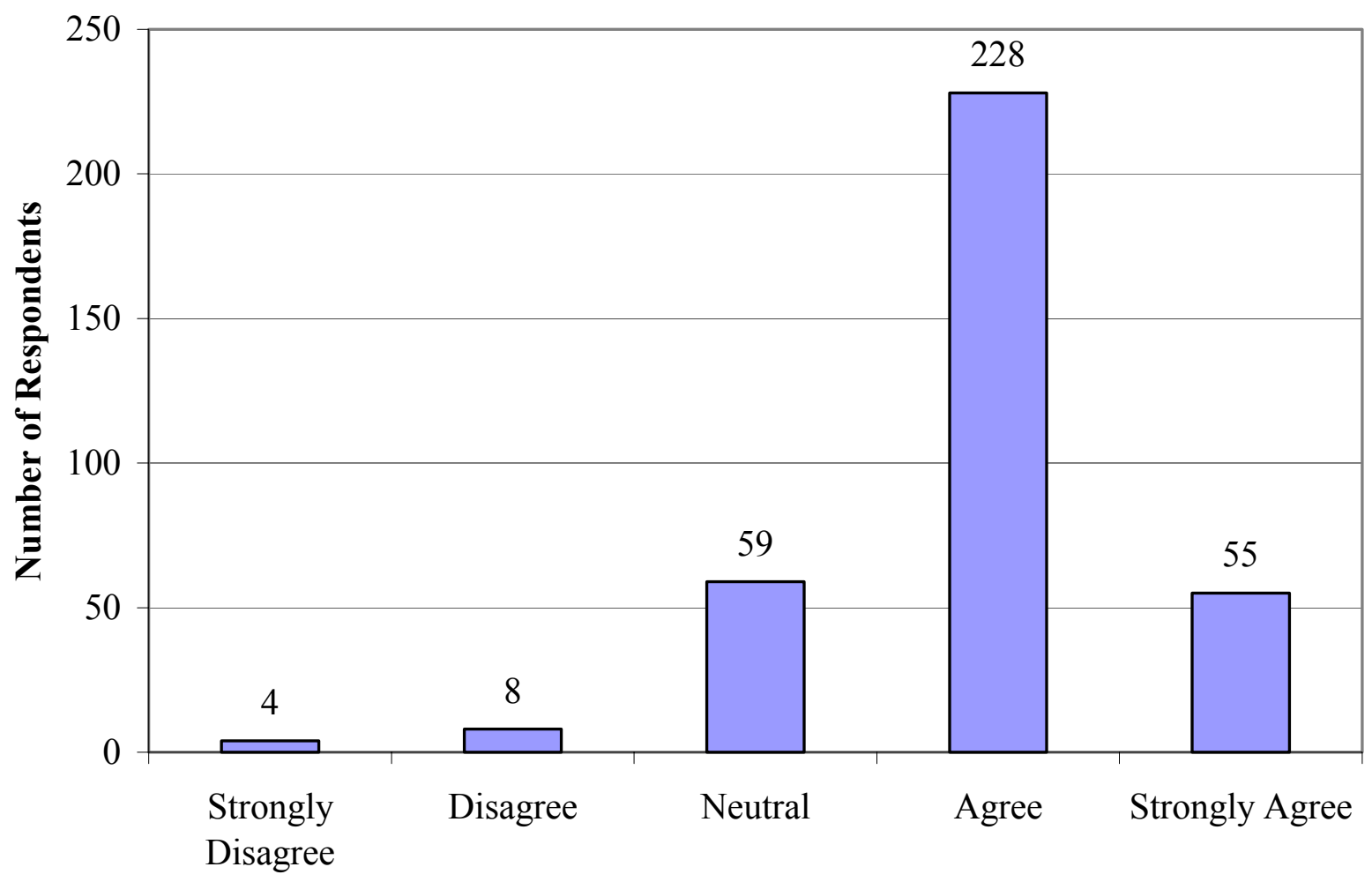

\section{Opinion}

Figure 4.29. Physical therapy students demonstrate professional behavior.

Research question 3 (Clinician Survey). Based on their observation of new graduates during the first year of clinical practice, do licensed physical therapists view new graduates as 
possessing positive professional behaviors?

The research question was answered by analyzing Item 3, which asked the participants to respond to the following statement using a modified Likert scale from strongly disagree to strongly agree: The new graduates (less than 1 year of clinical experience) that I have worked with in the last two years have demonstrated professional behaviors. Of the 372 surveys returned, $338(90.9 \%)$ responded to Item 3, while $34(9.1 \%)$ left the item blank. Figure 4.30 depicts the participant's responses. Seventy six percent of the respondents agreed or strongly agreed with the statement, while only $4.4 \%$ disagreed or strongly disagreed.

Answer Research Question 3 (Clinician Survey). Based on these results, the majority of licensed physical therapists view new graduates as possessing positive professional behaviors; however, the level of professionalism among new graduates appears to be slightly less than for students.

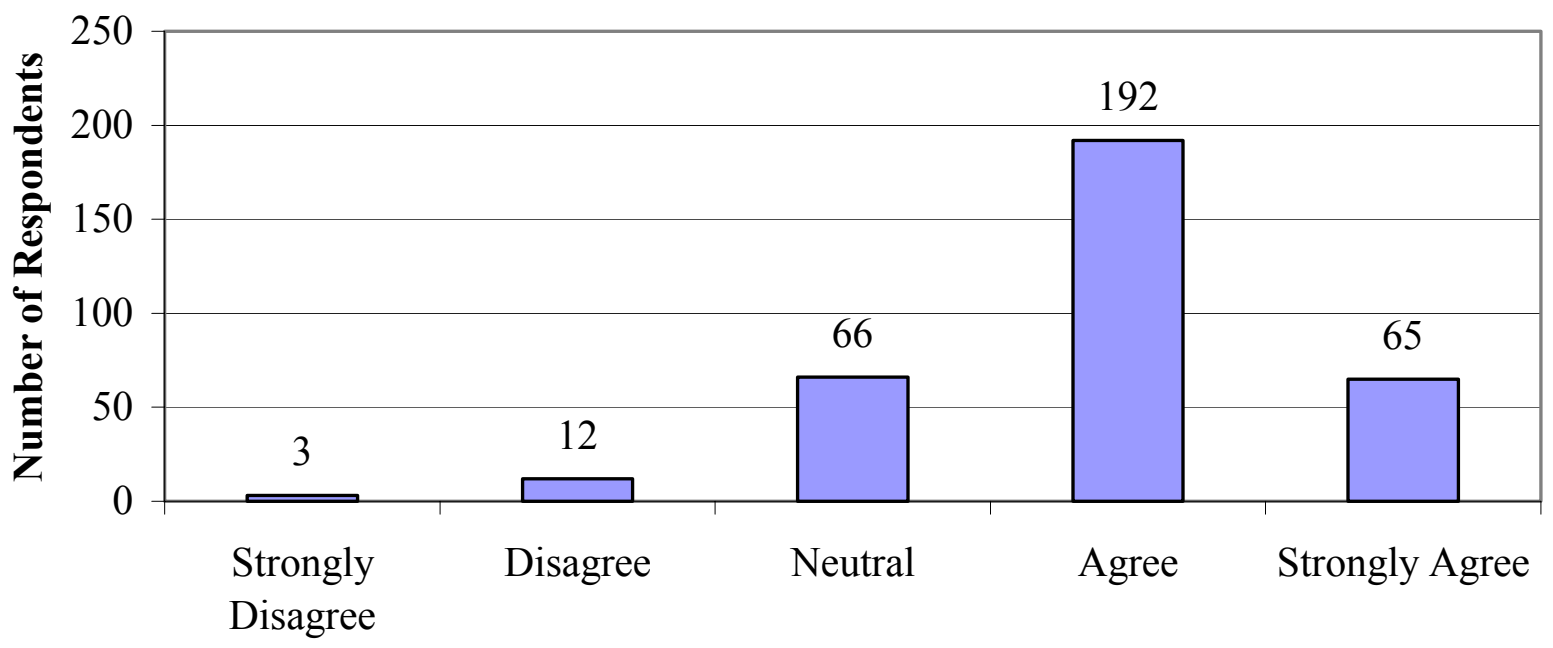

\section{Opinion}

Figure 4.30. Professional behaviors among new graduates. 
Research question 4 (Clinician Survey). Do licensed physical therapists believe that age is a predictor of professional behaviors among entry-level physical therapy students?

An analysis of Item 8 was used to answer this research question. Item 8 asked the participants to respond to the following statement on a modified Likert scale from strongly disagree to strongly agree: A student's age at the time of admission to an entry-level physical therapy program is a predictor of professional behavior during the physical therapy program. All 372 respondents marked an answer for Item 8. Figure 4.31 depicts the distribution of responses. Of the 372 responses, 193 (51.9\%) disagreed or strongly disagreed, while 92 (24.7\%) agreed or strongly agreed.

Answer Research Question 4 (Clinician Survey). Based on these results, it appears that the majority of licensed physical therapists do not think that age is a strong predictor of professionalism.

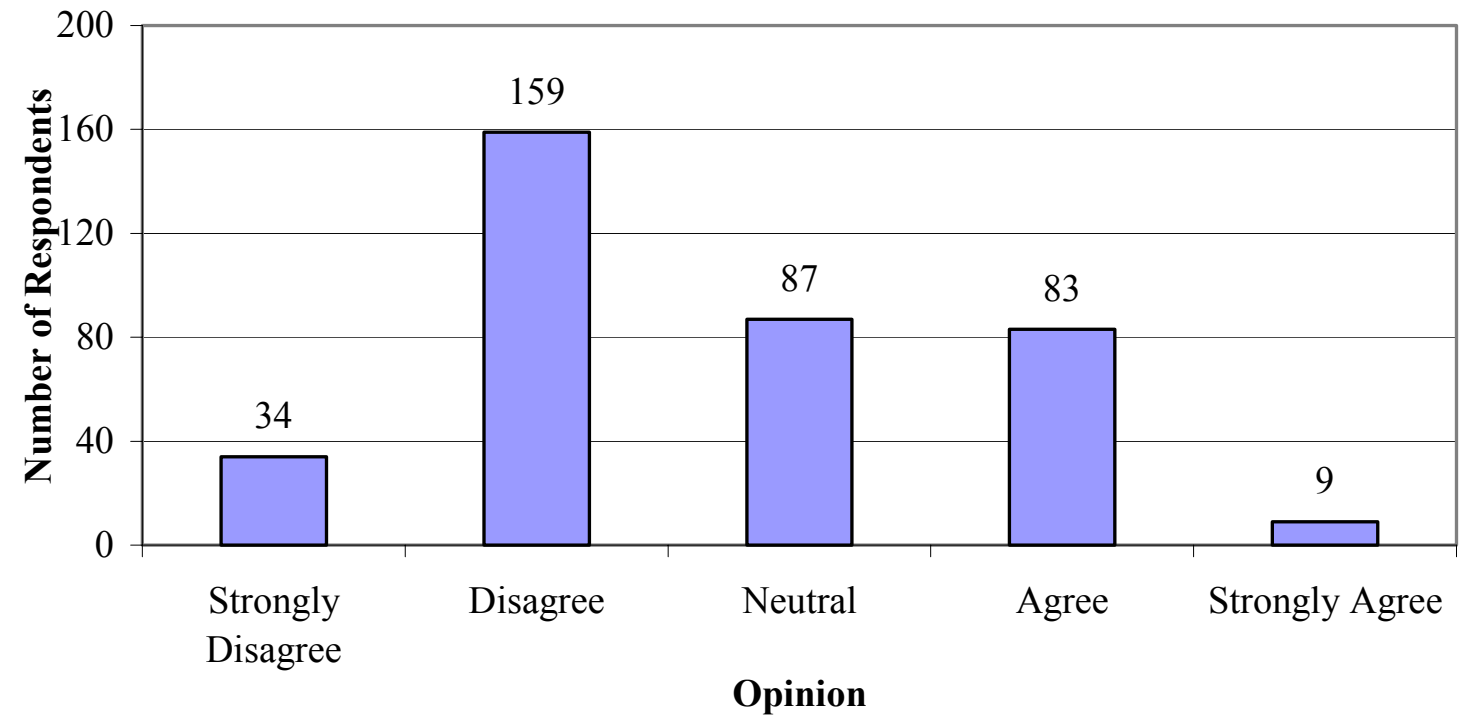

Figure 4.31. Age at the time of admission is a predictor of professional behaviors. 
Research question 5 (Clinician Survey). Compared to other professions, how do licensed physical therapists view the level of professionalism of the physical therapy profession?

An analysis of Item 9 was used to answer this research question. Item 9 asked the participants to rate the professional behavior of seven professional groups (physical therapy students, practicing physical therapists, medical doctors, occupational therapists, speech pathologists, clergy, and lawyers) on a scale of 1-10 (10 being the highest degree of professionalism). Data from this section were treated as continuous data; however, due to significant skewness and significant Shapiro-Wilk test (lack of normality) for each professional group, further analysis utilized nonparametric statistical analysis. Table 4.9 contains the skewness coefficient, the Shapiro-Wilk statistic, and the corresponding p-value. Figure 4.32 shows the median and mean ranking for each professional group.

Answer Research Question 5 (Clinician Survey). Based on these results, licensed physical therapists rate the professionalism of the physical therapy profession comparable to that of other similar professions. 
Table 4.9

Distribution Characteristics of Professional Groups

\begin{tabular}{lcccc}
\hline \multicolumn{1}{c}{ Professional Group } & Skewness Coefficient & $\mathrm{n}$ & Shapiro-Wilk statistic & $\mathrm{p}$-value \\
\hline PT Student & -0.70 & 331 & 0.93 & $<0.0001^{*}$ \\
PT Colleagues & -1.13 & 360 & 0.88 & $<0.0001^{*}$ \\
Medical Doctors & -1.04 & 356 & 0.90 & $<0.0001^{*}$ \\
Occupational Therapists & -1.02 & 322 & 0.91 & $<0.0001^{*}$ \\
Speech Therapists & -1.17 & 284 & 0.88 & $<0.0001^{*}$ \\
Clergy/Priest/Rabbi & -1.55 & 271 & 0.84 & $<0.0001^{*}$ \\
Lawyers & -1.04 & 245 & 0.89 & $<0.0001^{*}$ \\
\hline
\end{tabular}

$* p<0.05$ 


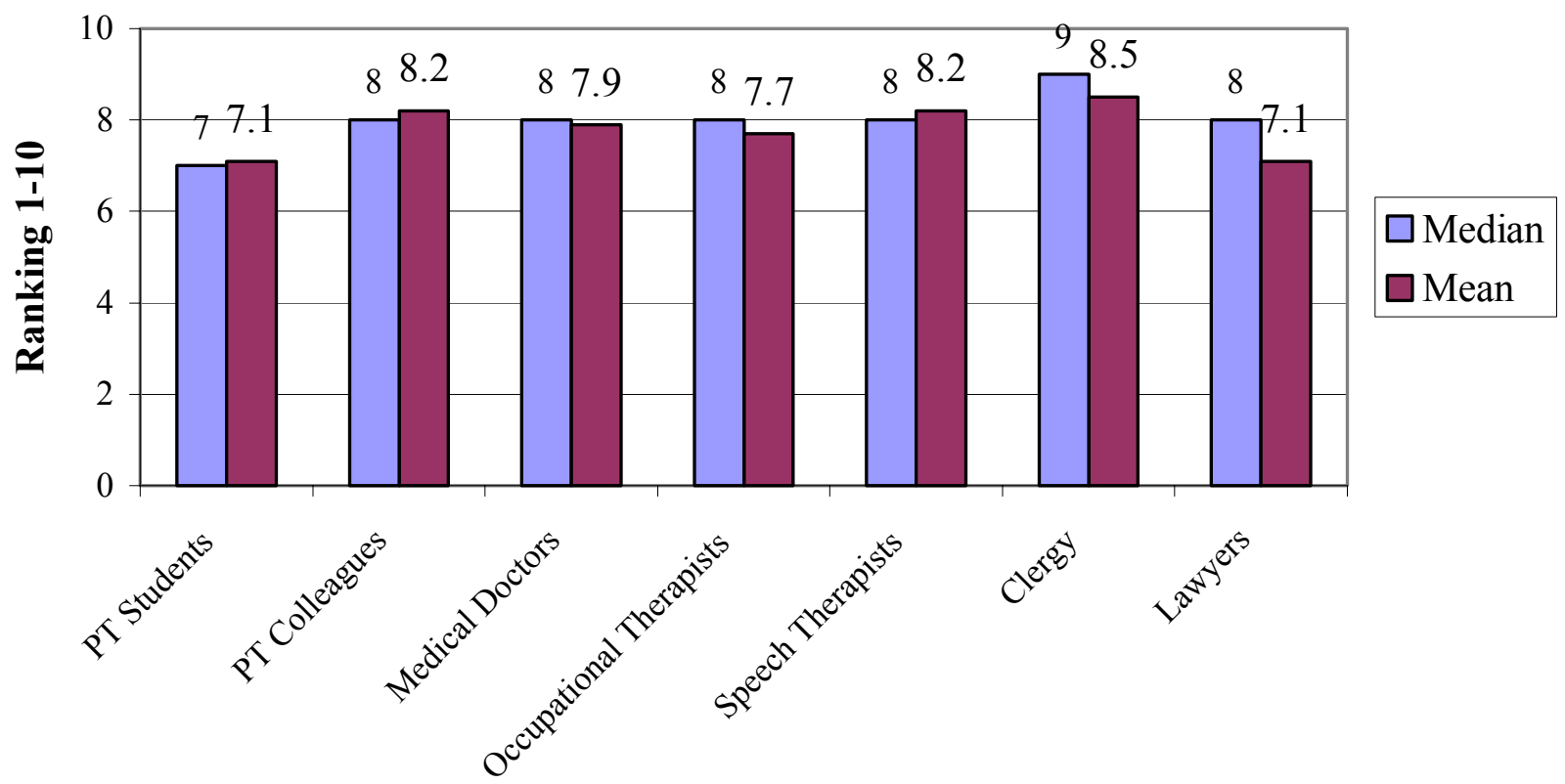

Professional Groups

Figure 4.32. Median and mean ranking of professionalism for each professional group.

Research question 6 (Clinician Survey). From a licensed physical therapist's perspective, what are the most frequent negative behaviors demonstrated by entry-level physical therapy students?

Data from Item 10 were used to answer this research question. The weighted averages for each negative behavior are presented in Figure 4.33. Weighted averages were calculated by assigning each rank with a number from one to five.

Answer Research Question 6 (Clinician Survey). Based on these results, licensed physical therapists identified tardiness, dress code violations, and lack of responsibility as the three most frequent negative behaviors observed among physical therapy students. 


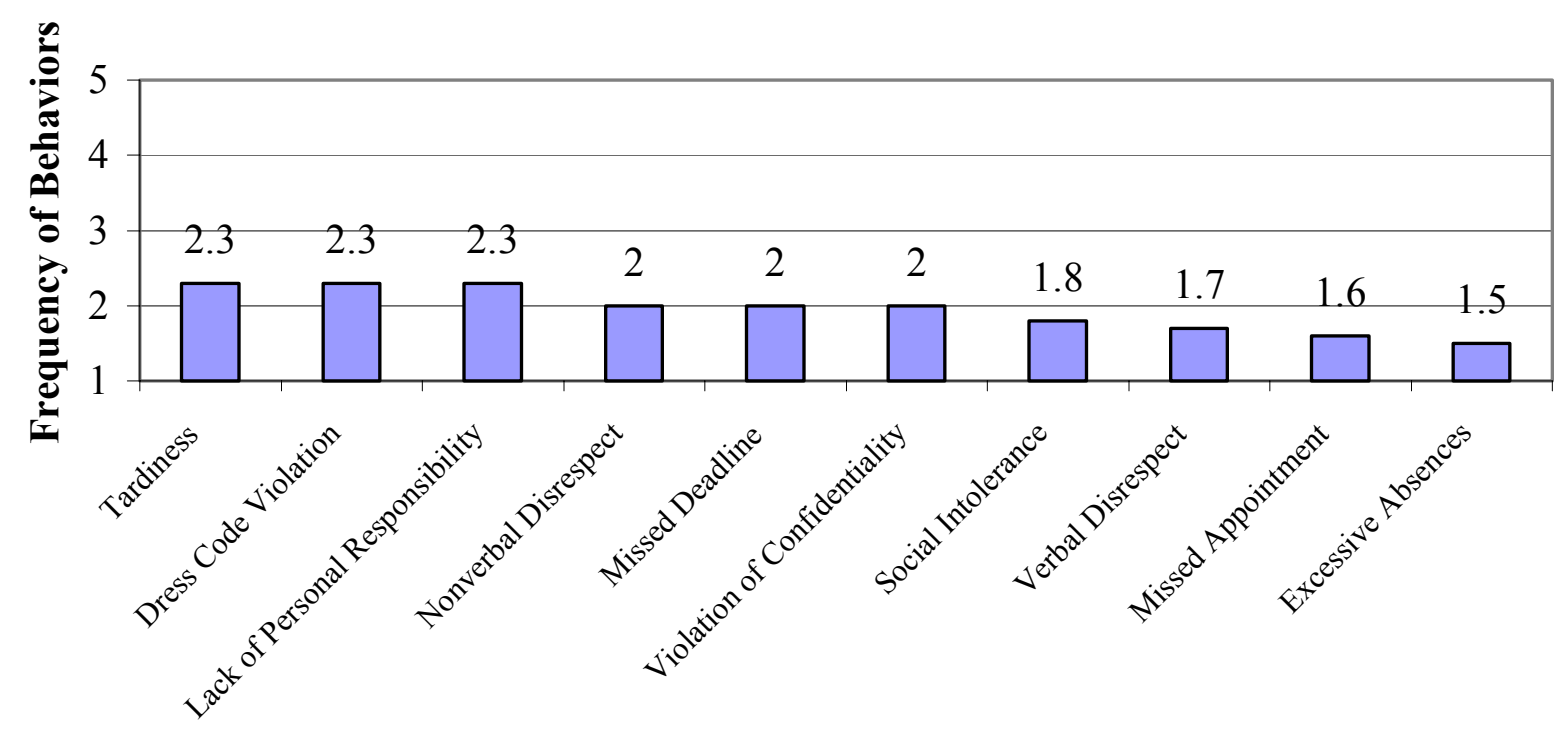

Negative Behaviors

Figure 4.33. Weighted averages of negative behaviors. $(1=$ never; $2=$ infrequently, $3=$ occasionally; $4=$ often, 5 = very often)

Research question 7 (Clinician Survey). From a licensed physical therapist's perspective, what are the seven most important professional skills?

This research question was answered by analyzing Item 13 . This item asked the participants to identify the seven most important professional behaviors for a practicing physical therapist from a list of 15 behaviors identified in the literature. The seven most frequently identified professional behaviors are listed in Figure 4.34, while the eight least frequent behaviors are presented in Figure 4.35. All 372 participants responded to Item 13.

Answer Research Question 7 (Clinician Survey). Based on these results, the seven most important professional skills or behaviors for a practicing physical therapist were clinical reasoning, oral communication, integrity, responsibility, compassion/caring, accountability, and written communication. 


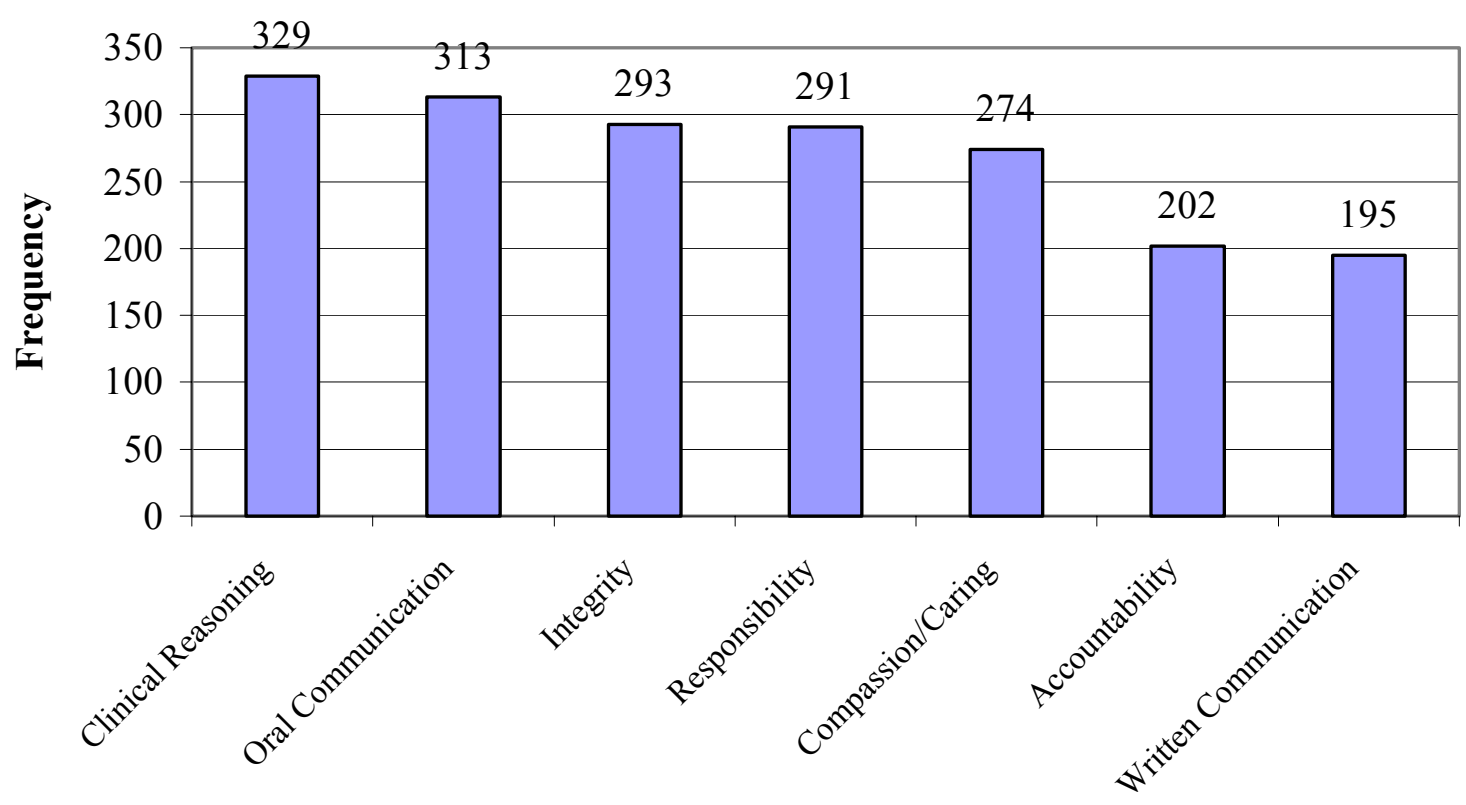

Professional Skill/Behaviors

Figure 4.34. The seven most frequently identified professional skills/behaviors.

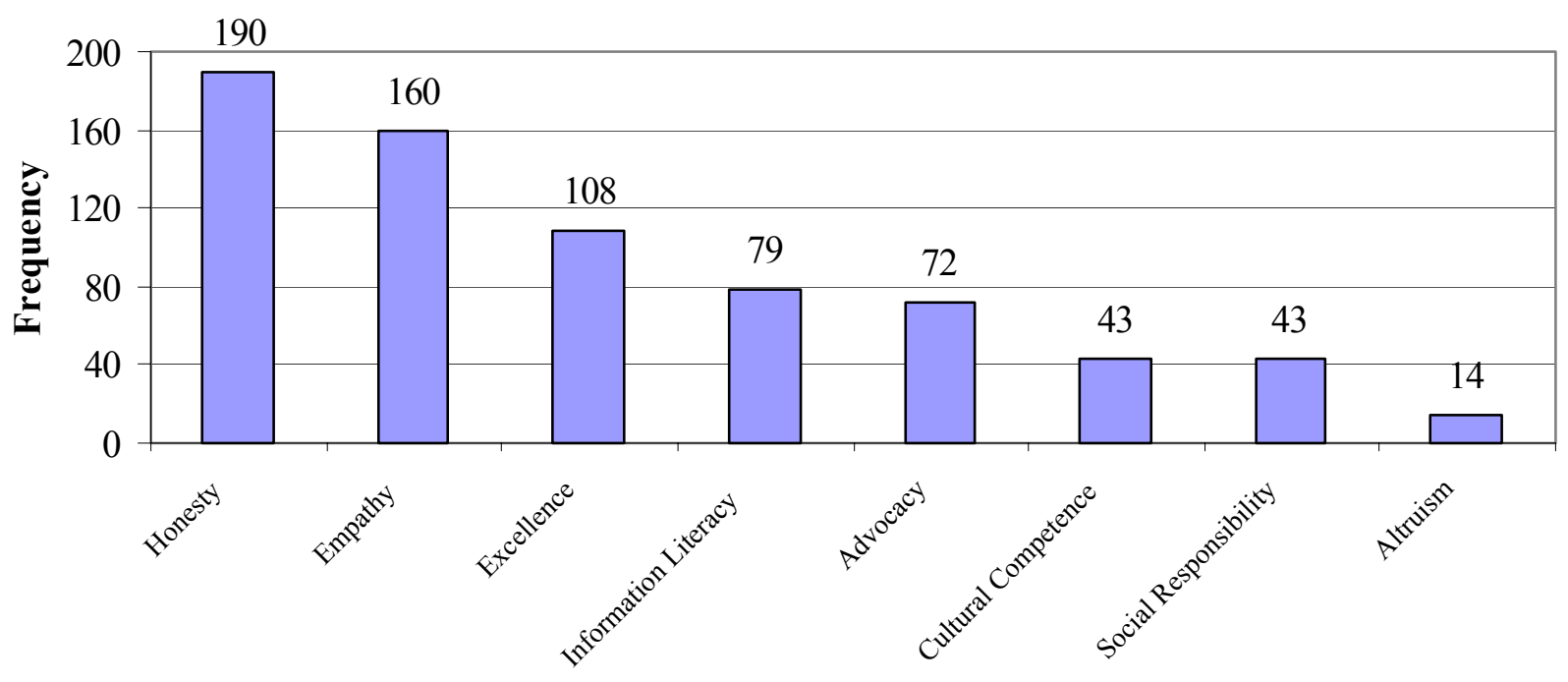

Professional Skills/Behaviors

Figure 4.35. The eight least frequently identified professional skills/behaviors. 
Research question 8 (Clinician Survey). Based on the opinions of licensed physical therapists with seven or more years of experience, are students and new graduates today, more professional than students or new graduates in previous years?

An analysis of Item 15 was used to answer this research question. Item 15 asked the respondents with seven or more years of clinic experience to respond to the following statement: Students and new graduates (last three years) are more professional than students or new graduates in previous years. Of the 372 surveys returned, $364(97.8 \%)$ participants responded to this item. Figure 4.36 contains the frequency distribution of the participant's responses on a modified Likert scale. Of the 364 responses, 175 (48.1\%) respondents disagreed or strongly disagreed with this statement, while only 56 (15.4\%) agreed or strongly agreed.

Answer Research Question 8 (Clinician Survey). Based on these results, licensed physical therapist do not believe that students are more professional today than they were several years ago. In fact, the results suggest that students today are less professional than they were in previous years. 


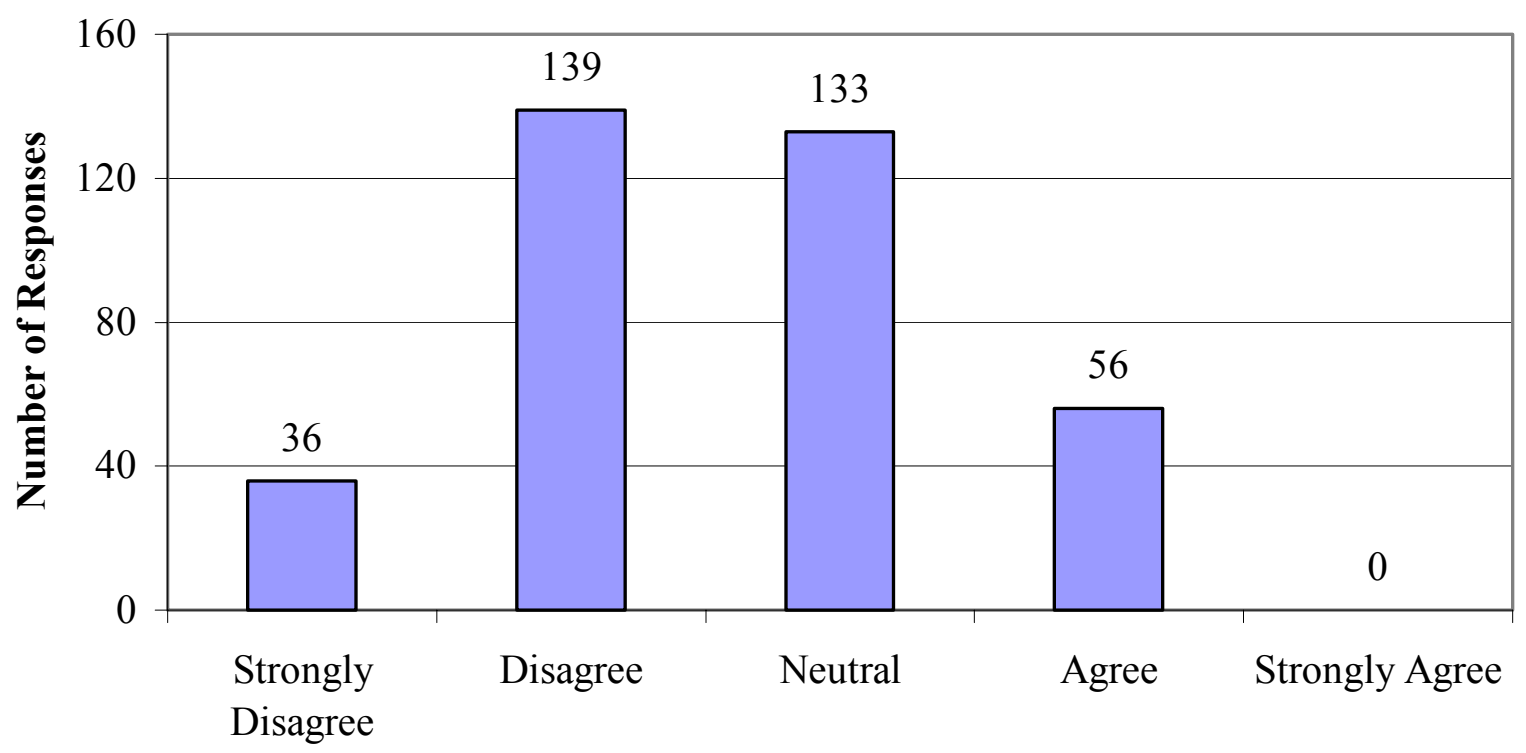

\section{Opinion}

Figure 4.36. Recent students are more professional than students were in previous years.

Research question 9 (Clinician Survey). Based on the opinions of licensed physical therapists, is there a difference in the level of student professionalism based on the following demographic variables?

- PT degree

- Years of clinical experience

- Age

- Gender

- Work Status

- Practice Setting

- Geographic Region

Again, because the variables in Item 9 were not normally distributed (see Table 4.9), nonparametric statistics were used to determine if there was a difference in PT student professionalism based on these demographic variables. Table 4.10 contains the results of each analysis. 
Answer Research Question 9 (Clinician Survey). Based on these results, the level of professionalism among physical therapy students appear to be greater while in outpatient settings than while in home health settings.

Table 4.10

Student Professionalism across the Demographic Variables

\begin{tabular}{|c|c|c|c|}
\hline Demographic Variable & Kruskal-Wallis Statistic & p-value & Post-hoc Comparisons \\
\hline PT degree & 3.49 & 0.479 & \\
\hline Years of experience & 2.76 & 0.598 & \\
\hline Age & 7.28 & 0.201 & \\
\hline Gender & 0.288 & 0.593 & \\
\hline Work Status & 0.027 & 0.869 & \\
\hline Practice Setting & 11.92 & $0.036^{*}$ & Outpatient $>$ Home Health \\
\hline Geographic Region & 1.414 & 0.842 & \\
\hline
\end{tabular}


Qualitative data analysis (Clinician Survey). Of the 372 surveys returned, 133 (35.8\%) participants provided qualitative data in the form of a written response to Item 17, which stated: Please offer any additional information regarding your experience with the state of professionalism in the physical therapy profession. The initial screening of the comments provided in Item 17 revealed six broad themes. These included mentoring/role-modeling ( $\mathrm{n}$ $=14)$, personality/family values $(\mathrm{n}=17)$, negative comments related to the state of professionalism among PT students $(\mathrm{n}=35)$, positive comments related to the state of professionalism among PT students $(\mathrm{n}=21)$, negative comments related to the DPT degree $(\mathrm{n}=$ 13), and comments rationalizing their response $(\mathrm{n}=15)$. Additionally, 18 responses did not appear to fit any particular theme. Tables 4.11 a through $4.11 \mathrm{c}$ summarize the overall qualitative findings and provide representative examples of each theme. 
Table 4.11a

Summary of Qualitative Data for the Practicing Clinician Survey

\begin{tabular}{|c|c|c|}
\hline Themes & Count & Representative Examples \\
\hline $\begin{array}{l}\text { Mentoring and } \\
\text { role-modeling }\end{array}$ & 14 & $\begin{array}{l}\text { \#218 "Entry level students need to be mentored in professional } \\
\text { behavior and responsibility from the start of their education, not } \\
\text { when they are ready for clinical externships." } \\
\text { \#250 "Professionalism is also fostered and will be easier to } \\
\text { portray in an environment where it is practiced by all. It should } \\
\text { come from the top down." } \\
\text { \#288 "I truly feel professionalism can be taught and is best } \\
\text { modeled with clinical supervision for new graduates practicing." }\end{array}$ \\
\hline $\begin{array}{l}\text { Personality/family } \\
\text { values }\end{array}$ & 17 & $\begin{array}{l}\text { \# } 134 \text { "It has been my experience that professionalism is } \\
\text { something that you either have or you don't." } \\
\text { \#5 "I feel that professionalism is largely a personality trait that } \\
\text { cannot be taught to someone without a tendency towards it in the } \\
\text { first place." } \\
\text { \#85 "I believe that respect for yourself and others is from your } \\
\text { upbringing by your parents." }\end{array}$ \\
\hline
\end{tabular}


Table 4.11b

Summary of Qualitative Data for the Practicing Clinician Survey

\begin{tabular}{|c|c|c|}
\hline Themes & $\overline{\text { Count }}$ & Representative Examples \\
\hline Negative & 35 & \#208 "Have noticed a definite decline in maturity, \\
\hline comments & & professionalism, desire to work for a living in newer physical \\
\hline regarding & & therapists." \\
\hline \multirow[t]{5}{*}{ professionalism } & & \#192 "It is very troubling to see the shift in professionalism that \\
\hline & & has taken place in PT over the last decade." \\
\hline & & \#309 "I am quite concerned with the lack of professionalism \\
\hline & & within the younger PT graduates. I am only 36 but I continue to \\
\hline & & be amazed at the unprofessionalism I observe in new graduates." \\
\hline Positive comments & 21 & \#194 'I think physical therapists display great professionalism \\
\hline regarding & & towards each other and to their patients." \\
\hline \multirow[t]{5}{*}{ professionalism } & & \# 2 “Most PT's I know are responsible, knowledgeable, self- \\
\hline & & assured, and interested in professional growth." \\
\hline & & \#75 "Professionalism is one of the strong points of our \\
\hline & & profession." \\
\hline & & \#228 "Professionalism is an important topic" \\
\hline
\end{tabular}


Table 4.11c

Summary of Qualitative Data for the Practicing Clinician Survey

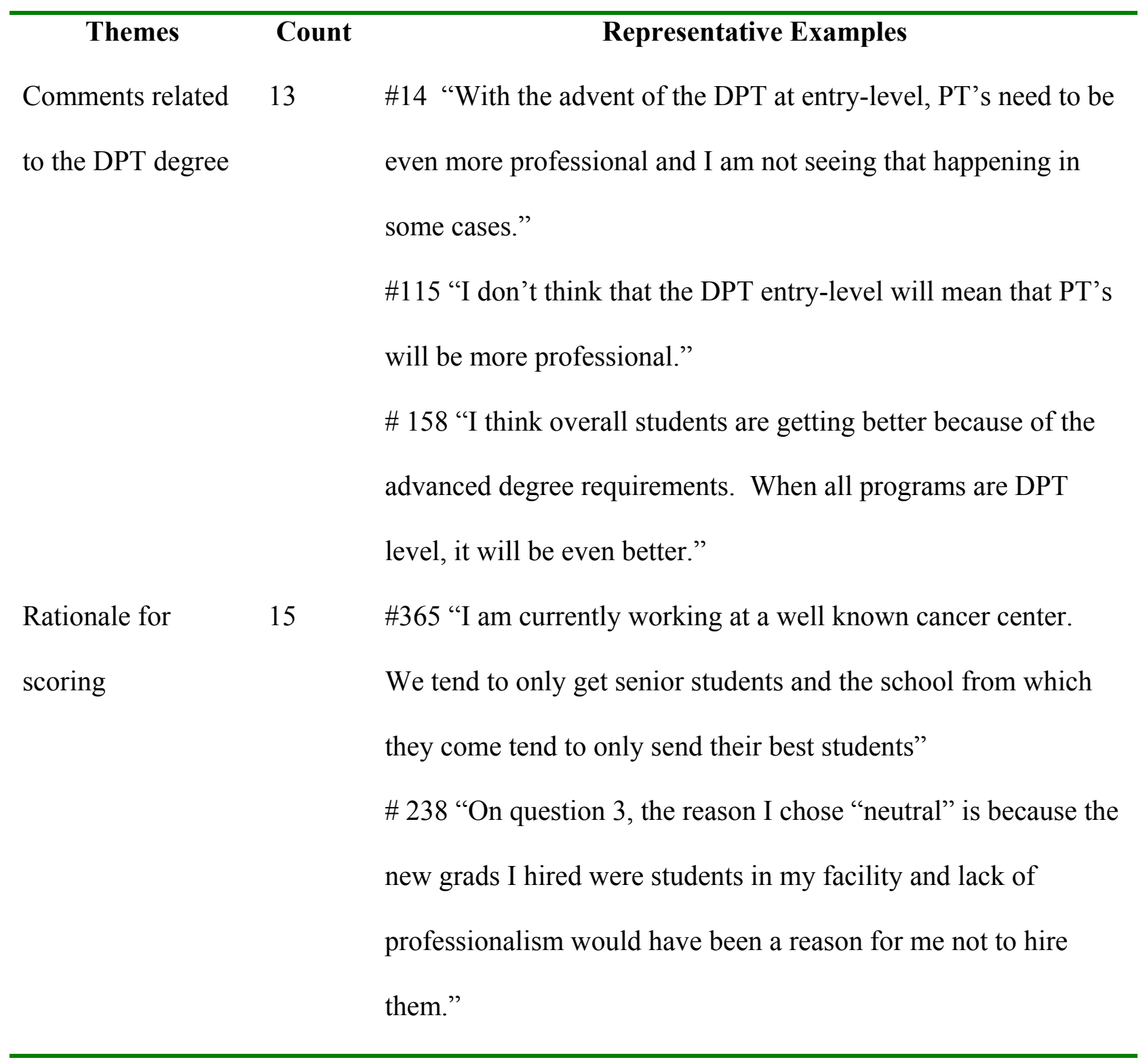




\section{CHAPTER 5}

\section{DISCUSSION}

The primary purpose of this investigation was to identify the state of professionalism in the physical therapy profession. This was accomplished by designing two separate but parallel investigations that attempted to quantify and qualify the issues that surround the teaching and development of professionalism among entry-level physical therapy students and practicing clinicians. The investigation consisted of two surveys, one designed to assess the opinions, experiences, and beliefs of physical therapy students and the other designed to assess the opinions, experiences, and beliefs of practicing clinicians. Each investigation was guided by a set of specific research questions. The results obtained from these two investigations will be discussed relative to each research question.

Physical Therapy Student Survey (Investigation A)

From the 2030 surveys mailed, 336 (16.6\%) surveys were returned by participating students. However, the apparent low response rate may not be an accurate reflection of the true response rate. The number of surveys that were mailed to each program was based on program data obtained on the Internet, which typically refers to the maximum number of students accepted per class, rather than an accurate number of students enrolled at the time of the survey. In order to obtain a more accurate number of students enrolled in each of the 20 programs, a post-analysis phone call was made to each program to identify the actual number of students enrolled at the time of the survey. The phone survey revealed three very important findings. 
First, one program (Sacred Heart University) indicated that they never received the survey package. In the post-analysis phone survey, Sacred Heart University reported having 73 students enrolled at the time of the survey. With an overall response rate of $22 \%$, the loss of Sacred Heart University, represents an approximately loss of 17 students from the overall investigation.

Second, physical therapy programs are often rigorous and some attrition before matriculation is common. Upon inspection, attrition was found in several of the programs. Thirdly, in the last few years most of the accredited programs have transitioned to the DPT degree from the MPT degree. This transition has resulted in a decline in enrollment in many programs. According to the CAPTE Fact Sheet (2005), the average number of students enrolled per program dropped from 87.3 to 79.7 between 2002 and 2004 . This trend is evident by the fact that one program reported a significant reduction in enrollment and returned 41 extra surveys. The phone survey revealed that 1,525 students were available to respond to the survey. As a result, the actual response rate of this investigation was $22 \%$.

The proportion of women to men in this investigation was $75.9 \%$ women to $24.1 \%$ men. Based on the CAPTE Fact Sheet (2005), the average female to male ratio is $73 \%$ women to $27 \%$ men. Therefore, this sample appears to be representative of the population of interest with respect to gender.

The proportion of full-time to part-time students in this investigation was $99 \%$ full-time and $1 \%$ part-time. According to the CAPTE Fact Sheet (2005), only eight (4\%) CAPTE accredited programs offer a part-time curriculum. Of the 20 programs randomly sampled in this investigation, one (5\%) program (State University of New York, Downstate Medical Center) 
offers a part-time curriculum. Although the sample in this investigation is consistent with the CAPTE Fact Sheet (2005) relative to attendance status, no statistical comparisons were made based on attendance status, due to the small number of part-time students available.

The distribution of age, revealed that the largest number of student participants were between the ages of 21 and 25 years, with the second largest group being between 26 and 30 years of age. Consistent with contemporary educational trends, several non-traditional students were represented in this sample. There were $16(4.8 \%)$ students between the ages of 36 and 50 years, and one student reported being over 50 years of age. The CAPTE Fact Sheet (2005) does not offer any information relative to age, thus it is impossible to know if the sample is representative of the population based on age.

The largest percentage (45.9\%) of respondents were in their second year of the physical therapy program. First-year students represented 39\% of the sample, while third-year students consisted of $15 \%$. The limited number of students responding in their third year was probably because many of the students in their third-year were training off campus, working on clinic affiliations. In many programs, the third professional year largely consists of clinical affiliation experience in the community. Therefore, this sample somewhat under represents third-year students.

The majority of the respondents (74\%) had less than six weeks of clinical affiliation experience. According to the CAPTE Fact Sheet (2005), the average number of weeks for clinical affiliation is 31.4 weeks. Only ten $(2.9 \%)$ respondents had greater than 24 weeks of clinical experience. This sample represents students across the spectrum of experience, but it is heavily weighted toward the low end of the spectrum. As mentioned previously, many of the 
third-year students, who would have possessed the greatest degree of clinical experience, were likely off campus at the time of the survey. As was discussed in the Chapter 4, an error in the development of this item resulted in those with exactly six weeks of clinical experience being forced to choose either less than 6 weeks or 7-12 weeks. It is unclear how many participants were affected by this error. It is clear that this error did not prevent students from responding to this item.

Of the 336 respondents, 249 (74.1\%) expected to matriculate with a DPT degree. According to the CAPTE Fact Sheet (2005), 68\% of the programs offer the DPT degree, while $32 \%$ offer the MPT degree. Therefore, this sample represents the trend toward the DPT degree. The goal of the APTA is to have all the accredited programs offering the DPT degree by 2020. The average class size in this investigation was 33.6, with a median of 32 . The data obtained from the Internet for each program suggested a class size range of 24-90. According to the CAPTE Fact Sheet (2005), the average expected class size in 2004 was 32; however, the average number of students offered a place in the class was 56. Clearly, some programs are not currently filling their classes.

The average number of full-time faculty per program was 8.7 with a median of eight. The CAPTE Fact Sheet (2005) reported that the average number of full-time faculty in 2004 was 9.0. With an average of 8.7 full-time faculty, the average student to faculty ratio in this sample was 11.6 to 1 . According to the CAPTE Fact Sheet (2005), the average student to faculty ratio was 11.8 to 1 . Thus, based on the number of faculty and the faculty to student ratio, it appears that this sample is very representative of the population of interest. 
In this sample, it was found that $176(52.7 \%)$ students attended a public college or university. This is compared to $52.4 \%$ reported by the CAPTE Fact Sheet (2005). Again, based on institution type, this sample is very representative of the population of interest.

Although the random sample produced six programs from the Northeast, six programs from the South, four programs from the Midwest, and four programs from the West, the sampling distribution from the Northeast was considerably less than the other three regions. The sample contained $37.3 \%$ from the South, while only $6.0 \%$ were from the Northeast. There are two reasons for this disparity. The first is that one program (Sacred Heart University) in the Northeast did not participate in the investigation as planned. The second is that the chairperson has the potential to greatly influence the number of students who may respond. It is very possible that some chairs strongly encouraged participation, while other chairs may have simply distributed the surveys without verbal or written encouragement.

Based on the demographic variables of class size, gender, attendance status, degree type, number of full-time faculty, student to faculty ratio, and institution type, it appears that the sample in this investigation is very representative of the population of interest and thus the external validity of this sample is supported. The only variables that suggest the sample may not be fully representative of the population are year in PT school, degree of clinical experience, and geographic region. The impact of this finding will be discussed later as a limitation of this investigation.

Specific Research Questions

Research question 1 (Student Survey). Do entry-level physical therapy students have a positive appreciation for the importance of learning professionalism as part of a physical therapy 
education?

In response to Item 1, Teaching and fostering professional behaviors is an important part of a physical therapy education, $98 \%$ of the respondents agreed or strongly agreed, while only $1.8 \%$ disagreed or strongly disagreed. Based on this response, it appears that physical therapy students have a positive appreciation for the importance of learning professionalism.

In response to Item 5, Professionalism is a construct (concept) that can be learned, $87.7 \%$ agreed or strongly agreed, while only $4.8 \%$ disagreed or strongly disagreed. In response to Item 6, Professionalism is a construct (concept) that can be taught, $82 \%$ agreed or strongly agreed, while $4.8 \%$ disagreed or strongly disagreed. Although the percentage of individuals who believe that professionalism can be learned and taught is high, it is interesting to compare the percentage of those who agree professionalism should be taught (98\%) compared to the percentage that agree that professionalism can be learned $(87.7 \%)$ and taught $(82 \%)$. Based on the response to Items 1, 5 and 6, it appears that physical therapy students have a positive appreciation for the importance of learning professionalism as part of an entry-level physical therapy education.

As presented previously, Bloom (1956) states that the affective domain relates to student interests, attitudes, values, and appreciation of learning. Based on the results of these three items, it appears that the students who responded in this sample have at least achieved the internalization level of the affective domain. The premise of the affective domain is that if students have a positive appreciation for learning a particular subject matter, they will be more open and accepting of instruction. 
Research question 2 (Student Survey). Do entry-level physical therapy students view their professors and clinical instructors as positive professional role models who possess a high degree of professionalism compared to their own?

Items 2 and 9 were used to answer this research question. In response to Item 2, My professors demonstrate professional behaviors suitable for a professional role model, 94\% of the respondents agreed or strongly agreed, while only $1.5 \%$ disagreed or strongly disagreed. In response to Item 9, How would you rate your degree of professionalism compared to your professors, $63.7 \%$ indicated that they possessed the same degree of professionalism, while $29.8 \%$ rated themselves as having less professionalism, and 6.5\% indicated that they were more professional than their professors.

Based on the response for these two items, it appears that students generally think that their professors are professional, but they fail to recognize a difference in their degree of professionalism compared to their professors. As discussed in Chapter 2, Vygotsky (1978) believed that cognitive learning requires a "zone of proximal development" where skills are developed with the help and support of individuals with greater knowledge and skill. The application of Vygotsky's theory to learning professionalism would require professors and clinical instructors to have a greater degree of professionalism than the student. The results of this investigation suggest that some students do not recognize a differential between their own degree of professionalism and that of their professors. Three hypotheses can be drawn from this finding. First, physical therapy students may have an inflated self-perception of professionalism. Secondly, faculty behaviors may not be different enough to be recognized as unique by the students. Thirdly, students are very quickly learning and internalizing these professional 
behaviors.

Research question 3 (Student Survey). Do entry-level physical therapy students view their clinical instructors as positive professional role models that possess a high level of professionalism compared to their own?

Three items were used to answer this question (Items 3, 10, and 14). In response to Item 3, My clinical instructors demonstrate professional behaviors suitable for a professional role model, $89 \%$ agreed or strongly agreed, while only $5.5 \%$ disagreed or strongly disagreed. This is slightly less than the $94 \%$ who agreed or strongly agreed that their professors demonstrate professional behaviors.

In response to Item 10, How would you rate your professionalism compared to your clinical instructors, $61.9 \%$ indicated they possessed the same degree of professionalism, while $21.4 \%$ indicated they possessed more professionalism than their clinical instructors. Only $16.8 \%$ of the respondents stated that they were less professional than their clinical instructors. Again based on self-perception, there does not appear to be an ample zone of proximal development that would foster ideal role modeling. This finding is particularly interesting, given the sample in this investigation was skewed toward the first and second-year students with little clinical experience.

Item 14, asked the students to indicate the frequency of negative behaviors observed among their clinical instructors. The three most frequent negative behaviors were tardiness, non-verbal disrespect, and verbal disrespect. As will be discussed in a later section, the same three behaviors were identified as the most frequent negative behaviors observed in classmates. It should be noted that all three of these behaviors were only observed infrequently. Despite the 
lack of frequency, clinical instructors or faculty should make every effort to avoid modeling negative behaviors. Based on this research, most clinical instructors appear to be serving as adequate role models; however, students do not recognize a differential between their degree of professionalism and that of their clinical instructors. Clinical instructors need to be aware of how they are being perceived by students and attempt to minimize these negative behaviors. Research question 4 (Student Survey). Are physical therapy students aware of the American Physical Therapy Associations efforts to promote professionalism?

This question was answered by analyzing Item 8 of the survey, which asked the participants to respond to the following statement on a modified Likert scale from strongly disagree to strongly agree: I am aware of the APTA's "Core Values" as it is stated in the Normative Model of Physical Therapy Education. Of the 335 respondents, 41 (12.2\%) disagreed or strongly disagreed to being familiar with the APTA's Core Values, while $70.1 \%$ agreed or strongly agreed with the statement. Based on this response it appears that the majority of the students have been exposed to the APTA's Core Values document. Faculty are responsible for meeting CAPTE accreditation standards, but they are also motivated intrinsically to indoctrinate their students in the culture and values of the profession. Based on this sample it appears that faculty are disseminating the APTA's message.

Research question 5 (Student Survey). Compared to other professions, how do entrylevel physical therapy students view the level of professionalism of the physical therapy profession?

Item 12 asked the students to rate the degree of professionalism of eight groups (themselves, classmates, clinical instructors, faculty, medical doctors, occupational therapists, 
speech pathologists, and clergy). Of the eight groups rated on a scale of 1-10, faculty were rated the highest at 8.94 , followed by clergy at 8.80 and medical doctors at 8.54 . Students rated clinical instructors at 8.46 , themselves at 8.07 and classmates were rated the lowest at 7.38 . Again, it is evident that students do not recognize a significant differential between their own degree of professionalism and that of other professional groups. This apparent lack of differential may result in a barrier to learning professionalism because students do not appear to recognize that their behaviors are different from faculty and clinical instructors. As stated previously, this lack of differential is particularly important given the majority of the students who responded were first and second-year students.

Research question 6 (Student Survey). From an entry-level physical therapy student's perspective, what are the most frequent negative behaviors demonstrated by physical therapy students?

Respondents rated the frequency of negative behaviors of their classmates on a modified Likert scale from never to very often. The analysis revealed that tardiness, verbal disrespect, and nonverbal disrespect were the most frequent negative behaviors. The same three behaviors were identified by students as being the most frequent among clinical instructor. This apparent agreement may reflect modeling of negative behaviors observed in clinical instructors.

Research question 7 (Student Survey). From an entry-level physical therapy student's perspective, what are the seven most important professional skills?

Item 15 asked the students to identify the seven most important professional skills or behaviors from a list of 15 professional skills or behaviors identified in the literature. The seven most important skills identified by the students were oral communication, clinical reasoning, 
responsibility, compassion/caring, integrity, honesty, and accountability. The seven core skills or behaviors identified in the Normative Model (American Physical Therapy Association, 2004) are accountability, altruism, compassion/caring, integrity, communication, cultural competence, and clinical reasoning. In comparison, the students agreed with the Normative Model (2004) in five of the seven behaviors. The two behaviors, which were not included in the seven most important, were altruism and cultural competence. In fact, cultural competence and altruism were ranked 12 and 14 out of the 15 behaviors, respectively.

Based on these results, it appears that students recognize the importance of many of the same skills and behaviors as those professionals who developed the Normative Model (2004). However, students did not recognize the relative importance of cultural competence and altruism. Based on these results, faculty and clinical instructors may want to focus more of their efforts on explaining and modeling the virtues of altruism and cultural competence.

Research questions 8 (Student Survey). Which teaching strategies are being used to teach professionalism and do entry-level physical therapy students find these strategies appealing? Items 16 and 17 asked the students to identify the teaching strategies used by their program to teach professionalism and to identify their preferred teaching methods to learn professionalism. The five most frequent methods being used to teach professionalism were lecture, small group discussion, reading assignments, generic abilities, and role modeling. The five most desired teaching methods were role modeling, small group discussion, case studies, role-playing, and lecture. Based on this investigation, role modeling, small group discussion, and lectures are utilized and enjoyed by students, while reading assignments and generic abilities are heavily used but not enjoyed by students. It is important that teachers try to identify teaching 
strategies that are both interesting and efficacious. To date, no investigations have attempted to compare the efficacy of different teaching methods for fostering professional behaviors.

Research question 9 (Student Survey). Is there a relationship or difference in self-perception of professionalism based on the following demographic variables?

- Years in PT program

- PT GPA

- Age

- Gender

- Clinical experience

- Degree Type

- Size of Class

The only two variables that were statistically significant $(\mathrm{p}<0.05)$ were years in the PT program and clinical experience. First-year students were found to have a lower self-perception of professionalism (7.8/10) than second (8.2/10) and third-year (8.4/10) students do, but there was no difference between second and third-year students. Based on these results, there appears to be a clinically small but statistically significant change that occurs between the first and second year relative to one's self-perception of professionalism. It is unclear if this small change in self-perception is recognizable by observation. It can be hypothesized that this change may be due to both formal instruction and clinical experience. It is interesting to note that despite their continued education there was not a statistically significant change between their second and third year. Further research is needed to understand the self-actualization process of becoming a professional.

There was also a statistical difference based on clinical experience. The difference was between those students with no clinical experience (7.8/10) and those with some clinical experience (8.2/10). Again, it is difficult to determine if this clinically small but statistically significant improvement is observable by faculty and clinical instructors. It is interesting to note 
that the amount of clinical experience did not improve the degree of professionalism. Based on these results it may be beneficial to provide clinical experience as early as possible in the curriculum. Caution is warranted with interpretation of these results, as years in the PT program may be confounded with clinical experience. The low response rate from those with extensive clinical experience and those in their third-year should also be considered. It is also important to note that age, GPA, gender, degree type, and class size were not statistically significant variables relative to a student's self-perception of professionalism.

Research question 10 (Student Survey). Is there a difference in frequency of observed negative behaviors based on selected program and demographic variables?

An examination of the frequency of the four most common negative behaviors (tardiness, verbal disrespect, non-verbal disrespect, and dress code violations) based on selected demographic variable (degree type, institution type, size of the university and geographic region) revealed five significant comparisons. Relative to tardiness, institutional type, size of the institution, and geographic region were statistically significant. Post hoc analysis revealed that public schools (3.1/5) had a higher incidence of tardiness than private schools (2.8/5). Large schools (3.1/5) had a higher degree of tardiness than medium schools (2.6/5), but there was no difference relative to small size schools (2.9/5). The difference between large schools and medium sized schools was 0.5 on a scale from $1-5$. It is unclear if this small but statistically different incidence of tardiness is clinically meaningful. Additionally, students who attended colleges or universities in the Midwest (2.6/5) had a lower incidence of tardiness than those who attend programs in the Northeast (3.1/5) and West (3.2/5). Students who attended programs in the South (2.9/5) also had a lower incidence of tardiness compared to the West. Based on these 
results, tardiness and the importance of being on time may be linked to cultural norms that are affected by geographic region, and the size and type of the institution. Irrespective of these differences, professionals are expected to possess time management skills. This is particularly important in clinical settings where patients are scheduled by appointment.

There was no difference in verbal and non-verbal disrespect relative to these demographic variables. Two independent variables were statistically significant relative to dress code. These included institution type and size of the university. Public schools (2.1/5) were found to have a higher incidence of dress code violations than private schools (1.8). Additionally, large schools (2.2/5) were found to have a higher incidence of dress code violations than small (1.8/5) and medium (1.8/5) sized schools. Again, cultural norms may be different among those who attend large public institutions compared to those who attend small private schools. Despite these differences, professionals are expected by the public to wear professional attire. A study by Cha, Hecht, Nelson, and Hopkins (2004) found that patients view medical residents who wear a lab coat and surgical scrubs more favorably than those who wear casual clothes. Some faculty believe that a dress code during classroom hours should be the same as that expected in a clinical setting, and those programs have instituted a classroom dress code, while other programs do not have a dress code while in class. However, to date, there is no scientific evidence that states that a formal dress code while in class carries over to a clinical setting.

Qualitative data (Student Survey). Qualitative data often provide depth and perspective that enhances understanding. Unfortunately, this investigation was not richly supported by qualitative data supplied by the participants. Of the 336 respondents, only $35(10.4 \%)$ of the 
respondents offered additional qualitative data. Despite the limited number of responses, several themes did emerge. The most predominant theme was that physical therapy programs are emphasizing professionalism as part of their curriculum. This finding is extremely important. As stated previously, one of the major foci of the APTA's Vision 2020 is to foster and promote professionalism. It is important that goals established by the professional association be disseminated to both members and students. Based on this theme, it appears that this professional goal is being realized by both faculty and students.

The second most frequent theme that was identified related to role modeling and mentoring. It is critical that students recognize the benefits and potential rewards of developing a mentoring relationship with a more experienced members of the profession. This qualitative finding supports and enhances the findings reported in research question 8, which revealed rolemodeling as the students most preferred method of learning professionalism.

The third theme that emerged was that students are observing negative behaviors of both their professors and clinical instructors. It was concerning that; this was the third most frequent comment. If the physical therapy profession is going to be successful in educating students who embody the characteristics of professionalism, professors and clinical instructors are going to have to be more cognizant about how they are being perceived by their students. As discussed by Wright and Carrese (2002), in their work with medical students, effective role models think about their responsibility as a role model and are thus consciously aware of how they are being perceived by students. Despite the emergence of this qualitative theme, the quantitative data suggests that negative behaviors among clinical instructors and faculty are a relatively infrequent observation. On a scale of 1-10 (10 being the highest degree of professionalism) professors 
received a mean score 8.9 , while clinical instructors received a mean score of 8.5. Additionally, one of the qualitative themes was that student experiences were quite variable, with some very positive professional role models and some very poor role models. Faculty and facility administrators need to carefully identify individuals who should and should not serve as formal student role models.

Limitations (Student Survey). Although several limitations will be identified, the most important limitation of this investigation was the response rate. The response rate was low at $22 \%$. Additionally, the fact that one Northeast program reported not receiving the survey package resulted in a sample that underrepresented the Northeast compared to the other three regions. Before the start of this investigation, it was anticipated that the response rate for this investigation would be low (20\%-30\%) given the nature of the participants being busy college students. Because direct contact with the participants was not possible, a follow-up mailing was not developed. An electronic mail message was sent to the program chair of each program asking him or her to remind the students to complete the survey. The reminder and encouragement were dependent on the willingness of the chairperson to pass along the two-week follow-up e-mail. Since the study was primarily descriptive in nature, the impact of the low response rate on the internal validity of the investigation was minimal, while the primary concern is with the external validity of the study.

The second limitation is the limited number of open-ended responses in Item 19. The small number of participants willing to offer qualitative data was most likely related to the fact that the participants were busy college students. Given the age of the participants and the fact that this generation is extremely computer literate, it is possible that students would have been 
more willing to provide comments if the survey had been administered electronically. Future investigations should improve the survey instrument by encouraging more qualitative data from the participants. This could be accomplished by having an open-ended qualitative question after each section of the survey instrument, rather than one section at the end of the survey.

The third limitation of the investigation was the fact that many students were confused by "professional phase" in Item 18. Of the 336 participants, only 295 students responded to this question. Additionally, many students indicated that they were unsure of the meaning of "professional phase." As such, this item was not used as an independent variable. Of the 19 programs, which participated, only three schools (Saint Francis University, Drexel University, and Husson College) offer a freshman admission program; therefore, the majority of the students were not familiar with the term "professional phase."

The fourth limitation of the investigation was the limited number of third-year students who participated. As stated previously, the third year of most physical therapy curricula is comprised of off-site clinical affiliations. It is common for students to be off site for nine months or more during this final year. Without additional funding, it was impractical to ask the programs to forward the paper and pencil surveys to the student's off site address. This limitation also resulted in most of the participants having a limited amount of clinical affiliation experience. This limitation may have been lessened if the survey had been offered electronically; however, the participating programs would have still been required to forward the survey's web address to the third year students.

Despite these limitations, this investigation is the only study that has attempted to obtain the opinions, beliefs, and experiences of physical therapy students relative to learning 
professional behaviors.

\section{Practicing Clinician Survey (Investigation B)}

The response rate of the practicing clinician survey was more robust at $37.9 \%$, providing good external validity of the sample. The sample consisted of $73.6 \%$ women and $26.4 \%$ men. Based on the APTA Demographic Profile (2004), the average women to men ratio for 2004 was $72.1 \%$ to $27.9 \%$. Therefore, relative to gender, this sample appears to be representative of the population of interest. The sample consisted of therapists who were predominately $(98 \%)$ between the ages of 31 to 60 years, while only $2 \%$ were between the ages of 21 to 30 or greater than 61 years of age. According to the APTA Demographic Profile (2004), the average age of APTA members is 41.8 years. The APTA Demographic Profile (2004) information also indicates that two age groups, 30-34, and 35-39 are the two largest cohorts. Based on the APTA Demographic Profile (2004), it appears that the sample is representative of the overall population, but somewhat underestimates therapists between 21 and 30 years of age. The sample was selected randomly; therefore, it is believed that the sample reflects the willingness of younger APTA members to complete and return the survey. Further discussion related to this sample bias will be added as a limitation of this investigation.

The sample characteristics based on years of experience revealed that the majority (78.9\%) of the respondents possessed between 11 and 20 years of clinical experience, while only $2 \%$ of the respondents had less than 11 years of experience and $18.4 \%$ had more than 21 years of clinical experience. According to the APTA Demographic Profile (2004), the average APTA member has 16.6 years of clinical experience. Although direct comparison is difficult, it appears that the sample in this investigation, under-represents physical therapists with less than 11 years 
of clinical experience. The APTA Demographic Profile (2004) indicated that $63.7 \%$ of the APTA members have more than ten years of clinical experience, while the sample in this investigation found 97.4 percent of the respondents had greater than ten years of clinical experience.

This investigation found that $58.6 \%$ of the respondents have a bachelor's degree. The APTA Demographic Profile (2004) indicated that $54 \%$ of the APTA members possessed a bachelor's degree. This investigation found that 6.7 percent possessed a DPT degree, while the APTA report, identified 3.1\% earned a DPT degree. Overall, this sample is very representative of the larger population based on physical therapy degree type and reflects the fact that more therapists are seeking the DPT degree.

In this investigation, $77.6 \%$ of the respondents worked full-time, while $22.4 \%$ worked part-time. The APTA Demographic Profile (2004) found 69.1\% worked full-time. Thus, based on work status, the sample in this investigation is reasonably consistent with the population of interest.

The results of this investigation suggest that the largest percentage $(32.6 \%)$ of the respondents work in an outpatient setting. Direct comparison to the APTA data is difficult due to a different coding system for categorizing work setting. Despite this difference, careful comparison reveals that the sample in this investigation appears representative of the population. For instance, $10.8 \%$ of the respondents reported working in home health compared to $7.4 \%$ in the APTA Demographic Profile (2004). Additionally, 14.3\% of the respondents reported working in acute care, while the APTA Demographic Profile (2004) reported 11.8\%. 
Overall, the sample in this investigation closely resembles the data provided by the APTA for gender, work status, degree and practice setting, while under representing the opinions and experiences of clinicians between 21 and 30 years of age and those with less than ten years of clinical experience.

Specific Research Questions

Research question 1 (Clinician Survey). Do licensed physical therapists have an appreciation for the importance of learning professionalism as part of a physical therapy education?

In response to Item 1, Teaching and fostering professional behaviors is an important part of a physical therapy education, $94.9 \%$ of the respondents agreed or strongly agreed, while only $4.6 \%$ disagreed or strongly disagreed. Based on the response to this question, it appears that most physical therapists recognize the importance of teaching and fostering professional behaviors. From this sample, 14 individuals strongly disagreed with this statement. In a few surveys it was clear that some individuals did not carefully look at the rating scheme prior to marking an answer, as they appeared to initially mark strongly disagree, but then marked out their first response and changed it to strongly agree. Closer examination of these surveys did not suggest an overall concern for teaching and fostering professionalism, supporting the theory that some individuals marked the wrong end of the scale. It would be very enlightening to know why some of these individuals have such a strong disagreement with the importance of teaching professionalism. Unfortunately, none of these individuals qualified their responses in the qualitative section. 
In response to Item 5, Professionalism is a construct (concept) that can be learned, $85.9 \%$ agreed or strongly agree, while only $4.3 \%$ disagreed or strongly disagreed. In response to Item 6, Professionalism is a construct (concept) that can be taught, 85.8\% agreed or strongly agreed, while $2.9 \%$ disagreed or strongly disagreed. Apparently, based on these responses, physical therapists make little distinction between the ability to learn and the ability to teach professionalism. Based on the response to Items 1, 5 and 6, it appears that physical therapists have a positive appreciation for the importance of learning professionalism as part of an entrylevel physical therapy education. This attitude and belief is critical if the profession has any hope of fostering professionalism.

Research question 2 (Clinician Survey). Based on their observation of physical therapy students, do licensed physical therapists view PT students as possessing positive professional behaviors?

Items 2 was used to answer this research question. In response to Item 2, The physical therapy students that I have worked with or observed in the last two years have demonstrated professional behavior, $79.9 \%$ of the respondents agreed or strongly agreed, while $3.4 \%$ disagreed or strongly disagreed. Interestingly, $11.9 \%$ of the respondents were neutral. Based on the response to this item, it appears that physical therapist generally think that students demonstrate professional behaviors, but some clinicians have clearly had negative experiences. This supports the idea that most students are developing and demonstrating professional behaviors, but a small group of students is having difficulty with the transition to professionalism.

Research question 3 (Clinician Survey). Based on their observation of new graduates during the first year of clinical practice, do licensed physical therapists view new graduates as 
possessing positive professional behaviors?

This question was answered by examining Item 3 . In response to Item 3, The new graduates (less than 1 year of clinical experience) that I have worked with in the last two years have demonstrated professional behaviors, $66 \%$ agreed or strongly agreed, while only $4.4 \%$ disagreed or strongly disagreed. When comparing new graduates to students, there appears to be a decrease in professionalism from the students $(79.9 \%)$ to the new graduates $(66 \%)$. Students realize that they are being graded on professionalism, and may have more of an extrinsic motivation to demonstrate professional behaviors. It is concerning that the same physical therapists rated new graduates with up to two years of experience has having less professionalism than students.

Research question 4 (Clinician Survey). Do licensed physical therapists believe that age is a predictor of professional behaviors among entry-level physical therapy students?

In response to Item $8, A$ student's age at the time of admission to an entry-level physical therapy program is a predictor of professional behavior during the physical therapy program, $51.9 \%$ disagreed or strongly disagreed, while only $24.7 \%$ agreed or strongly agreed. As identified previously in the student survey, the majority of the PT students are between 21 and 25 years of age; however, there has been a general trend in higher education of increasing enrollment of non-traditional students. If age were found to be a strong predictor of professionalism, then perhaps this suggests that professionalism is influenced more by learning and life experiences than by innate characteristics such as emotional intelligence. It is clear from this survey that the majority of the physical therapists do not believe that age is a predictor of professionalism. 
Research question 5 (Clinician Survey). Compared to other professions, how do licensed physical therapists view the level of professionalism of the physical therapy profession?

Item 9 asked the participants to rate the degree of professionalism of seven groups (physical therapy students, current physical therapy colleagues, medical doctors, occupational therapists, speech pathologists, clergy and lawyers). Of the seven groups rated on a scale of 110 , clergy were rated the highest at 8.5 , followed by physical therapy colleagues and speech pathologists both at 8.2. The practicing therapists rated PT students and lawyers the lowest at 7.1, while medical doctors and occupational therapists were rated 7.9 and 7.7, respectively. Based on this finding, physical therapists recognize a slight differential between the professionalism of PT students and their colleagues. As discussed previously, physical therapy students did not identify this differential. Although, physical therapists may be biased in their rating, it appears that physical therapists were rated as having comparable professionalism to the three quintessential or prototypical professional groups (medical doctors, lawyers and clergy).

Research question 6 (Clinician Survey). From a licensed physical therapist's perspective, what are the most frequent negative behaviors demonstrated by entry-level physical therapy students?

Item 10 asked the physical therapists to rank the frequency of negative behaviors observed in PT students. The five most frequent negative behaviors were tardiness, dress code violations, lack of personal responsibility, nonverbal disrespect and missed deadlines. The average ranking for each of these behaviors was between infrequently and occasionally. A similar question asked PT students to rate the frequency of observed behaviors in their clinical instructors. The top five negative behaviors identified by the students were tardiness, verbal 
disrespect, nonverbal disrespect, excessive absences, and missed deadlines. In both groups, tardiness was the most frequent negative behavior. Three of the five behaviors (tardiness, nonverbal disrespect, and missed deadlines) were consistent between groups. Perhaps the students are merely modeling the behaviors demonstrated by their clinical instructors.

Research question 7 (Clinician Survey). From a licensed physical therapist's perspective, what are the seven most important professional skills?

Item 13 asked the physical therapists to identify the seven most important professional skills or behaviors from a list of 15 professional skills or behaviors identified in the literature. The seven most important skills identified by the physical therapists were clinical reasoning, oral communication, integrity, responsibility, compassion/caring, accountability, and written communication. The seven most important professional skills or behaviors identified by the students were oral communication, clinical reasoning, responsibility, compassion/caring, integrity, honesty, and accountability. The seven core skills or behaviors identified in APTA Normative Model (2004) are accountability, altruism, compassion/caring, integrity, communication, cultural competence, and clinical reasoning. It is very interesting to note that the students and licensed physical therapists agree on six of the seven most important professional behaviors. The only difference was students included honesty and licensed therapists included written communication. Since written communication is a large component of a practicing clinicians job, this response was not surprising. Both groups (students and licensed therapists) agreed with the Normative Model (2004) for all the skills and behaviors except altruism and cultural competence. These results suggest, that for the most part, everyone in the profession, students, clinicians, and APTA leaders agree which behaviors are vitally 
important for the profession. Based on these results, the APTA may consider efforts to educate both students and clinicians on the merits of altruism and cultural competence.

Based on these results, it appears that licensed physical therapists recognize the importance of many of the same skills and behaviors as those who developed the Normative Model (2004). It is unclear if this is due to some intrinsic understanding of professional behaviors or if their conformity is due to instruction and indoctrination.

Research questions 8 (Clinician Survey). Based on the opinion of licensed physical therapists with seven or more years of clinical experience, are students and new graduates today, more professional than students or new graduates in previous years?

In response to Item 15, Students and new graduates today (last three years) are more professional than students or new graduates in previous years, $48.1 \%$ disagreed or strongly disagreed, while only $15.4 \%$ agreed or strongly agreed. In this sample, 36 participants strongly disagreed, while no participants strongly agreed. Based on the opinions of licensed therapists, there has been a decline in professionalism in recent years. This finding supports the literature that suggests a general decline in professionalism across many professions (Ber \& Alroy, 2002; Braithwaite, 1990; Diefendorf, 2003; Lima-Basto, 1995; MacDonald et al, 2002; Morehead, 1998).

Research question 9 (Clinician Survey). Based on the opinion of licensed physical therapists, is there a difference in the level of student professionalism based on the following demographic variables?

- PT degree

- Years of clinical experience

- Age

- Gender

- Work status 
- Practice setting

- Geographic region

Of the seven demographic variables investigated, only one variable was found to be statistically significant relative to the degree of perceived student professionalism. There was a difference in the rating of student professionalism based on the clinicians practice setting. The only statistically significant difference was between therapists who work in home health versus outpatient practice. Therapists who work in an outpatient setting rated the students higher (7.33/10) compared to those who work in home health $(6.4 / 10)$. The difference between these two groups represents almost a one-point change on a scale from 1-10, which appears to be clinically significant. This difference appears to be a clinically meaningful separation between the two practice settings. Working in someone's home is very different from working in an outpatient facility. When entering someone's home you must have great respect for the individual's living environment. It is often eye-opening for many students to visit someone's home, because of issues such as cleanliness and poverty. These extreme conditions may be a catalyst that provokes comments or nonverbal behaviors that would not be observed in an outpatient environment.

Qualitative data (Clinician Survey). This investigation was more richly supported by qualitative data than the student investigation. Of the 372 respondents, $133(35.8 \%)$ of the respondents offered additional qualitative data. Several important themes emerged from the participant's comments. The most predominant theme was that physical therapists are observing an increase in negative behaviors by physical therapy students. Of the 133 surveys containing qualitative data, 35 (26.3\%) expressed concerns about the professionalism of entry-level physical therapy students and new graduates. Despite the large number of negative comments, 21 
(15.8\%) participants had positive comments relating to the state of professionalism in the physical therapy profession. Based on the dichotomy of these two themes, it appears that some students and new graduates are struggling and some are demonstrating exceptional professionalism.

The second theme that emerged was that professionalism is a construct that is related to personality traits that are viewed as fixed rather than a skill or behavior that can be learned. This theme seemed to merge with comments that suggested that professionalism is a skill that is learned from the family unit rather than from other members of the profession.

The third theme that was identified related to the importance of mentoring and role modeling. Of the 133 qualitative responses, 14 (10.5\%) participants indicated that professionalism is best learned and fostered through a collegial relationship with a mentor. This finding is consistent with the results from the quantitative portion of the survey. As stated previously, both clinicians and students identified role modeling as their preferred method of learning professionalism.

The previous two themes appear to be somewhat dichotomous. Some respondents believe that professionalism is an innate attribute or learned earlier in life from the family unit, while others believe that mentoring and role-modeling as part of a professional education is important. Like the controversy over nature versus nurture, professionalism is probably multifactorial, consisting of psychological and personality factors as well as learning that takes place both in the home and during formal education. When the innate factors and the early childhood learning fail to promote positive professional behaviors, it becomes the responsibility of professional programs to intervene. 
The last theme that relates specifically to professionalism, focused on the impact of the DPT degree on professionalism. There were individuals who thought that the DPT degree would improve professionalism and there were individuals who thought that the DPT degree would have no impact on professionalism. These statements may have more to do with the fact that the DPT degree raised strong emotions on both sides, rather than a true reflection of the DPT degree on professionalism.

Limitations (Clinician Survey). One limitation of this investigation was that the participants were randomly sampled from members of the American Physical Therapy Association. Thus, the opinions of non-APTA members were not assessed. There is no evidence that suggests a potential difference between members and non-members, but the limitation is worth noting.

The response rate was modest at $37.9 \%$; however, a larger sample size would improve the external validity of the investigation. The sample also failed to significantly capture the opinions of new graduates. There are two possible reasons for this finding. The first is that many new graduates do not join the APTA, due to the cost of dues. The second is that new graduates may have been too focused on issues related to their own career to take the time to complete the survey.

Additionally, the investigation was not robust with qualitative data. Although participants were encouraged to offer any additional insight related to teaching and learning professionalism, only $35.8 \%$ of the participants chose to offer additional comments. These limitations primarily affect the external validity of the investigation rather than internal validity. Future investigations should improve the survey instrument by encouraging more qualitative data 
from the participants. This could be accomplished by having a small qualitative section after each section of the survey instrument, rather than one section at the end of the survey instrument.

Future research (Clinician Survey). Wright and Carrese (2002) found that medical role models who consciously thought about their influence on medical students were better role models. Because role modeling was identified by both students and practicing clinicians as a desirable method of learning professionalism, future investigations related to professionalism in the physical therapy profession should attempt to identify the characteristics of effective role models.

Since most physical therapy programs admit students on a competitive basis, future research should also attempt to identify predictors of those students who will have difficulty learning professional behaviors. Psychological and personality assessments such as emotional intelligence (Salovey and Mayer, 1990), attribution theory (Rotter, 1966), self-identity (Chickering, 1969, 1993; Josselson, 1987; Marcia, 1980), attachment (Bowlby, 1969), moral development (Kohlberg, 1972, 1976), and cognitive staging (Kuhn et al, 1977) may hold some promise in this area. In addition to using these assessments as an admissions tool, this information would be helpful in order to provide targeted assistance to those students who are identified as at risk.

Research should also focus on assessing the impact of curricular changes designed to improve professionalism. As stated previously, no research has been conducted to assess the efficacy of the models proposed by Triezenberg and Davis (2000) and Masin's participant centered problem-solving model (2002). A comparison of traditional curricula to problem based learning (PBL) curricula would also be very enlightening, given than most students favored 
small group discussion as a preferred learning environment. It is also recommended that a follow-up investigation similar to this one be conducted in five or ten years to determine if improvements have been made in the level of professionalism within the profession.

It would also be very helpful to know how the general public and other professional groups such as occupational therapy, speech therapy and physicians who work with physical therapists, perceive the professionalism of the profession. Perhaps, this is the ultimate assessment of the state of professionalism in the physical therapy profession.

\section{Practical Implications}

In order for physical therapy programs and faculty to develop meaningful and effective professionalism instruction, they must understand the strengths and weaknesses of the current instructional efforts. Based on this investigation, it appears that most students are learning and developing positive professional behaviors; however, it is clear that some students are struggling to meet the standards set by the APTA and individual programs. This investigation offers several practical suggestions for teaching and fostering professionalism in the physical therapy profession.

First, the students who participated in this investigation identified active learning methods such as role-playing, small group discussions, and role modeling as their preferred methods of learning professionalism. This investigation supports the position posited by Ringness, who suggested that learning in the affective domain should involve enlightenment and self-actualization rather than indoctrination. The students in this investigation appeared to recognize the benefits of active learning and rated the active learning methods higher than more traditional passive learning methods that are heavily instructor-centered, rather than student- 
centered. Many colleges and universities offer faculty development seminars, which are presented by educational experts trained in contemporary instruction design. Many educators may find these seminars to offer insight and practical examples of how to create a more active learning environment in the classroom.

Second, this investigation found that both students and practicing clinicians do not recognize altruism and cultural competence as critical or core professional skills or behaviors. Altruism and cultural competence were identified by the APTA consensus group as part of the Core Behavior that should be fostered among all practicing physical therapists. It is clear that we as a profession need to do a better job of educating and enlightening both students and practicing clinicians to the benefits of these two very important behaviors.

Third, faculty, clinicians, and clinical supervisors need to set the highest possible example, and do a better job of recognizing and addressing negative behaviors as they occur. This investigation found that students do not recognize a meaningful difference between their own professional behavior and that of their faculty and clinical instructors. It is the responsibility of everyone engaged in the physical therapy profession to serve as both positive role models, but also good stewards of the profession. We need to ensure that students are carrying these professional skills and behaviors forward in clinic practice as new graduates. This investigation revealed that practicing clinicians rated new graduates as having a lower level of professionalism than students. Senior therapists and administrators need to take an active role in helping new graduates maintain the high standards set forth by the academic programs.

Lastly, faculty and clinical instructors need to be aware of the most frequent negative behaviors. This investigation found that tardiness, verbal disrespect, nonverbal disrespect, and 
lack of person responsibility were the four most frequent negative behaviors. With this knowledge, faculty and clinical instructors need to identify ways of monitoring and correcting these negative behaviors. It is possible that many students simply do not recognize how they are being viewed, or they do not understand the implications these negative behaviors have on their relationship with faculty, clinicians, patients, and other healthcare professionals.

\section{Conclusion}

Cullen (1978) identified the following dimensions of professionalism: complex occupational task, the ability to be self-employed, altruistic service, a lengthy educational program or training, a professional organization, a code of ethics, competence testing via licensure examination or certification, and being viewed by society as a prestigious occupation. Physical therapy as a profession has worked hard to achieve these criteria and has been successful in meeting each of these dimensions; however, the area of greatest concern is to be viewed by society as a prestigious profession that provides altruistic service. Professionalism is not just something that should be strived for, it is something that must be achieved and maintained if the physical therapy profession has any hopes to continue to grow as it has over the last 70 years.

The American Physical Therapy Association, the Commission on Accreditation in Physical Therapy Education, physical therapy programs, and physical therapists are justified in being concerned about the state of professionalism in the physical therapy profession. Based on the results of this investigation, there is a trend of decreasing professionalism among entry-level physical therapy students and new graduates. The cause of this trend is not known, but there appears to be concerns by both students and practicing physical therapists. This study found that 
new graduates demonstrate less professional behavior than physical therapy students do, suggesting that students are not retaining and implementing the skills learned while in PT school. Despite these concerns, this investigation found that most students are demonstrating professional behaviors; however, some students are failing to achieve a level of professionalism that is consistent with the values and expectations of the physical therapy profession. Role modeling was identified by both students and practicing clinicians as the best way of learning and fostering professionalism. Future investigations should attempt to identify the reasons for this perceived decline in professionalism and to try to identify ways of improving professional behaviors of both students and practicing physical therapists. 


\section{References}

American Board of Internal Medicine. (2001). Project Professionalism. Retrieved June 12, 2005, from http://www.abim.org/pdf/profess.pdf

American Physical Therapy Association. (2004). A normative model of physical therapist professional education, Alexandria: American Physical Therapy Association.

American Physical Therapy Association. (2004). Physical therapist member demographic profile. Retrieved September 15, 2005, from http://www.apta.org/AM/Template.cfm ?Section=Surveys_and_Stats1\&Template=/MembersOnly.cfm \&ContentID=25286

American Physical Therapy Association (2005). Vision statement for physical therapy 2020. Retrieved June 18, 2005, from http:/www.apta.org/AM/Template.cfm? Section=Home $\&$ TEMPLATE $=/$ CM/ContentDisplay.cfm \&CONTENTID $=16884$

American Physical Therapy Association (2005). Physical Therapy Education Fact Sheet. Retrieved September 30, 2005, from http://www.apta.org/AM/Template.cfm Section=PT_Programs1\&TEMPLATE=/CM/ContentDisplay.cfm\&CONTENTID=23836

Anderson, E. (1995). Why some patients sue: Learning from a plaintiff's lawyer. Physician's Management, 35, 6-12. 
Atkinson, R., \& Shiffrin, R. (1968). Human memory: A proposed system and its control processes. In K.Spence \& J. Spence (Eds.), The psychology of learning and motivation: Advances in research and theory (pp. 90-195). New York, NY: Academic Press.

Babbie, E. (1990). Survey research method ( $2^{\text {nd }}$ ed.). Belmont: Wadsworth Publishing.

Baddeley, A. (1998). Human memory (2nd ed.). Boston: Allyn and Bacon.

Bandura, A., \& Walters, R. (1963). Social learning and personality development. New York: Holt, Rinehart, and Winston, Inc.

Ber, R., \& Alroy, G. (2002). Teaching professionalism with the aid of trigger films. Medical Teacher, 24, 528-531.

Blank, B., Kimball, H., McDonald, W., \& Merino, J. (2003). Medical professionalism in the new millennium: A physician charter 15 months later. Annals of Internal Medicine, 138, 839841.

Bloom, B.S. (1956). Taxonomy of educational objectives: The classification of educational goals. Handbook II: Affective Domain. New York: D. McKay Co. 
Borden, S. (1998). Avoiding the pitfalls of case studies. Journal of Mass Media Ethics, 13, 5-13.

Bowlby, J. (1969). Attachment and loss. London: Hogarth.

Braithwaite, W. (1990). Hearts and minds. American Bar Association Journal, 9, 70-73.

Cha, A., Hecht, B.A., Nelson, K., \& Hopkins, M.P., (2004). Resident physician attire: Does it make a difference to our patients? American Journal of Obstetrics and Gynecology, 190, 1484-1488.

Chauvin, S. (2002). Professionalism: A shared responsibility for a rich and enduring tapestry. Medical Education, 36, 410-411.

Chickering, A. (1969/1978). Education and identity. San Francisco: Jossey-Bass.

Chickering, A., (2000). Creating community within individual courses. New Directions for Higher Education, 109, 23-32.

Chickering, A., \& Gamson, Z. (1999). Development and adaptation of the seven principles for good practice in undergraduate education. New Directions for Teaching and Learning, $80,75-81$. 
Chickering, A., \& Reisser, L. (1993). Education and identity. San Francisco: Jossey-Bass Publishers.

Cullen, J. (1978). The structure of professionalism. New York: Petrocelli Books.

Davies, M., Stankov, L., \& Roberts, R. (1998). Emotional intelligence: In search of an elusive construct. Journal of Personality and Social Psychology, 75, 989-1015.

DeHart, G., Sroufe, L., \& Cooper, R. (2003). The nature of development. In Child development: Its nature and course (pp. 1-33). Boston: McGraw Hill.

Dempster, F. (1981). Memory span: Sources of individual and developmental differences. Psychological Bulletin, 89, 63-100.

Diefendorf, A. (2003). Professionalism and conflicts of interest. ASHA Leader, 8, 25.

Erikson, E. (1963). Childhood and society (2 ed.). New York: W.W. Norton \& Company, Inc.

Evans, N.J., Forney, D.S., \& Guido-DiBrito, F. (1998). Student development in college. San Francisco: Jossey-Bass. 
Fetzer, S. (2003). Professionalism of associate degree nurses: The role of self-actualization. Nursing Education Perspectives, 24, 139-143.

Fontaine, S. \& Wilkinson, T. (2003). Monitoring medical students' professional attributes: Development of an instrument and process. Advances in Health Science Education, 8, $127-137$.

Freud, S. (1960). The ego and the id, translated by James Strachey. New York: Norton (Original work published 1923)

Friedman-Ben-David, M., Davis, M., Harden, R., Howie, P., Ker, J., \& Pippard, M. (2001). AMEE medical education guide No 24: Portfolios as a method of student assessment. Medical Teacher, 23, 535-551.

Furnham, A., \& Steele, H. (1993). Measuring locus of control: A critique of general, child, health, and work-related locus of control questionnaires. British Psychological Society, $84,443-479$.

Gandy, J., \& Jensen, G. (1992). Group work and reflective practicums in physical therapy education: Models for professional behavior development. Journal of Physical Therapy Education, 6, 6-10. 
Gay, L.R., \& Airasian, P. (2000). Educational Research: Competencies for Analysis and Application. Upper Saddle River: Merrill Prentice Hall.

Gilligan, C. (1977). In a different voice: Women's conceptions of self and morality. Harvard Educational Review, 47, 481-517.

Gilligan, C. (1981). Moral development in college years. In A. W. Chickering \& Associates, The modern American college: Responding to the new realities of diverse students and a changing society. San Francisco: Jossey-Bass.

Goleman, D. (1995). Emotional Intelligence. New York: Bantam Books.

Gordon, J. (2003). Assessing students' personal and professional development using portfolios and interviews. Medical Education, 37, 335-340.

Happerty, F. (2002). What medical students know about professionalism. The Mount Sinai Journal of Medicine, 69, 385-397. 
Hemmer, P., Hawkins, R., Jackson, J., \& Pangaro, L. (2000). Assessing how well three evaluation methods detect deficiencies in medical student's professionalism in two settings of an internal medicine clerkship. Academic Medicine, 75, 167-173.

Jette, D., \& Portney, L. (2003). Construct validation of a model for professional behavior in physical therapist students. Physical Therapy, 83, 432-443.

Josselson, R. (1987). Finding herself: Pathways to identity development in women. San Francisco: Jossey-Bass Publishers

Kohlberg, L. (1972). A cognitive-development approach to moral education. Humanist, 6, 1316.

Kohlberg, L. (1976). Moral stages and moralization: The cognitive-developmental approach. In T. Lickona (Ed.), Moral development and behavior: Theory, research, and social issues. New York: Hold, Rinehart \& Winston.

Kuhn, D., Langer, J., Kohlberg, L., \& Haan, H. (1977). The development of formal operations in logical and moral judgement. Genetic Psychology Monographs, 95, 97-188. 
Larkin, G. (2003). Mapping, modeling, and mentoring: Charting a course for professionalism in graduate medical education. Cambridge Quarterly of Healthcare Ethics, 12, 167-177.

Lima-Basto, M. (1995). Implementing change in nurses' professional behaviors: limitations of the cognitive approach. Journal of Advanced Nursing, 22, 480-489.

Ludmerer, K. (1999). Instilling professionalism in medical education. Journal of the American Medical Association, 282, 881-882.

MacDonald, C., Cox, P., Bartlett, D., \& Houghton, P. (2002). Consensus on methods to foster physical therapy. Journal of Physical Therapy Education, 16, 27-35.

Marcia, J. (1980). Identity in adolescence. In J.Alelson (Ed.), Handbook of adolescent psychology (pp. 159-187). New York: Wiley.

Masin, H. (2002). Education in the affective domain: A method/model for teaching professional behaviors in the classroom and during advisory sessions. Journal of Physical Therapy Education, 16, 37-45. 
May, W., Morgan, B., Lemke, J., Karst, G., \& Stone, H. (1995). Model for ability-based assessment in physical therapy education. Journal of Physical Therapy Education, 9, 3-6.

May, W., Straker, G., \& Foord-May, L. (2001). Opportunity favors the prepared: A guide to facilitating the development of professional behaviors. Stoneham: May \& Associates.

McAlister, A., Vartiainen, E., \& Lehtovuori, R. (2000). Role playing in smoking prevention: Use caution. Journal of School Health, 70, 3-4.

McGregor, J. (1993). The effectiveness of role playing and antiracist teaching in reducing student prejudice. Journal of Educational Research, 86, 216-226.

Miettinen, O. \& Fiegel, K. (2003). Professionalism in medicine. Journal of Evaluation in Clinical Practice, 9, 356.

Miller, C., Fitch, T., \& Marshall, J. (2003). Locus of control and at-risk youth: A comparison of regular education high school students and students in alternative education. Education, $123,548-552$.

Morehead, M. (1998). Professional behaviors for the beginning teacher. American Secondary Education, 26, 22-26. 
Mostrom, E. (2004). Professionalism in physical therapy: A reflection on ways of being in physical therapy education. Journal Physical Therapy Education, 18, 2-3.

Nowicki, S. \& Duke, M. (1974). A locus of control scale for college as well as non-college adults. Journal of Personality Assessment, 38, 136-137.

Patton, M. Q. (1990). Qualitative Evaluation and Research Methods. (2 ${ }^{\text {nd }}$ ed.). Newbury Park: Sage Publications, Inc.

Piaget, J. (1965). The moral judgment of the child. New York: Free Press.

Piaget, J. (1972a). Intellectual evolution from adolescence to adulthood. Human Development, $15,1-12$.

Piaget, J. (1972b). The child's conception of the world. Translated by Joan and Andrew Tomlinson. Totowa: Littlefield Adams.

Plumert, J. (1994). Flexibility in children's use of spatial and categorical organizational strategies in recall. Developmental Psychology, 30, 738-747. 
Ringness, T.A. (1975). The affective domain in education. Boston: Little, Brown and Company.

Rotter, J. (1954). Social learning and clinical psychology. Englewood Cliffs: Prentice Hall.

Rotter, J. (1966). Internal-external control of reinforcement. Psychological Monographs, 80, 128.

Salovey, P. \& Mayer, J. (1990). Emotional intelligence. Imagination, Cognition, and Personality, 9, 185-211.

Schlossberg, N.K. (1981). A model for analyzing human adaptation to transition. Counseling Psychologist, 9, 2-18.

Schlossberg, N.K. (1984). Counseling adults in transition. New York: Springer.

Skinner, B. F. (1953). Science and human behavior. New York: Macmillan.

Smith, J.A. \& Osborn M. (2003). Interpretive phenomenological analysis. In J.A. Smith (Eds.), Qualitative psychology: A practical guide to research methods. Thousand Oaks: Sage Publications Inc. 
Sox, H.C. (2002). Medical professionalism in the new millennium: A physician's charter. Annals of Internal Medicine, 136, 243-246.

Spielberger, C.D., Gonzalez, H.P., and T. Fletcher. (1979). Cognitive and Affective Learning Strategies. In H.F. O’Neil \& C.D. Spielberger (Eds.), New York: Academic Press.

Triezenberg, H. \& Davis, C. (2000). Beyond the code of ethics: Educating physical therapists for their role as moral agents. Journal of Physical Therapy Education, 14, 48-57.

U.S. Census Regions and Divisions (2004). Retrieved July 1, 2004, from http://www.eia. doe.gov/emeu/reps/maps/us_census.html

Vygotsky, L. S. (1978). Mind and society. Cambridge: Harvard University Press.

Walker, L.J. (1988). The development of moral reasoning. Annals of Child Development, 5, 3378.

Wear, D. \& LaCivita-Nixon, L. (2002). Literary inquiry and professional development in medicine. Perspectives in Biology and Medicine, 45, 104-124. 
Wilkinson, T., Swick, H., Szenas, P., Danoff, D., \& Whitcomb, M. (1999). Teaching professionalism in undergraduate medical education. Journal of the American Medial Association, 282, 830-832.

Wilson, R., Gaff, J., Dienst, E., Wood, L., \& Bavry, J. (1975). College professors and their impact on students. New York: John Wiley \& Sons.

Wright, S. \& Carrese, J. (2002). Excellence in role modeling: insight and perspectives from the pros. Canadian Medical Association Journal, 167, 638-644. 


\section{Appendix A}

\section{Survey of Professionalism in Physical Therapy Entry-level Students}

Directions: Please circle or place a check mark next to the response that best matches your beliefs and experiences regarding the state of professionalism among the physical therapy profession and entry-level physical therapy education.

Section A

1. Teaching and fostering professional behaviors is an important part of a physical therapy education.

Strongly Disagree $\quad \square$ Disagree $\quad \square$ Neutral $\quad \square$ Agree $\quad \square$ Strongly Agree

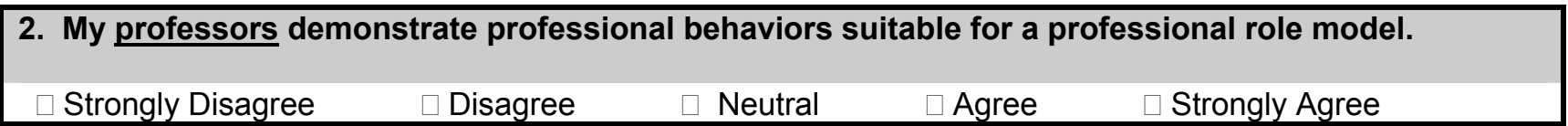

3. My clinical instructors demonstrate professional behaviors suitable for a professional role model.
Strongly Disagree
Disagree
Neutral
Agree
Strongly Agree

Unable to answer (no clinical experience to date)

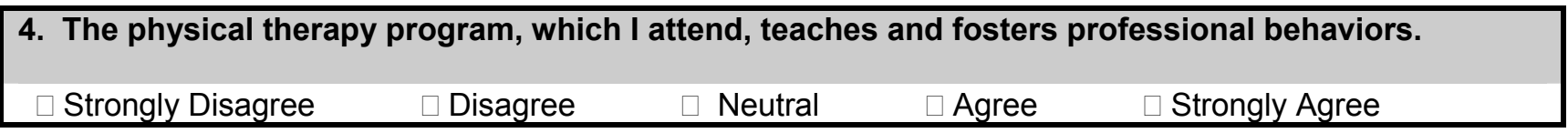

5. Professionalism is a construct (concept) that can be learned.

Strongly Disagree $\quad \square$ Disagree $\quad \square$ Neutral $\quad \square$ Agree $\quad \square$ Strongly Agree

6. Professionalism is a construct (concept) that can be taught.

Strongly Disagree $\quad \square$ Disagree $\quad \square$ Neutral $\quad \square$ Agree $\quad \square$ Strongly Agree

7. The physical therapy program, which I attend, offers a course or unit specifically designed to teach and/or promote professionalism.
No
$\square$ I am unsure
Yes

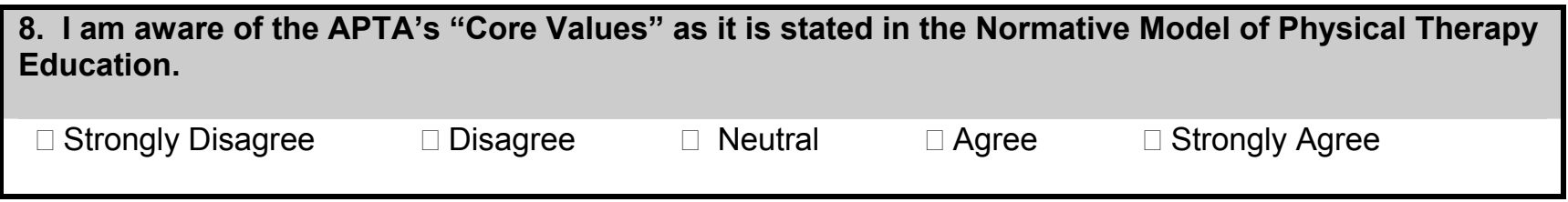




\section{Section B}

9. How would your rate your degree of professionalism compared to your professors?
Much less
$\square$ less
$\square$ Same
More
Much More

10. How would your rate your degree of professionalism compared to your clinical instructors?
Much less
$\square$ less
Same
$\square$ More
Much More

$\square$ Unable to answer (no clinical experience to date)

\section{How would your rate your degree of professionalism compared to your classmates?}

Much less

less

Same

More

Much More

12. Based on your own personal experiences, rate the degree of professional behavior of each of these groups on a scale of 1-10 (10 being the highest degree of professionalism). Choose UO (unobserved) if you have been unable to observe a particular professional group.

\begin{tabular}{|c|c|c|c|c|c|c|c|c|c|c|c|}
\hline Yourself & 1 & 2 & 3 & 4 & 5 & 6 & 7 & 8 & 9 & 10 & \\
\hline Classmates & 1 & 2 & 3 & 4 & 5 & 6 & 7 & 8 & 9 & 10 & UO \\
\hline PT Clinical Instructors & 1 & 2 & 3 & 4 & 5 & 6 & 7 & 8 & 9 & 10 & UO \\
\hline Physical Therapy Faculty & 1 & 2 & 3 & 4 & 5 & 6 & 7 & 8 & 9 & 10 & UO \\
\hline Medical Doctors & 1 & 2 & 3 & 4 & 5 & 6 & 7 & 8 & 9 & 10 & UO \\
\hline Occupational Therapists & 1 & 2 & 3 & 4 & 5 & 6 & 7 & 8 & 9 & 10 & UO \\
\hline Speech Therapists & 1 & 2 & 3 & 4 & 5 & 6 & 7 & 8 & 9 & 10 & UO \\
\hline Clergy/Priest/Preacher/Rabbi & 1 & 2 & 3 & 4 & 5 & 6 & 7 & 8 & 9 & 10 & UO \\
\hline
\end{tabular}

\section{Section C}

\begin{tabular}{|c|c|c|c|c|c|}
\hline \multicolumn{6}{|c|}{ 13. How often do you see these negative behaviors demonstrated by your classmates? } \\
\hline Tardiness & $\square$ Never & $\square$ Infrequently & $\square$ Occasionally & $\square$ Often & $\square$ Very Often \\
\hline Verbal disrespect of others & $\square$ Never & $\square$ Infrequently & $\square$ Occasionally & $\square$ Often & $\square$ Very Often \\
\hline Nonverbal disrespect of others & $\square$ Never & $\square$ Infrequently & $\square$ Occasionally & $\square$ Often & $\square$ Very Often \\
\hline Excessive absences & $\square$ Never & $\square$ Infrequently & $\square$ Occasionally & $\square$ Often & $\square \mathrm{V} \epsilon$ \\
\hline Failure to meet deadline & $\square$ Never & $\square \ln$ & $\square($ & $n$ & en \\
\hline Missed appointments & $\square$ Never & $\square$ Infrequently & $\square$ Occasionally & $\square$ Often & $\square$ Very Often \\
\hline Violation of dress code & $\square$ Never & $\square$ Infrequently & $\square$ Occasionally & $\square$ Often & $\square$ Very Often \\
\hline Social intolerance & $\square$ Never & $\square$ Infrequently & $\square$ Occasionally & $\square$ Often & $\square$ Very Often \\
\hline Violation of confidentiality & $\square$ Never & $\square$ Infrequently & $\square$ Occasionally & $\square$ Often & $\square$ Very Often \\
\hline Lacks personal responsibility & $\square$ Never & $\square$ Infrequently & $\square$ Occasionally & $\square$ Often & $\square$ Very Often \\
\hline
\end{tabular}




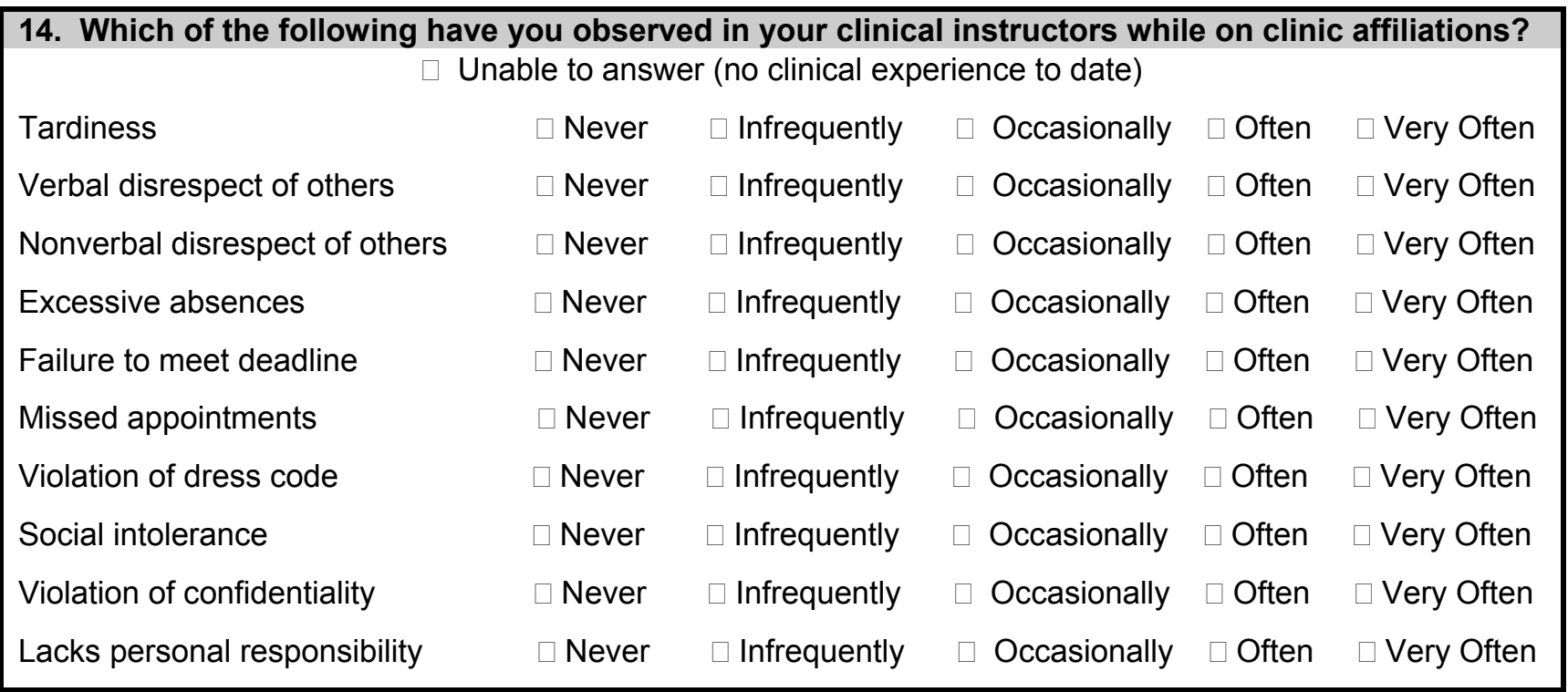

\section{Section D}

\begin{tabular}{|c|c|c|}
\hline $\begin{array}{l}\text { 15. From the list of prof } \\
\text { items for a practicing ph }\end{array}$ & $\begin{array}{l}\text { nal skills or behavio } \\
\text { I therapist. }\end{array}$ & below, circle the Seven (7) $\underline{m}$ \\
\hline Oral communication skills & Altruism & Excellence \\
\hline Cultural competence & Honesty & Empathy \\
\hline Responsibility & Information literacy & Integrity \\
\hline Clinical reasoning & Advocacy & Written communication skills \\
\hline Accountability & Social responsibility & Compassion/Caring \\
\hline
\end{tabular}

\section{Section E}

16. Which of the following teaching methods is used in your program to teach or foster professionalism? Check all that apply.
Portfolios
$\square$ Reading assignments
Role playing
Small group discussions
Lectures
$\checkmark$ Case studies
$\square$ Generic abilities self-assessment
Formal meetings with faculty advisor Journals
$\square$ Literature/Metaphors

Watching an experienced clinician (role modeling)

Other(s): Specify:

17. Which of the following teaching methods are the most appealing to you as a means of learning professionalism? Check all that apply.
Portfolios
$\square$ Reading assignments
Case studies
Role playing
Small group discussions
Lectures
with faculty advisor
Generic abilities self-assessment
Journals
$\square$ Literature/Metaphors

Watching an experienced clinician (role modeling)

Other(s): Specify: 


\section{Section F}

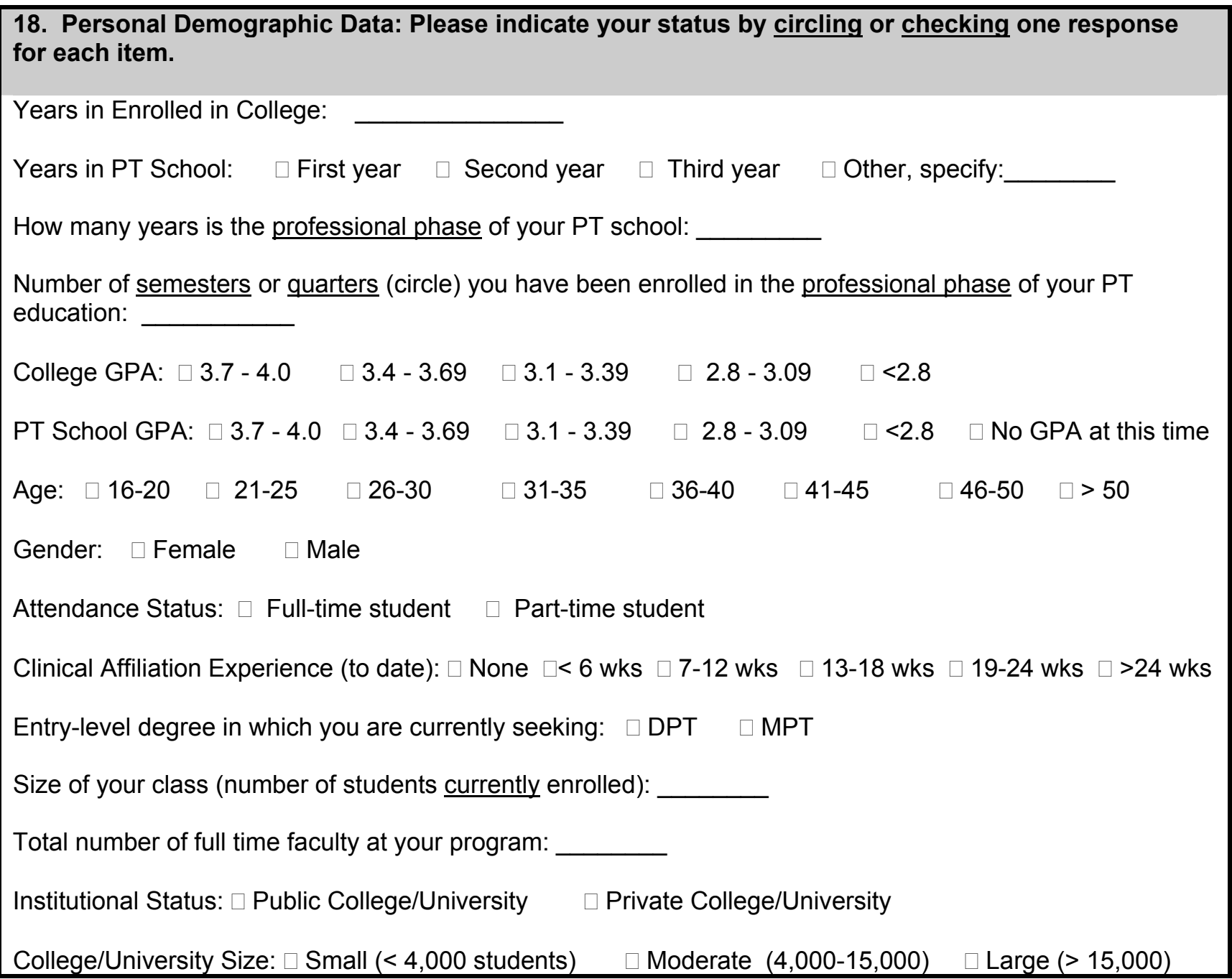

Section G

19. Additional Comments: Please offer any additional information regarding your experiences with learning or observing professionalism while in physical therapy school.

Comments: 
Appendix B

Results of Random Sample (2005)

\begin{tabular}{|c|c|c|c|c|c|c|c|c|c|c|}
\hline College or University & \begin{tabular}{|c|} 
US \\
Region \\
\end{tabular} & Degree & $\begin{array}{c}\text { Program } \\
\text { Type }\end{array}$ & \begin{tabular}{|c|}
$\begin{array}{c}\text { Institution } \\
\text { Type }\end{array}$ \\
\end{tabular} & $\begin{array}{c}\text { Class } \\
\text { Size }\end{array}$ & $\begin{array}{l}\text { Number } \\
\text { Faculty }\end{array}$ & $\begin{array}{c}\text { PhD } \\
\text { Program } \\
\end{array}$ & Semesters & $\begin{array}{c}\text { Carnegie } \\
\text { Classification } \\
\end{array}$ & $\begin{array}{c}\text { Faculty/Student } \\
\text { Ratio }\end{array}$ \\
\hline Univ Indianapolis & MW & DPT & $4+3$ & Private & 45 & 7 & Yes & 9 & Masters I & $1: 9$ \\
\hline St. Francis U & $\mathrm{NE}$ & DPT & $3+3$ & Private & 70 & 8 & No & 9 & Masters I & $1: 9$ \\
\hline \begin{tabular}{|l|} 
Univ Texas HSC (San \\
Antonio)
\end{tabular} & $\mathrm{S}$ & MPT & $3+3$ & Public & 40 & 7 & No & 6 & Spec-Med & $1: 16$ \\
\hline Sacred Heart & $\mathrm{NE}$ & DPT & $3+3$ & Private & 45 & 10 & No & 9 & Masters I & $1: 5$ \\
\hline Southwest Baptist U & MW & DPT & $4+3$ & Private & 40 & 6 & No & 8 & Masters II & $1: 8$ \\
\hline U of Utah & W & DPT & $4+3$ & Public & 40 & 10 & No & 9 & Extensive & $1: 11$ \\
\hline Drexel U & $\mathrm{NE}$ & DPT & $4+3$ & Private & 26 & 10 & Yes & 8 & Intensive & $1: 8$ \\
\hline Hardin-Simmons U & $S$ & DPT & $4+2.5$ & Private & 24 & 8 & No & 7 & Masters I & $1: 7$ \\
\hline U of Central Florida & $S$ & MPT & $4+2$ & Public & 28 & 5 & No & 7 & Intensive & $1: 7.8$ \\
\hline $\begin{array}{l}\text { U of Wash Med } \\
\text { Center }\end{array}$ & $\mathrm{NE}$ & DPT & $4+3$ & Public & 30 & 6 & No & 8 & Extensive & $1: 6$ \\
\hline Hampton U & $\mathrm{s}$ & DPT & $4+3$ & Private & 26 & 6 & No & 8 & Masters I & $1: 6$ \\
\hline U of Puget Sound & $\mathrm{NE}$ & DPT & $4+3$ & Private & 30 & 6 & No & 9 & Baccalaureate & $1: 9.5$ \\
\hline Ohio State U & MW & MPT & $4+2.5$ & Public & 40 & 8 & No & 8 & Extensive & $1: 6$ \\
\hline Wayne State U & MW & DPT & $2+3$ & Public & 28 & 5 & No & 9 & Extensive & $1: 11.8$ \\
\hline
\end{tabular}


Appendix C

Comparison of Sample Characteristics to Population Data (2005)

\begin{tabular}{|c|c|c|}
\hline Classification & Sample & 2005 APTA Fact Sheet \\
\hline Geographic Region & $30 \%$ South & $32.5 \%$ South \\
& $20 \%$ Midwest & $25.8 \%$ Midwest \\
& $40 \%$ Northeast & 28.2, Northeast \\
& $10 \%$ West & $13.5 \%$ West \\
\hline Degree Type & $35 \%$ MPT, 65\% DPT & $35.5 \%$ MPT, 64.5\% DPT \\
\hline Program Type & $45 \%$ were $4+3$ & $31.2 \%$ were $4+3$ \\
\hline Institution Type & $50 \%$ Public & $52.3 \%$ Public \\
& $50 \%$ Private & 47.7 Private \\
\hline Average Class Size & $37.8 /$ class & 32 \\
\hline Average Number of Faculty & 7.6 & 9.0 \\
\hline Carnegie Classification & $35 \%$ Master 1 & $34.1 \%$ Master I \\
& $10 \%$ Master II & $2.9 \%$ Master II \\
& $10 \%$ Special & $17.8 \%$ Special \\
& $20 \%$ Intensive & $16.3 \%$ Intensive \\
& $20 \%$ Extensive & $23.1 \%$ Extensive \\
\hline Faculty Student Ratio & $5 \%$ Baccalaureate & $5.8 \%$ Baccalaureate \\
\hline
\end{tabular}




\section{Appendix D \\ Cover Letter Chairperson}

September 30, 2005

Dear Dr.

As I am sure you aware, professionalism has become a topic of great interest in many professions including medicine, law, and physical therapy. In an effort to identify ways of improving professional behaviors among entry-level physical therapy students and as partial fulfillment of my doctoral dissertation at West Virginia University, I am asking you to help me distribute the enclosed survey packets to all of your students currently enrolled in the professional phase of the physical therapy program.

This investigation is part of a larger study that is intended to examine the current state of professionalism in the physical therapy profession. The enclosed survey will focus on the attitudes, beliefs, and experiences of physical therapy students relative to developing the values and skills that constitute professionalism.

To thank you for your assistance in distributing the enclosed surveys to your student, your program has been automatically entered in a drawing for a \$100.00 APTA gift certificate that can be used for books, continuing education, or other APTA products.

Thank you in advance for your participation and willingness to advance the physical therapy profession.

Sincerely,

D. Scott Davis MS, PT, OCS

Assistant Professor

(Doctoral Candidate)

8312 HSS PO Box 9226

Division of Physical Therapy

West Virginia University

Morgantown, WVU 26505 


\section{Appendix E \\ Cover Letter to Student Participants}

September 30, 2005

Dear Physical Therapy Student,

Professionalism has become a topic of great interest in many professions including medicine, nursing, law, speech pathology, and physical therapy. As such, I am asking you to participate in a research project that is being conducted to advance the profession of physical therapy and will serve as partial fulfillment of my doctoral dissertation. This survey is part of a larger study that is intended to examine the current state of professionalism in physical therapy. The enclosed survey will attempt to assess your attitudes and beliefs relative to your development of professional behaviors.

Your participation in this survey is voluntary and you may refuse to answer any question. Your responses will be kept confidential and every attempt has been made to ensure anonymity of your response. In no way will your participation or lack of participation affect your grade or class standing. Each survey has been coded by geographical region (Northeast, Midwest, South, West). You will not be asked to identify yourself in anyway. Please place the completed survey in the self-addressed stamped envelope and place it in the mail.

To thank you for your participation, you may enter your name in a drawing for a $\$ 100.00$ APTA gift certificate that can be used for dues, books, continuing education, etc. To enter your name in the drawing, please fill out the enclosed entry form and mail it back separately from your completed survey.

I thank you in advance for your participation and willingness to advance the physical therapy profession.

Sincerely,

D. Scott Davis MS, PT, OCS

Assistant Professor

8312 HSS PO Box 9226

Division of Physical Therapy

West Virginia University 


\section{Appendix F \\ Entry-Form for Drawing}

To enter your name in the drawing for a $\$ 100.00$ APTA gift certificate, fill in the following information and place in the U.S. Mail.

First Name:

Middle Initial:

Last Name:

Street Address:

City:

State:

ZIP Code:

Did you complete and mail your survey? $\square$ Yes $\quad \square$ No

The winner of the random drawing will be notified by mail on or before January 30 , 2006. 
Appendix G

(US Census Bureau Map)

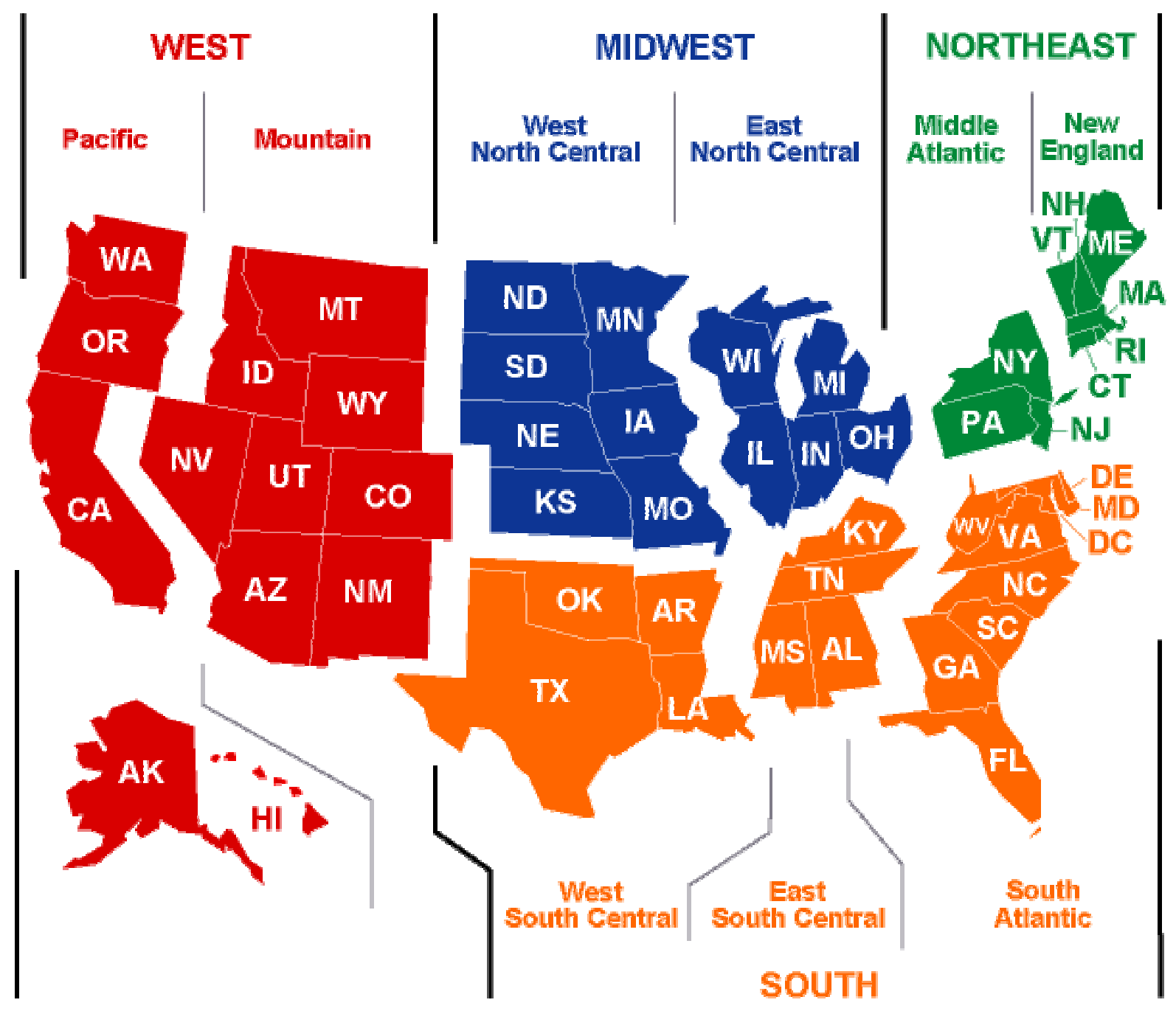




\section{Appendix H \\ Survey of Professionalism in Physical Therapy \\ Practicing Clinician}

Directions: Please circle or place a check mark next to the response that best matches your current beliefs, attitudes, and experiences regarding the state of professionalism among entry-level physical therapy students, new graduates, and practicing physical therapists.

\section{Section A}

1. Teaching and fostering professional behaviors is an important part of a physical therapy education.

Strongly Disagree $\quad \square$ Disagree $\quad \square$ Neutral $\quad \square$ Agree $\quad \square$ Strongly Agree

2. The physical therapy students that I have worked with or observed in the last two years have demonstrated professional behavior.

$\square$ Strongly Disagree $\quad \square$ Disagree $\quad \square$ Neutral $\quad \square$ Agree $\quad \square$ Strongly Agree

3. The new graduates (less than 1 year of clinical experience) that I have worked with in the last two years have demonstrated professional behaviors.

Strongly Disagree $\quad \square$ Disagree $\quad \square$ Neutral $\quad \square$ Agree $\quad \square$ Strongly Agree

4. The practicing physical therapy clinicians (greater than 1-year clinical experience) that I have worked with in the last two years have demonstrated professional behaviors.

Strongly Disagree $\quad \square$ Disagree $\quad \square$ Neutral $\quad \square$ Agree $\quad \square$ Strongly Agree

5. Professionalism is a construct (concept) that can be learned.

Strongly Disagree $\quad \square$ Disagree $\quad \square$ Neutral $\quad \square$ Agree $\quad \square$ Strongly Agree

6. Professionalism is a construct (concept) that can be taught.

$\square$ Strongly Disagree $\quad \square$ Disagree $\quad \square$ Neutral $\quad \square$ Agree $\quad \square$ Strongly Agree

7. The physical therapy program, which I attended, offered a course or unit specifically designed to teach and/or promote professionalism.
No
$\square$ I am unsure
$\square$ Yes

8. A student's age at the time of admission to an entry-level physical therapy program is a predictor of professional behavior during the physical therapy program.
Strongly Disagree
Disagree
Neutral
Agree
Strongly Agree 


\section{Section B}

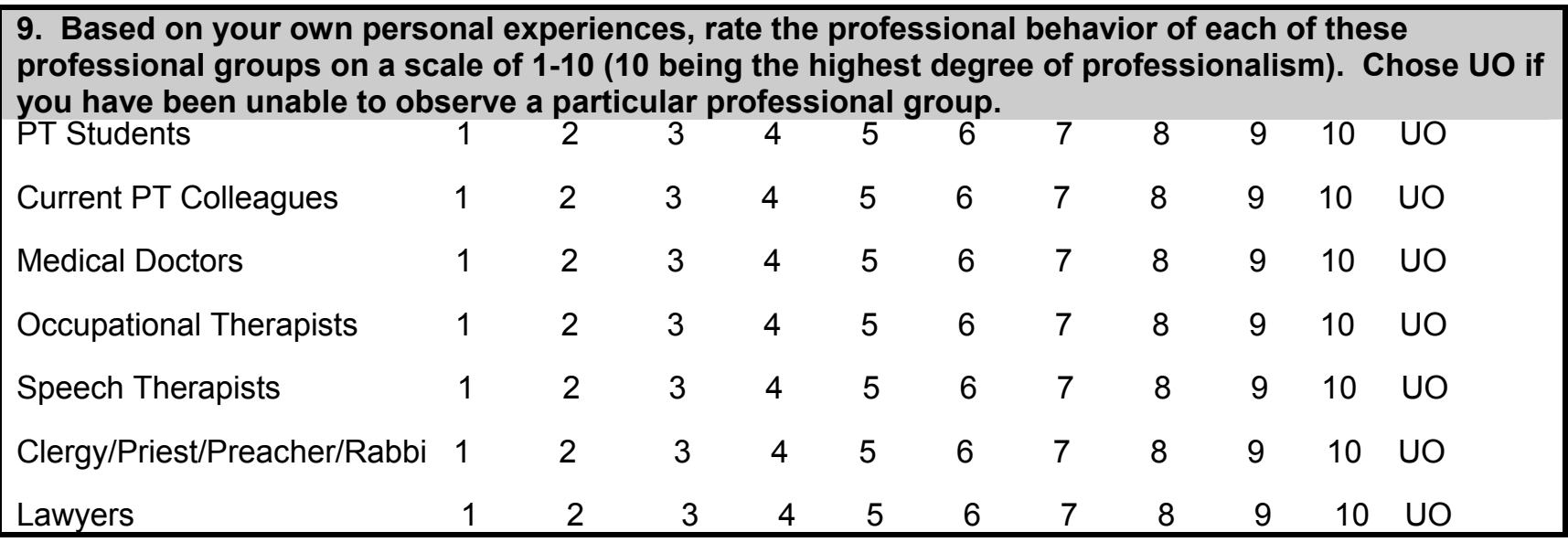

\begin{tabular}{|lllll|}
\hline 10. How often do you observe these negative behaviors demonstrated by PT students who are on \\
clinical affiliations? \\
Tardiness & $\square$ Never & $\square$ Infrequently & $\square$ Occasionally $\quad \square$ Often $\quad \square$ Very Often \\
Verbal disrespect of others & $\square$ Never & $\square$ Infrequently & $\square$ Occasionally $\quad \square$ Often $\quad \square$ Very Often \\
Nonverbal disrespect of others & $\square$ Never & $\square$ Infrequently & $\square$ Occasionally $\quad \square$ Often $\quad \square$ Very Often \\
Excessive absences & $\square$ Never & $\square$ Infrequently & $\square$ Occasionally $\quad \square$ Often $\quad \square$ Very Often \\
Failure to meet deadline & $\square$ Never & $\square$ Infrequently & $\square$ Occasionally $\quad \square$ Often $\quad \square$ Very Often \\
Missed appointments & $\square$ Never & $\square$ Infrequently & $\square$ Occasionally $\quad \square$ Often $\quad \square$ Very Often \\
Violation of dress code & $\square$ Never & $\square$ Infrequently & $\square$ Occasionally $\quad \square$ Often $\quad \square$ Very Often \\
Social intolerance & $\square$ Never & $\square$ Infrequently & $\square$ Occasionally $\quad \square$ Often $\quad \square$ Very Often \\
Violation of confidentiality & $\square$ Never & $\square$ Infrequently & $\square$ Occasionally $\quad \square$ Often $\quad \square$ Very Often \\
Lacks personal responsibility & $\square$ Never & $\square$ Infrequently & $\square$ Occasionally $\quad \square$ Often $\quad \square$ Very Often \\
\hline
\end{tabular}

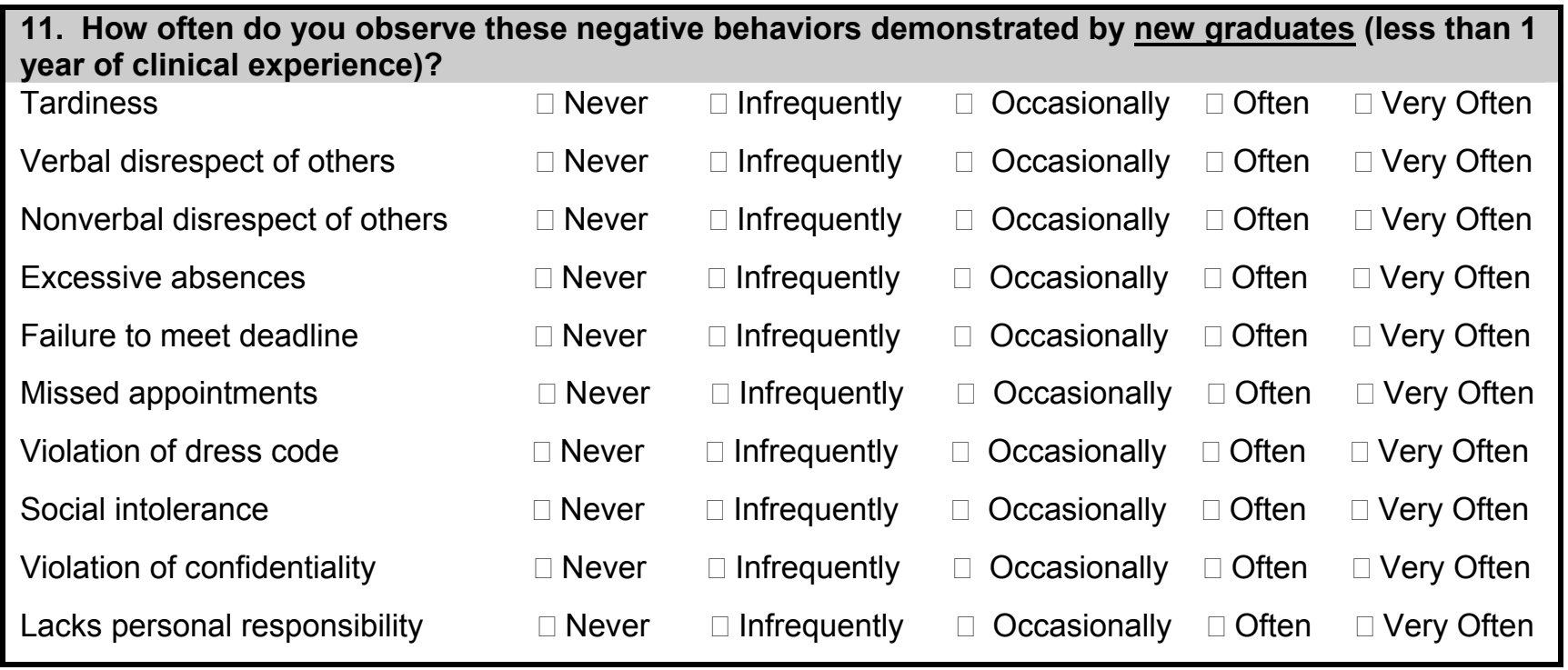




\begin{tabular}{|lllll|}
\hline $\begin{array}{l}\text { 12. How often do you observe these negative behaviors demonstrated by practicing physical } \\
\text { therapists in your facility? }\end{array}$ ? Never $\quad \square$ Infrequently $\quad \square$ Occasionally $\quad \square$ Often $\quad \square$ Very Often \\
\hline Tardiness & $\square$ Never & $\square$ Infrequently & $\square$ Occasionally $\quad \square$ Often $\quad \square$ Very Often \\
Verbal disrespect of others & $\square$ Never & $\square$ Infrequently & $\square$ Occasionally $\quad \square$ Often $\quad \square$ Very Often \\
Excessive absences & $\square$ Never & $\square$ Infrequently & $\square$ Occasionally $\quad \square$ Often $\quad \square$ Very Often \\
Failure to meet deadline & $\square$ Never & $\square$ Infrequently & $\square$ Occasionally $\quad \square$ Often $\quad \square$ Very Often \\
Missed appointments & $\square$ Never & $\square$ Infrequently & $\square$ Occasionally $\quad \square$ Often $\quad \square$ Very Often \\
Violation of dress code & $\square$ Never & $\square$ Infrequently & $\square$ Occasionally $\quad \square$ Often $\quad \square$ Very Often \\
Social intolerance & $\square$ Never & $\square$ Infrequently & $\square$ Occasionally $\quad \square$ Often $\quad \square$ Very Often \\
Violation of confidentiality & $\square$ Never & $\square$ Infrequently & $\square$ Occasionally $\quad \square$ Often $\quad \square$ Very Often \\
Lacks personal responsibility & $\square$ Never & $\square$ Infrequently & $\square$ Occasionally $\quad \square$ Often $\quad \square$ Very Often \\
\hline
\end{tabular}

Section C

13. From the list of professional skills or behaviors listed below, circle the Seven (7) most important behaviors or skill for a practicing physical therapist.

\begin{tabular}{lll}
\hline Oral communication skills & Altruism & Excellence \\
Cultural competence & Honesty & Empathy \\
Responsibility & Information literacy & Integrity \\
Clinical reasoning & Advocacy & \\
Accountability & Social responsibility & \\
Compassion/Caring & Written communication skills & \\
\hline
\end{tabular}

\begin{tabular}{|c|c|c|}
\hline $\begin{array}{l}\text { 14. Which of the following teaching } \\
\text { fostering professional behaviors? }\end{array}$ & $\begin{array}{l}\text { g methods do you think has the great } \\
\text { Check all that apply. }\end{array}$ & potential for te \\
\hline$\square$ Portfolios & $\square$ Reading assignments & $\square$ Role playing \\
\hline$\square$ Small group discussions & $\square$ Lectures & $\square$ Case studies \\
\hline$\square$ Generic abilities self-assessment & $\square$ Formal meetings with faculty advisor & $\square$ Journals \\
\hline$\square$ Watching an experienced clinician & (role modeling) & \\
\hline Other: Specify: & & \\
\hline
\end{tabular}


15. ANSWER ONLY IF YOU HAVE 7 OR MORE YEARS OF CLINICAL EXPERIENCE.

Students and new graduates today (last three years) are more professional than students or new graduates in previous years.

$\square$ Strongly Disagree $\quad \square$ Disagree $\quad \square$ Neutral $\quad \square$ Agree $\quad \square$ Strongly Agree

Section D

16. Personal Demographic Data: Please indicate your status by circling or checking one response for each item.

PT Degree: $\quad \square$ Certificate $\quad \square$ BS $\quad \square$ MPT $\quad \square$ DPT $\quad \square$ Other, specify:

Clinical Experience: $\square<1 \mathrm{yr} \quad \square 2-5 \mathrm{yrs} \quad \square 6-10 \mathrm{yrs} \quad \square 11-20 \mathrm{yrs} \quad \square 21-30 \mathrm{yrs} \quad \square>30 \mathrm{yrs}$

Age: $\square 21-30 \quad \square 31-40 \quad \square 41-50 \quad \square 51-60 \quad \square 61-70 \quad \square>70$

Gender: $\square$ Female $\square$ Male

Work Status: $\quad \square$ Full-time $\square$ Part-time

Practice Setting: $\quad \square$ Acute Care $\quad \square$ Nursing Home $\quad \square$ Home Health $\quad \square$ Out-patient $\square$ Private Practice Other, specify

Number of PT's in your facility (including self) $\square$ 1-2 $\square$ 3-5 $\square 6-10 \quad \square 11-15 \quad \square$ 16-20 $\square>20$

Number of PT students in your facility in the last two years: $\square$ None $\square$ 1-4 $\square$ 5-10 $\square$ 10-15 $\square>15$

Number of new graduates hired in your facility in the last two years: $\square$ None $\square$ 1-2 $\square 3-5 \quad \square>5$

In what State did you attend PT school:

Are you an APTA member? $\square$ No $\square$ Yes, specialty area if applicable

\section{Section E}

17. Additional Comments: Please offer any additional information regarding your experiences with the state of professionalism in the physical therapy profession.

Comments: 


\section{Appendix I \\ Cover Letter Practicing Clinicians}

September 1, 2005

Dear Mr. or Ms.

As you may be aware, professionalism has become a topic of great interest in physical therapy with the advent of the DPT degree. In an effort to identify ways of improving professional behaviors among entry-level physical therapy students and as partial fulfillment of my doctoral dissertation at West Virginia University, I am asking you to complete the enclosed survey.

This investigation is part of a larger study that is intended to examine the current state of professionalism in the physical therapy profession. The enclosed survey will attempt to identify your attitudes, beliefs, and experiences related to the development of professional behaviors by physical therapy students. Please complete the enclosed survey and return it in the selfaddressed stamped envelope.

To thank you for your participation in this survey, you may return the enclosed post card for a chance to win a \$100.00 APTA gift certificate that can be used for dues, books, continuing education, or other APTA products. Thank you in advance for your participation and willingness to advance the physical therapy profession.

Sincerely,

D. Scott Davis MS, PT, OCS

Assistant Professor

(Doctoral Candidate)

8312 HSS PO Box 9226

Division of Physical Therapy

West Virginia University

Morgantown, WVU 26505 
Appendix $\mathbf{J}$

Number of students enrolled based on post-analysis phone survey

\begin{tabular}{|l|l|}
\hline College or University & Total Number of Students \\
\hline Texas Woman's University & 138 \\
\hline University of Indianapolis & 137 \\
\hline College of Staten Island & 46 \\
\hline Saint Francis University & 125 \\
\hline University of Texas (San Antonio) & 115 \\
\hline Wheeling Jesuit University & 62 \\
\hline Sacred Heart University & $(73)$ Did not participate \\
\hline Southwest Baptist University & 45 \\
\hline University of Utah & 118 \\
\hline Drexel University & 54 \\
\hline Hardin-Simmons University & 73 \\
\hline State University of New York (Med C) & 46 \\
\hline Husson College & 72 \\
\hline University of Nevada Las Vegas & 57 \\
\hline University of Central Florida & 60 \\
\hline University of Washington & 90 \\
\hline Hampton University & 33 \\
\hline University of Puget Sound & 99 \\
\hline Ohio State University & 77 \\
\hline Wayne State University & 78 \\
\hline Total & $\mathbf{1 5 2 5}$ \\
\hline
\end{tabular}




\section{Curriculum Vitae}

Name: Duane "Scott" Davis PT, EdD, OCS

Date of Birth: September 15, 1966

Nationality: US citizen

Address and Phone Number: $\quad 155$ E. Hillview Dr. Morgantown, WV 26505 (304) 292-0121 Home (304) 293-0264 Work (304) 677-9400 Cell dsdavis@hsc.wvu.edu

$\begin{array}{lllll}\text { Education: } & \text { School } & \text { Degree } & \text { Year } & \text { Field } \\ \text { Doctoral } & \text { WVU HR\&E } & \text { EdD } & 2006 & \text { Ed. Psychology } \\ \text { Masters Degree } & \text { WVU ECAS } & \text { MS } & 2002 & \text { Statistics } \\ \text { Baccalaureate } & \text { WVU SOM } & \text { BS } & 1988 & \text { Physical Therapy }\end{array}$

Certification: Board Certified Clinical Specialist in Orthopedic Physical Therapy, American Board of Physical Therapy Specialties, July 1995-2005, recertified July 2005 through 2015.

Appointments: $\quad$ Assistant Professor, School of Medicine, West Virginia University. Twelve-Month Clinical Track. January 2000 - Present

Adjunct Assistant Professor, School of Medicine, West Virginia University. 1997-1999

Professional Licensure: West Virginia \#824, 1988-Present

Pennsylvania \# 008709E, 1995-1998 


\section{Supplemental Education:}

APTA Combined Section Meeting, San Diego, CA, February 2006

Advanced Clinical Practice: Manual Therapy for the Upper Quarter. Dr. Richard Erhard DC, PT, Morgantown, WV, July 15-16, 2005

Advanced Clinical Practice: Manual Therapy for the Lower Quarter. Dr. Richard Erhard DC, PT, Morgantown, WV May 20-21, 2005

APTA Combined Sections Meeting, New Orleans, LA, February 2005

Clinical Decision Making for the Orthopedic Clinician: The Upper Quarter. Dr. Richard Erhard DC, PT, Morgantown, WV March 26-27, 2004

Clinical Decision Making for the Orthopedic Clinician: The Lower Quarter. Dr. Richard Erhard DC, PT, Morgantown, WV June 28-29, 2004

Considerations for the Management of Low Back Pain: The Pelvic Component, Dr. Richard Erhard DC, PT, Morgantown, WV October 8-9, 2004

APTA Combined Section Meeting, Nashville, TN, February 2004

Functional Manual Therapy for the Upper Quarter, September, Alan Weismantel, PT, OMT, FAAOMPT, West Virginia University, 2003

APTA Combined Section Meeting, Tampa, FL, February, 2003

APTA Combined Section Meeting, Boston, MA, February 2002

APTA Combined Sections Meeting, San Antonio, TX, February 2001

Evaluation \& Manual Therapy Treatment of Sacroiliac Joint \& Lumbopelvic Dysfunction. Dr. Richard Erhard DC, PT: Pittsburgh, PA, September 8, 2000

Lower Extremity Injuries in the Athlete for the Athletic Trainer and Physical Therapist. Thomas Jefferson College. Department of Orthopedics. Philadelphia, PA August 11-12, 2000

APTA Combined Sections Meeting, Boston, MA, February 1998

APTA Scientific Meeting, San Diego, CA June 1997

Foot and Ankle Problems in the Athlete, WVU Department of Orthopedics, Seventeenth Annual Reunion Day Conference, Morgantown, WV, October 26, 1996. 
Overuse Syndromes of the Lower Extremity: A Biomechanical Approach, West Virginia University Sports Medicine, West Virginia University Hospitals, Morgantown, WV, October 2526, 1996.

Looked Inside the Wrist Lately? Carol Waggy PT, Ph.D., and CHT: West Virginia University Hospitals, Morgantown, WV, August 10-11, 1996

APTA Combined Sections Meeting, Atlanta GA, February, 1996

APTA, Sports Section Home Study Course 95-1 Topic: Current Concepts in Rehabilitation of the Shoulder, 1995

Orthopedic Section Home Study Course 94-1 Topic: Lumbar Spine, January 1995

Orthopedic Section Home Study Course 92-1 Topic: Lower Extremity, January 1995

Orthopedic Section Home Study Course, The Foot and Ankle, July 1995

Shoulder Examination and Treatment, West Virginia University Sport Medicine and West Virginia University Hospitals - July 8,9, 1994

Advanced Foot Biomechanics and Orthotic Therapy Columbus, OH - Steven Gershman, DPM, Instructor, September 18-19, 1993

Enhancing Your Performance Appraisal Skills, West Virginia University Hospitals, April 14, 1993

Kin Com Basic Training - Myra Buller, PT, Instructor, Chattex Corporation, Chattanooga, TN, March 19-21, 1993

Lower Extremity Biomechanics and Orthotic Therapy: The Dogwood Institute, Inc., Brain Pease, MS, PT, Instructor, Baltimore, MD, February 19-21, 1993

CIP Team Leader Training- Patty Horseman, West Virginia University Hospitals, December 3, 1992

Washington University Clinical Instructors Meeting, Legal issues in Clinical Education, St. Louis, MO - April 30-May 2, 1992

Industrial Rehabilitation, The Blankenship Corporation, Keith L. Blankenship, PT Instructor, Kansas City, MO - March 20-22, 1992 
Making Meetings Work, WVU Hospitals Training and Organizational Development, Morgantown, WV March, 1992

Foot and Ankle Problem Analysis through Biomechanics, Gait and Muscle Function, Richmond, Virginia - August 2-4, 1991

Introduction to the Evaluation and Treatment of Craniovertebral Craniomandibular Dysfunction (R2) IFORC, Mariano Roccabado, Instructor, Phoenix, AR September 1990

Orthopedic Assessment and Treatment of the Lumbar Spine and Sacroiliac Joint. Cliff Fowler, Instructor, Morgantown WV - June 1990

Biomechanical Evaluation of the Foot and Ankle Dan Vogalbach, Instructor, Morgantown, WV. April 1990

Assessment and Treatment of the Upper Quadrant Cliff Fowler, Instructor, Albany, NY November 1989

PNF - "Functional Integration of the Trunk," Tim Josten, PT, Kaiser Foundation Rehabilitation Center, Vallejo, California; Morgantown, West Virginia - October 1989

Foundation of Clinical Orthopedics: Stephen McDavitt, Instructor, Pittsburgh, PA, February 1989

Assessment and Treatment of Chronic Shoulder Dysfunction and Anterior Knee Pain Syndrome, Baltimore, MD, September 1988

West Virginia Physical Therapy Association Spring Conference, Wheeling, West Virginia, April 1988

\section{Publications}

\section{Manuscripts}

Davis DS, Bosley EE, Gronell LC, Keeney SA, Rossetti AM, Mancinelli CA, Petronis JJ. The relationship of body segment length and vertical jump displacement in recreational athletes. $J$ Strength Cond Res. 2006; 20: 136-140

Mancinelli CA, Davis DS, Aboulhosn L, Brady D, Davis DS, Eisenhofer J, Foutty S. The effects of massage on delayed onset muscle soreness and physical performance in female collegiate athletes. Phys Ther Sport. 2006; 7: 5-13. 
Mancinelli CA \& Davis DS. Range of Motion and Stretching. IN Huber FE \& Wells CL. Therapeutic Exercise: Treatment Planning for Progression. 2006: W B Saunders.

Haff G, Beck, Cramer, Davis, Egan, McBride Wathen. Round Table Discussion: Flexibility Training, Strength Cond J. IN PRESS

Davis DS, Ashby P, McCale K, McQuain J, Wine J. The effectiveness of three stretching techniques on hamstring flexibility. J Strength Conditioning Research. 2005; 19: 27-32.

Davis DS, Barnette B, Kiger J, Mirsola J, Young S. Physical characteristics that predict functional performance in college football players. J Strength Conditioning Research. 2004; 18: 115-120.

Davis DS, Briscoe D, Markowski C, Saville S, Taylor C. Physical characteristics that predict vertical jump performance in recreational male athletes. Physical Therapy in Sports. 2003, 4: 167-174.

Davis DS, Post WR: Segond fracture: Lateral capsular ligament avulsion. J Orthop Sports Phys Ther. 1997; 24:106-108

\footnotetext{
Abstracts

Davis DS, Bosley, EE, Gronell LC, Keeney SA, Rossetti AM, Mancinelli CA, Petronis JJ. T he relationship of body segment length and vertical jump displacement in recreational athletes $J$ Orthop Sports Phys Ther, 2005, A

Davis DS, Hagerman M, Midkiff M, Newsome J, Williamson J. The effectiveness of three proprioception neuromuscular facilitation stretching techniques on the flexibility of the hamstrings muscle group. J Orthop Sports Phys Ther, 2004, 34, A33

Davis DS, Bailey T, Burgess S, Underwood C, West A, The Comparison of plyometric and resisted jump training on vertical jump performance. J Orthop Sports Phys Ther, 2004; A43

Davis DS, Ashby P, McCale K, McQuain J, Wine J. The effectiveness of three stretching techniques on hamstring flexibility. J Orthop Sports Phys Ther. 2003; 33: PO306

Davis DS, Briscoe D, Markowski C, Saville S, Taylor C. Physical characteristics that predicts vertical jump performance in recreational male athletes. Physical Therapy in Sports. 2002; 32
} 
Davis DS, Petronis JJ, Adams R, Ball A, Stewart M, Crumbaker W. Reliability of subtalar joint neutral measurements: A large sample investigation with experienced testers. J Orthop Sports Phys Ther. 2002; 32

Petronis J, Davis DS, Gandee J, Gibson W, Hensley G, Hatfield R. Intertester reliability of measuring knee flexion using a light-referencing goniometer. J Orthop Sports Phys Ther. 2002; 32

Crumbaker W, Davis DS, Petronis J. Comparison of intratester reliability in determining subtalar joint neutral via visual congruency and palpation of the talar head. J Orthop Sports Phys Ther. 2001; 31: A42

Davis DS, Barnette B, Kiger J, Mirsola J, Young S. Physical characteristics that predict functional performance in college football players. J Orthopedic Sports Phys Ther. 2001; 31:

Davis DS, Nicoli JM, Brueck CS, Wilkins KM, Post WR. Intratester and Intertester reliability of fourteen tests commonly used to evaluate patients with patellofemoral pain syndrome. $J$ Orthopedic Sports Phys Ther. 1998; 27: PL57

\section{Membership in Professional Organization}

American Physical Therapy Association 1986-89, 1994-Present

West Virginia Chapter of APTA 1986-89, 1994-Present

APTA Section of Orthopedics 1986-89, 1994-Present

APTA Section of Sports 1994-96, 2000-2001

APTA Education Section 2004-Present

\section{Services to the Professional Organization}

Select Reviewer for the APTA Preferred Practice Patterns: Musculoskeletal Section. April 1996

\section{Medical Reviewer/ Expert witness}

Lenny Grace Henry Vs. Lincoln General Hospital, Becky Sherwin, Jennifer Williams and Ruston Outpatient Physical Therapy Services. West Monroe, Louisiana. 2002-2003

Gloria J. Walker, individually and as Administratix of the Estate of Susan R. Walker vs Saghir R. Mir MD., FAAOS, Montgomery General Hospital, Inc., opinion offered to Robert Aliff JD, Jackson and Kelly, 2003 
Robert A. Brown vs. The City of Summersville and Summersville Memorial Hospital (Civil Action No. 02-C-3), opinion offered to Robert Aliff JD, Jackson and Kelly 2003

\section{Teaching}

\section{Summer Term}

PT 706, Advanced Clinical Anatomy. Course Co-coordinator (15 contact hrs/wk)

\section{Fall Term}

PT 425, Physical Therapy Procedures II. Course coordinator (5 contact hrs/wk)

PT 402, Clinical Decision Making I. Course coordinator (2 contact hrs/wk)

PT 410, Musculoskeletal PT I. 19 hrs Lecture, Lab Assistant (6 contact hrs/wk)

PT 718 Evaluation Procedures. Course coordinator (5 contact hrs/wk)

\section{Spring Term}

PT 450, Orthopedics II. Instructor and Lab Assistant (6 contact hrs/wk)

PT 306, Kinesiology. Guest Lecturer (6 contact hours total)

\section{Continuing Education Workshops Organized}

Organized "Management of Shoulder Disorders: Surgery and Rehabilitation." Morgantown, WV WVU Alumni Weekend, September 30, 2005

Organized and coordinated "The 2004 Alumni Reunion Weekend Continuing Education Session. Morgantown, West Virginia, WVU October, 2004

Organized and coordinator of "The 2002 Alumni Reunion Weekend Continuing Education Session” Morgantown, West Virginia, WVU October 5, 2002

Organized and coordinator of "Orthopedic Physical Therapy Grand Rounds" A monthly community educational meeting including University faculty, local physical therapists, athletic trainers, physical therapy assistants, and students. 1994-1997

Organized/Coordinated "Overuse Injuries of the Lower Extremity: A Biomechanical Approach. Morgantown, WV, October 25-26, 1996

Organized and Co-Presenter "Shoulder Examination and Treatment," sponsored by West Virginia University Hospitals and the WVU Department of Orthopedics. July 1994 
Organized Clinical Instructors Meeting for WVU School of Physical Therapy, Jane Pertko, primary presenter, assisted with presentation. 1992

Organized Orthopedic Assessment and Treatment of the Lumbar Spine and Sacroiliac Joint, Cliff Fowler, Presenter, Sponsored by WVUH Hospitals. June 1990

\section{Services to the University}

Department of Human Performance and Exercise Science, Promotion and Tenure Committee, 2001-2003

Division of Physical Therapy, Admission Committee, Faculty representative 2000 - present

Division of Physical Therapy, Curriculum Committee, Musculoskeletal Track Representative 2000-2002 and 2004-present

Division of Physical Therapy, Academic and Professional Standards Committee, 2003 present

\section{Professional Presentations}

Davis DS. Learning and Teaching Professionalism: A Survey of Physical Therapy Educators. American Physical Therapy Association Combined Sections Meeting, New Orleans, LA Feb 2005

Davis DS. Examination and Clinical Diagnosis of Superior Glenoid Labral Tears. WVU PT Alumni Weekend, October 2004.

Davis DS. Advances in the Management of the Knee: Patellofemoral Syndrome. WVU Alumni Weekend Continuing Education. West Virginia University, Morgantown, WV. October 5, 2002.

Davis DS, Messaros A. Evidence Based Practice: The Marriage of Experience and Science. Presented to Charleston Area Medical Center through Mountaineer Doctors Television. March 26, 2002

Davis DS, Briscoe D, Markowski C, Saville S, Taylor C. Physical Characteristics that Predict Vertical Jump Performance in Recreational Male Athletes. Boston, MA, Jan 2002 
Davis DS, Petronis JJ, Adams R, Ball A, Stewart M, Crumbaker W. Reliability of Subtalar Joint Neutral Measurements: A Large Sample Investigation with Experienced Testers. Boston, MA, Jan 2002

Davis DS, Briscoe D, Markowski C, Saville S, Taylor C. Physical Characteristics That Predict Vertical Jump Performance in Recreational Male Athletes. Presented as a poster presentation at APTA Combined Sections Meeting, February 2002.

Davis DS, Petronis JJ, Adams R, Ball A, Stewart M, Crumbaker W. Reliability of Subtalar Joint Measurements: A Large Sample Investigation with Experienced Testers. Presented as a poster presentation at APTA Combined Sections Meeting, February 2002.

Davis D, Barnette B, Kiger J, Mirsola J, Young S. Physical Characteristics That Predict Functional Performance in College Football Players. Presented as a poster presentation at APTA Combined Sections Meeting, February 14, 2001.

Crumbaker W, Davis DS, Petronis J. Comparison of Intratester Reliability in Determining Subtalar Joint Neutral via Visual Congruency and Palpation on the Talar Head. Presented as a poster

Davis DS, Thermal Capsulorraphy. WVU Division of Physical Therapy Reunion Weekend. September 23, 2000

Davis DS, Glenohumeral Instability. Mountainview Regional Rehabilitation Hospital. October 11,2000

Davis DS, The Effectiveness of Three Stretching Protocols on Increasing the Length of the Iliotibial Band. Poster Presentation, APTA Combined Section Meeting. Seattle WA, February 1999

Davis DS, Nicoli J, Brueck C, Wilkins K, Post W. Intratester and Intertester Reliability of Fourteen Tests Commonly Used to Evaluate Patients with Patellofemoral Syndrome. Platform Presentation, Boston MA, February 12, 1998

Davis DS, "Is the Role of the Scapula Overemphasized in the Rehabilitation of the Shoulder Joint"? WVU Orthopedic Grand Rounds. December 9, 1998

Davis DS, "Foot Structure and Function" WVUH September Stride Running Dinner, September 12, 1997.

Davis DS, "Basic Radiology for Physical Therapist." WVU Orthopedic Grand Rounds, September 9, 1997. 
Davis DS, "Differential Diagnosis Acute Knee Effusion", WVU Orthopedic Physical Therapy Grand Rounds, November, 1996

Davis DS, "Lower Extremity Osseous Alignment," Overuse Syndromes of the Lower Extremity: A Biomechanical Approach. WVU Orthopedic Reunion Day, Morgantown, WV, October 25, 1996

Davis DS, "Kinetics of the Lower Extremity," Overuse Syndromes of the Lower Extremity: A Biomechanical Approach, WVU Orthopedic Reunion Day, Morgantown, WV, October 25, 1996

Davis DS, "Kinematics of the Lower Extremity," Overuse Syndromes of the Lower Extremity: A Biomechanical Approach, Orthopedic Reunion Day, Morgantown, WV, October 25, 1996

Davis DS, "Triple Varus Knee" Case Presentation- WVU Orthopedic Physical Therapy Grand Rounds, April 1996

Davis DS, "Segonds Fracture" Case Presentation- WVU Orthopedic Physical Therapy Grand Rounds, November 1995

Davis DS, "Rehabilitation following Bankart Repair" Lecture, "Shoulder Examination and Treatment" West Virginia University Hospitals and WVU Department of Orthopedics, July 1994

Davis DS, "Rotator Cuff Repair Rehabilitation" Lecture, "Shoulder Examination and Treatment" West Virginia University Hospitals and WVU Department of Orthopedics, July 1994 